\title{
Revision of Iberian species of the genus Merodon (Diptera: Syrphidae)
}

\author{
Maria Angeles MARCOS-GARCÍA ${ }^{1}$, Ante VUJiĆ ${ }^{2}$ and Ximo MENGUAL ${ }^{1}$ \\ ${ }^{1}$ Centro Iberoamericano de la Biodiversidad (CIBIO), Universidad de Alicante, E-03080 Alicante, Spain; e-mails: marcos@ua.es, \\ xmengual@ua.es \\ ${ }^{2}$ Department of Biology and Ecology, Faculty of Science, Trg Dositeja Obradov ića 2, 21000 Novi Sad, Serbia; \\ e-mail: antev@ib.ns.ac.yu
}

Key words. Syrphidae, Merodon, revision, Iberian Peninsula, new species, new synonymy, lectotype designation, map distribution, key

\begin{abstract}
This study is a revision of the Iberian Merodon Meigen, 1803 species, including an illustrated key, a discussion of taxonomic characters and a morphological diagnosis for all included species. Descriptions are provided for nine new species: $M$. antonioi sp. n., M. arundanus sp. n., M. cabanerensis sp. n., M. crypticus sp. n., M. hurkmansi sp. n., M. legionensis sp. n., M. longispinus sp. n., M. luteihumerus sp. n. and M. quercetorum sp. n. The taxon M. escorialensis Strobl, 1909 is redescribed and lectotype is designated. Lectotypes are designated for four taxa: M. albifrons Meigen, 1822; M. spinipes obscuritarsis Strobl in Czerny \& Strobl, 1909; M. spicatus Becker, 1907; and M. spinipes grossus Gil Collado, 1930. Three varieties are redefined and considered as valid species: M. obscuritarsis Strobl in Czerny \& Strobl, 1909 (as var. of spinipes); M. grossus Gil Collado, 1930 (as var. of spinipes); M. unicolor Strobl in Czerny \& Strobl, 1909 (as var. of aeneus). The following new synonymies are proposed: M. affinis Gil Collado, 1930 syn.n. (= junior synonym of M. longicornis Sack, 1913); M. lusitanicus Hurkmans, 1993 syn.n. (= junior synonym of M. serrulatus Wiedemann in Meigen, 1822); M. andalusiacus Paramonov, 1929 syn.n., M. bolivari Gil Collado, 1930 syn.n., M. hispanicus Sack, 1931 syn.n. (= all three are junior synonyms of M. unguicornis Strobl in Czerny \& Strobl, 1909); M. spicatus Becker, 1907 syn.n. (= junior synonym of M. chalybeus Wiedemann in Meigen, 1822); M. fuerteventurensis Barkemeyer, 2002 syn. n. (= junior synonym of M. obscuritarsis Strobl, 1909); and M. spinipes grossus (Gil Collado, 1930) syn.n. (= junior synonym of M. albifrons Meigen, 1822). Status of M. serrulatus Wiedemann in Meigen, 1822 is revised. Four species: M. longicornis Sack, 1913, M. pumilus Macquart, 1849, M. ottomanus Hurkmans, 1993 and M. segetum (Fabricius, 1794) are new for the Iberian Peninsula. Male genitalia are illustrated for all the species and a key of the 34 Iberian species (+ M. hurkmansi sp. $\mathrm{n}$.) for males and females (except for the unknown female of M. longispinus sp. n.) is appended. Distribution and biological data for the Iberian species are also included. A brief zoogeographic discussion is also presented. The level of endemism of genus Merodon on the Iberian Peninsula is extremely high (almost 50\%).
\end{abstract}

\section{INTRODUCTION}

The Old World genus Merodon Meigen, 1803 (Diptera: Syrphidae) is one of the most widespread in the Mediterranean region and the second largest genus of European Syrphidae with more than 50 European species (Speight, 2004). It is distributed over the Palaearctic and Ethiopian regions, with most species occurring on the steppes of eastern Europe and beyond, with over 60 species recorded from Turkey, for example (Siribiyic, pers. com.).

Merodon belongs to the tribe Merodontini (Edwards, 1915) and its distinctive characteristic is a triangular projection beneath the distal part of the hind femora and vein $\mathrm{R}_{4+5}$ curving deeply into cell $\mathrm{R} 5$. Most species are insufficiently treated in taxonomic works, and the lack of male genitalia descriptions increases the difficulty for their identification. The morphological intra-specific variability is well known in some species such as $M$. equestris (Fabricius, 1794) and M. aureus Fabricius, 1805 which show a wide range of colour varieties, or $M$. tricinctus Sack, 1913 which presents a high intra-specific variability in the anterior lobe of the surstyle of the male genitalia (Popov, 2000).
The biology of the Merodon species is poorly known and the larval cycle of all known species develops underground in bulbs or tubercles of monocotyledonous species in Liliaceae and Amarillidaceae (Seguy, 1961, Hurkmans, 1993). M. equestris larvae live in bulbs of commonly used garden plants such as Amaryllis, Hyacinthus and Narcissus (Rotheray, 1994) and in some cases, can be considered an horticultural pest (Stubbs \& Falk, 2002).

Large Merodon species can be confused with bumblebee mimics of various genera, and small and elongated species could be also confused with Eumerus Meigen, 1822. The adult flies are mostly found near the ground, flying among the vegetation, close to the ground or resting on stones or bare soil. Adults of the various species of Merodon appear to have a preference for flowers of Apiaceae (Hurkmans, 1993).

Up until now, the only comprehensive study of the Palaearctic species of this genus was that of Hurkmans (1993), a revision of 61 species. Radenković et al. (2002) established new synonyms and clarified the taxonomy of this group after the examination of type material of the ruficornis group of species. 

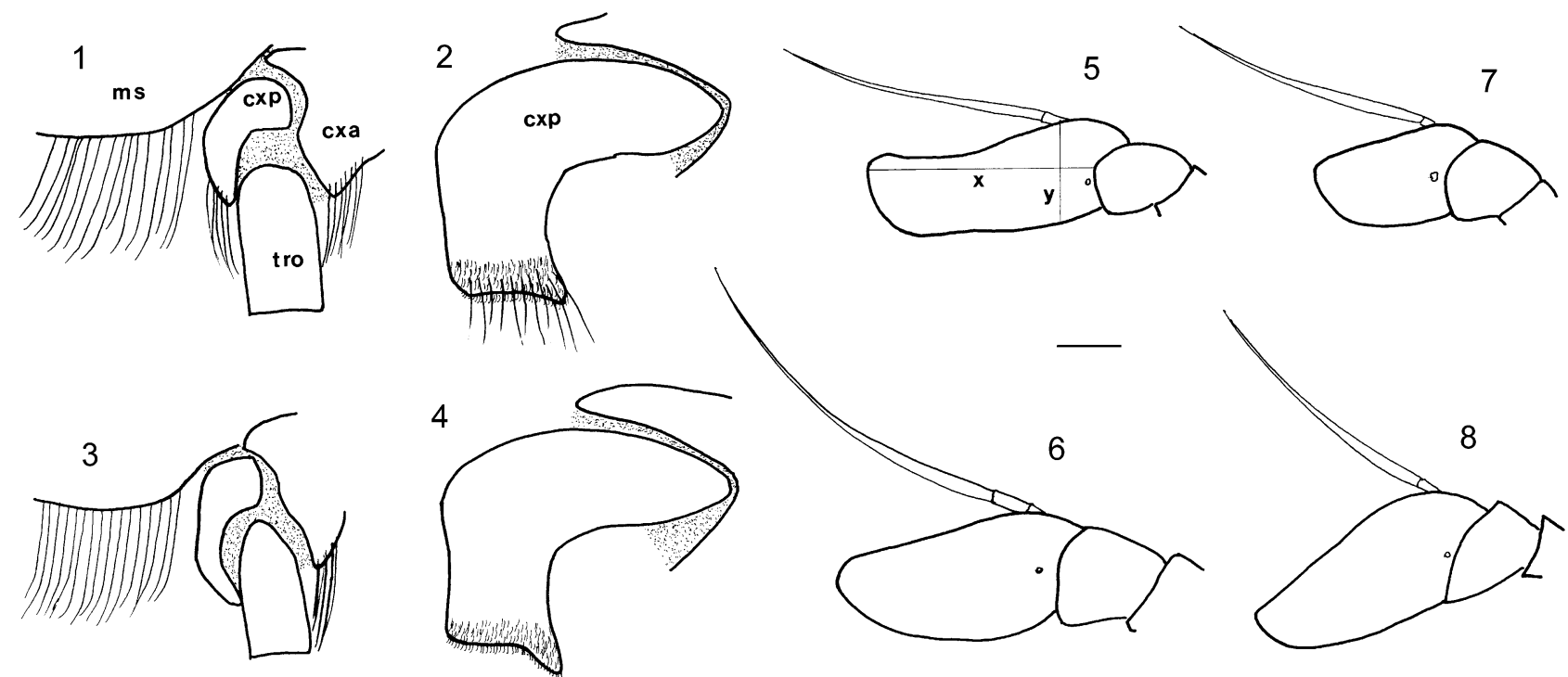

Figs 1-8. 1-4: Mid coxa. 1, 2 - Merodon albifrons; 3, 4-M. nigritarsis; 1, 3-right leg, lateral view; 2, 4 - mid coxa posterior view; cxa - anterior part of mid coxa; cxp - posterior part of mid coxa; ms - metasternum; tro - mid trochanter. 5-8: Right antenna, inner view (basoflagellomere and pedicel), males. 5 - Merodon longicornis; 6 - M. clavipes; 7 - M. aberrans; 8 - M. serrulatus. Scale $0.25 \mathrm{~mm}$

In the Iberian Peninsula 30 species of Merodon were recorded (Marcos-García et al., 2002) with $23 \%$ of the species being endemic. Data on adult habitats, visited flowers, flight periods and Spanish distributions are provided in Marcos-García (1985a, b, 1989, 1990a,b) but the Iberian Merodon species had not been comprehensively revised before. The high number of species and endemism in the Iberian Peninsula, the apparent similarities between species and deficiencies in the original description of some species and the lack of an integrated study, stimulated us to delve into the knowledge of the taxonomy and distribution of the Iberian species of Merodon to facilitate future studies on this genus. The present comprehensive study, in which eight new species are described, brings the total to 34 Iberian Merodon species plus M. hurkmansi sp. n. from Algeria. Whereas the latter does not presently belong to the Iberian fauna, it has also been included in this revision to facilitate its separation from M. albifrons Meigen, 1822 and considering the possible discovery of this species in the Iberian Peninsula due to the proximity and the high level of connection between Spain and this African country.

\section{MATERIAL AND METHODS}

The systematic portion of the present study is based on the examination of all the available material of this genus previously cited in bibliography or unpublished works and belonging to private collections. Type specimens of some species have also been studied.

The following acronyms of museums and entomological collections containing material studied are used in the text: WBC Werner Barkemeyer collection, Flensburg, Germany; BMNH The Natural History Museum, London, UK; CEUA - Colección Entomológica Universidad de Alicante, Spain; IEE - Instituto Español de Entomología (part of MNMS), Madrid, Spain; MNHN - Muséum National d'Histoire Naturelle, Paris, France; MNMS - Museo Nacional de Ciencias Naturales, Madrid,
Spain; MZLS - Musée de Zoologie de Lausanne, Switzerland; MZLU - Museum of Zoology Lund University, Sweden; NMBA - Naturhistorisches Museum der Benediktiner-Abtei, Admont, Austria; NS - Department of Biology and Ecology, Entomological Collection, University of Novi Sad, Serbia; NHMW - Naturhistorisches Museum Wien, Vienna, Austria; NMNH - National Museum of Natural History, Leiden, The Nederlands; ZMAN - Zoölogisch Museum Amsterdam, The Nederlands; ZMHB - Museum für Naturkunde, Von Humboldt Universität, Berlin, Germany; ZMKU - Zoological Museum, State Univeristy of Kiev, Ukraine; ZMUC - Zoological Museum, Copenhagen University, Denmark.

To avoid unnecessary repetitions, the collection is only mentioned when the studied material does not belong to the CEUA.

The characters used in the key, descriptions, and drawings employ the terminology established by Thompson (1999) and those relating to male genitalia are those employed by Hurkmans (1993) and Doczkal (1996). Colour characters are described from dry mounted specimens. Unless otherwise stated in the sections "Material examined", the specimens under study were collected by sweeping net. Some specimens were captured using Malaise traps (MT), dried after preservation in ethanol and mounted with entomological pins in the course of the study.

To study the male genitalia, specimens were relaxed and the genitalia were extracted with an insect pin with a hooked tip. The genitalia were stored in microvials containing glycerol.

Drawings were made with a FSA 25 PE drawing tube attached to a binocular microscope. Measurements were taken with an eyepiece graticule or micrometer.

\section{Abbreviations used in key, diagnosis and description}

cx - posterior part of mid coxa (Figs 1-4); bf - relation between distance from top of basoflagellomere and most prominent point of pedicel (Fig. 5: $\mathrm{x}$ ) and width of basoflagellomere at level of base of arista (Fig. 5: y); pa - posterior anepisternum (Figs 30-31).

\section{Male genitalia}

$\mathrm{AL}$ - anterior surstyle lobe; $\mathrm{C}$ - cercus; EA - ejaculatory apodeme; IL - interior accessory lobe of posterior surstyle lobe; L - 


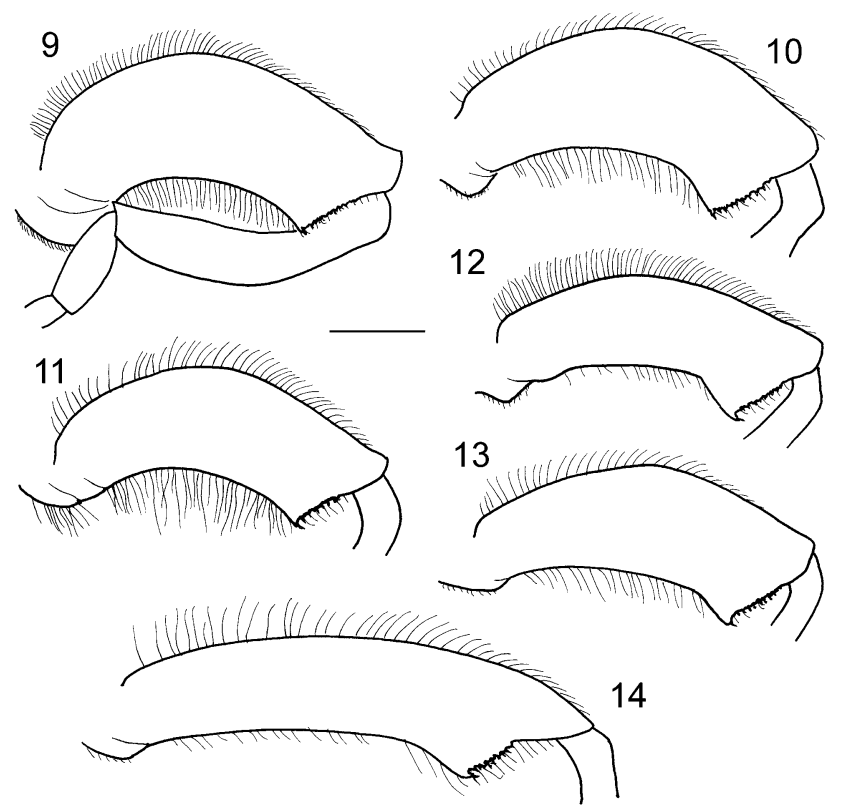

Figs 9-14. Left hind femur, lateral view (and tibia on Fig. 9), males. 9, 10 - Merodon clunipes; $11-M$. elegans; $12-M$. avidus; 13 - M. serrulatus; 14 - M. aberrans. Scale $1 \mathrm{~mm}$.

lingula; P - aedeagus; PL - posterior surstyle lobe; $\mathrm{S}$ - lateral sclerite of aedeagus; T - ctenidium (Figs 109-111).

For each new species we provide a short description and figures of adult morphological data. Diagnoses comprise accounts of unique characters relative to the species considered here and also combinations of characters that enable taxa to be distinguished and recognised. Keys are also provided to enable identification of adults. Under each species additional details of material examined, geographical distribution, biological data and institutions where holotypes may be studied are given. In the studied material, the country is only indicated if it is not Spain. World distribution is compiled from Peck (1988), Hurkmans (1993), Dirickx (1994), Marcos-García et al. (2002), Speight (2004) and van Veen (2004).

A summary of the world distribution and known biological data, such as preference of habitat and visited flowers (from Speight, 2004) is included in the treatment of each species, emphasizing the new data in bold. A map of the Iberian distribution is also included for each species (black circles refer to examined material and white squares unexamined material).

In the examined material, the locality is not indicated when absent in the original paper.

In the review of the Merodon names treated, the following order of data is used for each species: name, author, date, page number of original description; type, sex of the type, "content of original labels (data from different labels are separated in the text by a slash)", depository of the type(s); comments. The type material was examined by A. Vujić.

\section{KEY FOR IBERIAN SPECIES OF GENUS MERODON}

1 Mid coxa with at least few long hairs posteriorly (Figs 1,2).

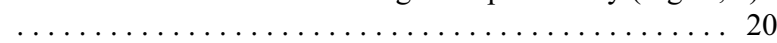

- Mid coxa without long hairs, posteriorly bare (Figs 3, 4). . 2

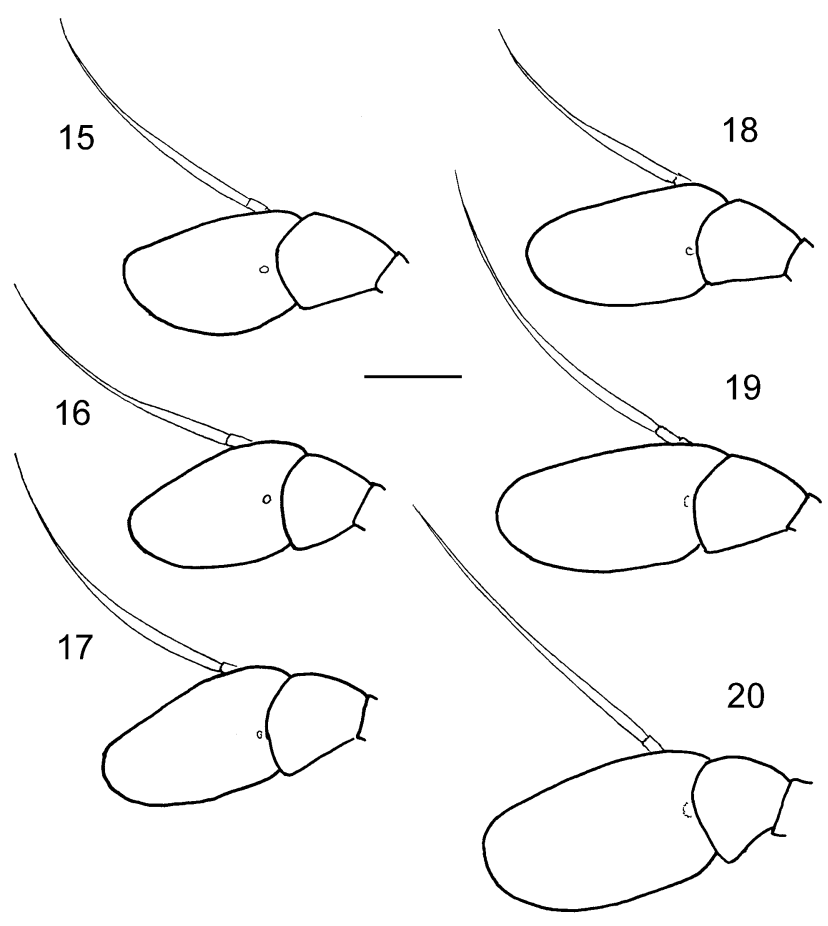

Figs 15-20. Right antenna, inner view (basoflagellomere and pedicel). 15, 18 - Merodon nigritarsis; 16, $19-$ M. avidus B; 17, 20 - M. avidus A; 15-17 - males; 18-20 - females. Scale $0.3 \mathrm{~mm}$.

2 Basoflagellomere very long, bf $=2.2$ (Fig. 5); male genitalia as in Figs 186-189. Medium to small sized, slender species; face, pleurae and legs with whitish hairs, vertex (and frons in female) with black hairs; scutum with stripe of black hairs between wing bases and four pollinose longitudinal stripes; knee, tibiae at both ends and tarsi at least ventrally, paler; tergites black in males, tergites II, III completely or partly red in females; tergites II-IV with white pollinose stripes. . . ........................ Merodon longicornis

Basoflagellomere less than 2 times as long as wide...... 3

3 Male............................ 4

- Female............................. 12

4 Big (17-23 mm), bumble bee-like species with long and dense body hairs; male genitalia as in Figs 145-147. Hind femora thickened; bf $=1.8$ (Fig. 6); white-yellow haired species with stripe of black hairs between wing basis, and red-yellow hairs on tergites III, IV; scutum with four more or less visible pollinose longitudinal stripes; tergites with pollinose stripes, less visible because of long tergal hairs; legs black. ................. Merodon clavipes

- Smaller species, with shorter and sparser body hairs. . . . . 5

5 Hind femora thickened (broader than length of hind basotarsomere) and strongly curved ventrally (Figs 9-11). . . . 6

- Hind femora less broad and not so curved (as in Fig. 12). . 7

6 Species with dark to brownish antennae, fore and mid tibiae with large dark ring, tarsi dorsally darkened; tergite II dark without pale lateral spots; male genitalia as in Figs 148-151. Medium sized, dark species; scutum with stripe of black hairs between wing bases and five longitudinal pollinose stripes; hind femora extremely thick (Figs 9, 10); basal part and top of tibiae and tarsi at least ventrally, paler; tergites

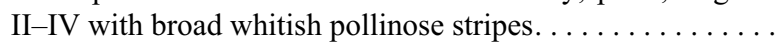
........................... Merodon clunipes 

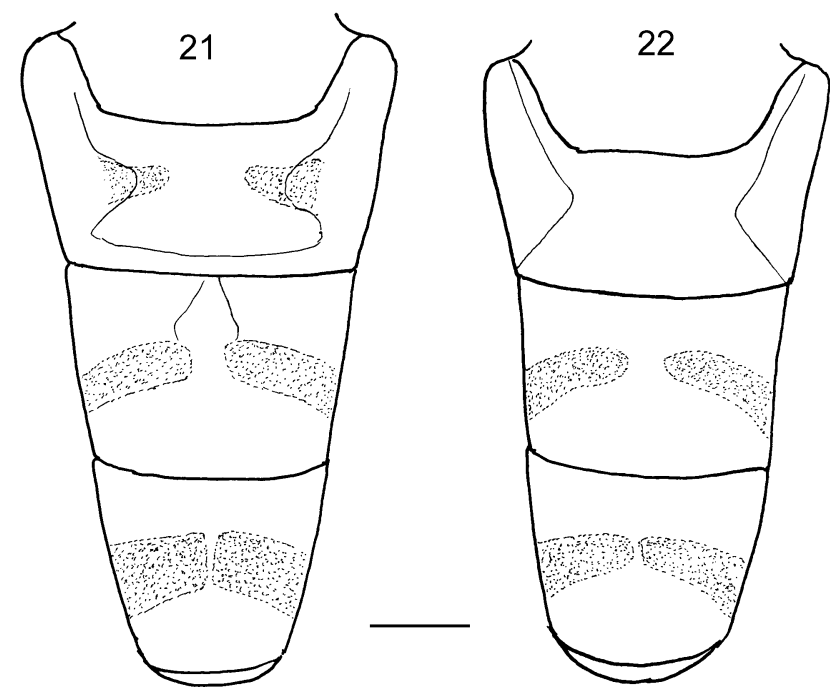

Figs 21, 22. Tergites II-IV, dorsal view, males. 21 - Merodon avidus $\mathrm{A} ; 22-$ M. avidus $\mathrm{B}$. Scale $1 \mathrm{~mm}$.

- Species with reddish antennae, predominantly pale fore and mid tibiae, pale tarsi; tergite II with clear reddish lateral spots; male genitalia as in Figs 152-154. Medium sized, slender species (related to Merodon avidus species group) with very thick hind femora covered with long pale hairs on ventral margin (Fig. 11); scutum with stripe of black hairs between wing basis and four longitudinal pollinose stripes; tergite II with lateral orange spots; tergites III, IV with whitish pollinose semicircular stripes, slightly interrupted in the middle................... Merodon elegans

7 Legs predominantly black. . . . . . . . . . . . . . . . 8

- At least basal 1/4 and top of fore and mid tibiae pale.... . 9

8 Basoflagellomere elongated $(\mathrm{bf}=1.9)$, arista about 1.1 times longer than basoflagellomere (Fig. 8); tergite II usually with small pale lateral spots; hind femora broader (Fig. 13); male genitalia as in Figs 116-121. Medium sized, dark species with olive-brown reflections; antennae dark; legs black; body hairs predominantly pale, except black hairs on vertex, scutum between wing bases, tergites III, IV and apical part of femora; scutum with narrow central and two pairs of lateral pollinose stripes; tergites II-IV with pollinose stripes. . . $\ldots \ldots \ldots \ldots \ldots \ldots \ldots$. . . . . . . . . . . . .

- Basoflagellomere shorter $(\mathrm{bf}=1.1)$, arista about 1.7 times longer than basoflagellomere (Fig. 7); tergite II dark; hind femora narrow and slender (Fig. 14); male genitalia as in Figs 109-111. Big, but slender species with dark tergites, black legs, dark antennae; scutum with black-bluish stripe between bases of wings covered with black hairs; tergites II-IV with pollinose stripes, narrower or absent on tergite IV....................... Merodon aberrans

9 Hairs on anterior anepisternum reduced, as in Fig. 30; tergite II always with reddish lateral spots; abdomen elongated. Group of medium sized, slender species with relatively short body hairs, with olive-brown ground colour; tergites III, IV always with whitish pollinose stripes. Colour of tergites very variable, from dark (except tergite II), to almost completely reddish (avidus species group) . . . . . . . . 10

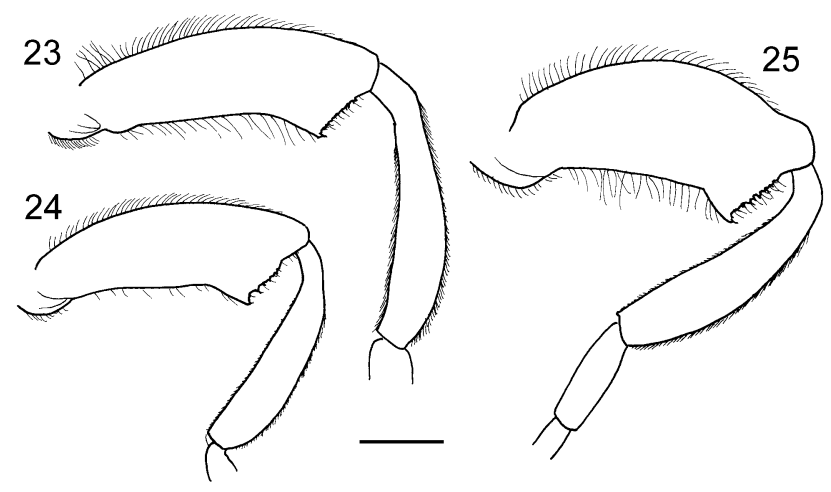

Figs 23-25. Left hind leg, lateral view, females. $23-$ Merodon aberrans; 24 - M. serrulatus; 25 - M. clunipes. Scale $1 \mathrm{~mm}$.

- Hairs on anterior anepisternum occupy larger area, as in Fig. 31; tergites dark, abdomen short and stocky; male genitalia as in Figs 211-214. Small species with olive-brown reflection and without pale spots on tergites; basoflagellomere reddish; knees, tarsi and ends of tibiae pale; body hairs pale, except black hairs on vertex, apex of femora, central part of scutum and tergites II-IV; scutum unpollinose, tergites II, III with small pollinose spots. Variability: Basoflagellomere from orange to brown; black hairs on scutum and pollinose spots on male tergites may be absent.

........................ Merodon ottomanus

10 Tarsi uniformly pale coloured; basoflagellomere longer, about twice as long than pedicel (Figs 16, 17). . . . . . 11

- Tarsi darkened dorsally; basoflagellomere shorter, 1.5-1.7 times longer than pedicel (Fig. 15), male genitalia as in Figs 202-204. . ................ Merodon nigritarsis

11 Basoflagellomere slightly more elongated, bf $=1.4$ (Fig. 17); tergite II always with a pair of whitish pollinose spots, from clear to almost indistinct (Fig. 21); tibiae usually pale; tergites II and III usually with reddish lateral spots; male genitalia as in Figs 130-132 ......... Merodon avidus A

- Basoflagellomere slightly less elongated, $\mathrm{fm}=1.3$ (Fig. 16); tergite II unpollinose (Fig. 22); hind tibiae partially dark; tergite III usually without reddish lateral spots. . . . . . . . . . ........................... Merodon avidus B

12 Tergites dark, only antero-lateral corners of tergite II can have pale spots. . . . . . . . . . . . . . 13

- Tergites II-IV with reddish parts, at least tergite II predominantly reddish, with red lateral sides and red posterior margin; abdomen elongated; group of medium sized, slender species with relatively short body hairs, olive-brown ground colour; tergites III, IV always with whitish pollinose stripes. Colour of tergites III, IV very variable, from dark to almost completely red (avidus species group). . . . . . . . . . 17

13 Hairs on anterior anepisternum reduced, as in Fig. 30 . . 14

- Hairs on anterior anepisternum occupy a larger area, as in Fig. 31; tergites dark, abdomen short and stocky. Small species with olive-brown reflections and without pale spots on tergites; basoflagellomere reddish; knees, tarsi, and ends of tibiae pale; body hairs pale, except black hairs on vertex and frons, top of femora, central part of scutum and tergites II-IV; scutum unpollinose, tergites II-IV with narrow pollinose stripes. ............... Merodon ottomanus

14 Tergites III, IV with clear pollinose stripes. . . . . . . . 15 


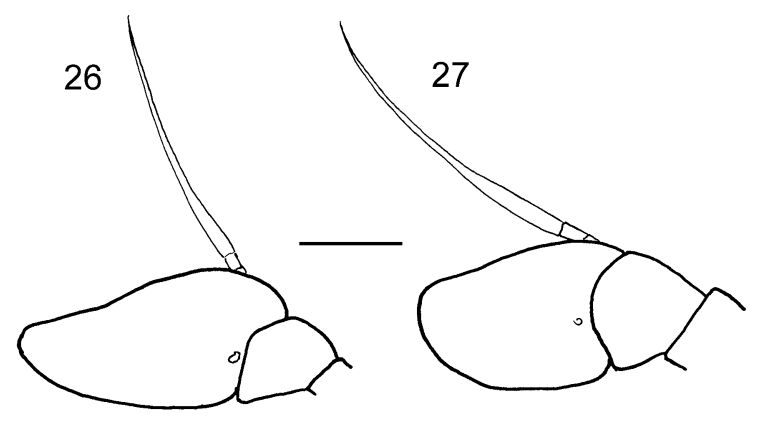

Figs 26, 27. Right antenna, inner view (basoflagellomere and pedicel), females. 26 - Merodon serrulatus; $27-$ M. aberrans. Scale $0.3 \mathrm{~mm}$.

- Tergites III, IV with or without small pollinose stripes; big species $(17-22 \mathrm{~mm})$ with long and dense body hairs. Body usually covered with yellowish-white hairs, except for a few black hairs between wing basis and predominantly black hairs on tergites III, IV; pollinose stripes on tergites covered with yellowish-white hairs........... Merodon clavipes

15 Lateral sides of scutum and haired parts of pleurae covered with dark pubescence; hind femora narrower (Figs 23, 24); pollinose stripes on tergites occupy less than $1 / 4$ of tergite length. .......................... 16 - Lateral sides of scutum and haired parts of pleurae with whitish pubescence; hind femora thickened (Fig. 25); pollinose stripes on tergite IV on broader part occupy about $1 / 3$ of tergite length. Medium sized, dark species; basoflagellomere reddish-brown; scutum with stripe of black hairs between wing basis and five longitudinal pollinose stripes; ends of tibiae and tarsi at least ventrally, pale; tergites black. ............................ Merodon clunipes

16 Basoflagellomere elongated $(\mathrm{bf}=1.8)$, arista short, about same length as basoflagellomere (Fig. 26); tergite II usually with small pale lateral spots; hind femora broader (Fig. 24). Medium sized, dark species with olive-brown reflection; antennae dark; legs black; body hairs predominantly pale, except black hairs on frons, on scutum between wing bases, on tergites III, IV and on apical part of femora; scutum with narrow central and two pairs of lateral pollinose stripes; tergites II-IV with pollinose stripes. . . . . Merodon serrulatus

- Basoflagellomere shorter ( $\mathrm{bf}=1.3$ ), arista 1.7 times longer than basoflagellomere (Fig. 27); tergite II dark; hind femora narrow and slender (Fig. 23). Big, but slender species with dark tergites, black legs, dark antennae; scutum with blackbluish stripe between wing bases, covered with black hairs; tergites II-IV with pairs of pollinose stripes that are narrower or absent on tergite IV . . . . . . . Merodon aberrans

17 Femora thickened and covered with long hairs on the ventral surface (Fig. 28). Species with reddish antennae, predominantly pale fore and mid tibiae and pale tarsi; scutum with stripe of black hairs between wing bases and four longitudinal pollinose stripes; tergite II with lateral orange spots; tergites III, IV with whitish pollinose semicircular stripes, slightly interrupted in the middle....... Merodon elegans

- Femora narrower and with short hairs on ventral surface (Fig. 29) ......................... 18

18 Tarsi uniformly pale coloured; basoflagellomere slightly longer (Figs 19, 20) . . . . . . . . . . . . . . . . . . . . 19

- Tarsi darkened dorsally; basoflagellomere slightly shorter

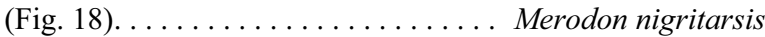

19 Tergite II with pollinose spots, tibiae usually pale. . . . . . . .

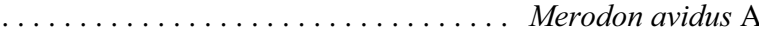
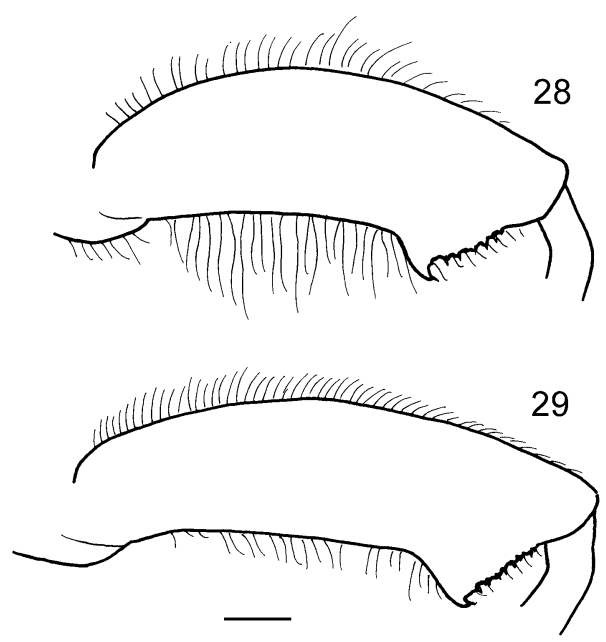

Figs 28, 29. Left hind femur, lateral view, females. 28 Merodon elegans. 29 - M. avidus. Scale $1 \mathrm{~mm}$.

- Tergite II unpollinose, hind tibiae always partly dark. ......

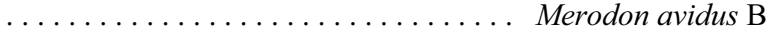

20 Anterior anepisternum below postpronotum with many long hairs (Fig. 31); small species with stocky abdomen. . . . . 21

- Anterior anepisternum below postpronotum with bare area (Fig. 30).......................... 31

21 Basoflagellomere elongated (bf: 1.2 and more); hind trochanter in male with thorn-like processes (Figs 40-43); on male genitalia anterior surstyle lobe reduced (as in Figs 126, 127). . . . . . . . . . . . . . . . . . . . . . . . . . 22

- Antenna (Figs 32, 33) short, basoflagellomere rounded (bf: 1.0); hind tibia with central nick (Figs 44, 45); hind trochanter in male without thorn (Fig. 44) (in some specimens with small sharp protuberance, Fig. 46); male genitalia with developed anterior lobe (Figs 133-136). Bare, central stripe occupies about $1 / 3$ of face; tergites shiny, unpollinose (in some specimens tergite III with very narrow and small pollinose stripes). . . . . . . . . . . Merodon cabanerensis sp. n.

22 Pedicel as long as basoflagellomere (Figs 34, 35); tergite IV with adpressed golden-greyish hairs, which clearly contrast with black haired central parts of tergites III (and II); on male genitalia posterior surstyle lobe pointed towards apex (Figs 170-173). Antennae usually dark; hairs on eyes from whitish to greyish; scutum medium punctured, usually with two narrow central and two broader lateral pollinose stripes; legs dark with pale knees, tibiae at both ends and tarsi (at least ventrally); tergites with very rough punctures, especially on dark haired parts of tergites II, III; tergites II-IV with pale pollinose stripes covered with pale hairs........ ........................ Merodon funestus

- Pedicel shorter than basoflagellomere; tergite IV with hairs arranged differently; posterior surstyle lobe with rounded apex (as in Fig. 126) . . . . . . . . . . . . . 23

23 Tergite II with reddish lateral spots; tergites unpollinose; thorn on hind male trochanter very small (Fig. 42). Antennae brown; eye hairs pale-brownish, darker on upper part; mesonotum and abdomen hairs pale; legs dark, knees and base of tibiae pale; male genitalia as in Figs 239-243. Tergite III usually also with reddish spots, but they can be small or absent in some specimens. . . Merodon unguicornis

- All tergites dark. . . . . . . . . . . . . . . . . . . . . . 24

24 Tibiae yellow, occasionally with dark traces in the middle; tarsi yellow, except two apical tarsomeres that can be darkened............................ 25 

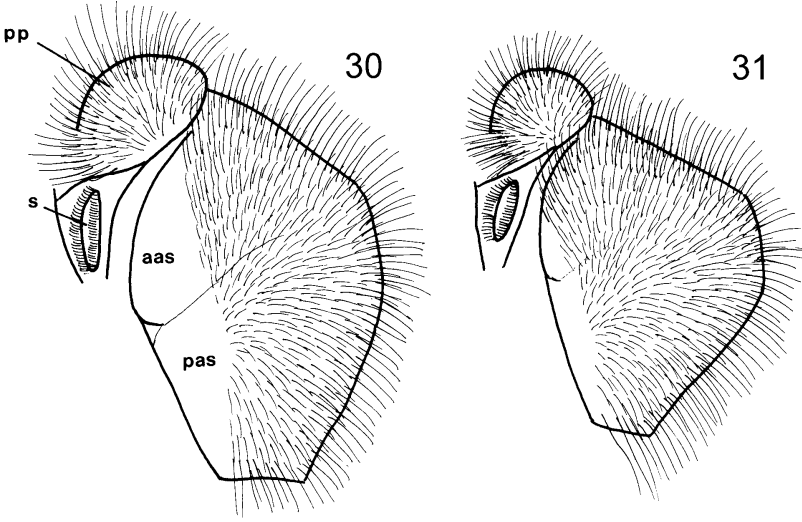

Figs 30, 31. Thorax (anepisternum), lateral view. $30-$ Merodon geniculatus; 31 - M. legionensis sp. n.; aas - anterior anepisternum; pas - posterior anepisternum; pp - postpronotum; $\mathrm{S}-$ anterior spiracle.

- Legs dark, tibiae at least with dark central ring, hind tarsi at least dorsally darkened. . . . . . . . . . . . . . . . 26

25 Upper $1 / 4$ of eyes black haired (black hairs usually also occur on the lower part of eyes); scutum covered with pale hairs; male abdomen completely pale haired; hind femora pale haired; male genitalia as in Figs $182-185 . . . \ldots \ldots \ldots$ ..................... Merodon legionensis sp. $\mathrm{n}$.

- Eyes pale haired, only a few black hairs may occur on the upper (and lower) part; mesonotum pale haired, usually with few black hairs at wing basis; in male posterior $1 / 3$ of tergite II and all of tergite III (except central pollinose stripes) black haired; apical part of hind femora at least with few black hairs; male genitalia as in Figs $223-226 . . . \ldots \ldots$. . . ................... Merodon quercetorum $\mathrm{sp} . \mathrm{n}$.

26 Male............................. 27

- Female............................ 29

27 Abdomen and mesonotum completely pale haired; body hairs dense, yellow-reddish; tegument of mesonotum and tergites with golden tomentum; hind femora pale haired. . 28

- Tergite II on posterior $1 / 3$ and central parts of tergite III (except pale stripes on the middle) black haired; mesonotum usually at least near wing bases with black hairs; body hairs sparser; mesonotum and tergites with dark-olive tegument; apical part of hind femora with black hairs; male genitalia as in Figs 137-144. Basoflagellomere (Fig. 49) reddish to brown; upper (and lower) part of eyes dark haired; body hairs whitish-grey to yellow-grey; legs dark, tibiae at both ends and tarsi in part can be paler; tergites II, III with small pollinose stripes. This species can be very variable in size (4-11 mm) (Figs 47, 48), length of eye line contiguity (Figs $51,52)$, pollinose areas on tergites: from pollinose areas present on all tergites (Fig. 53) to shiny tergites, except small pollinose spots on tergites II and III (Fig. 54), and length and density of body hairs. .......... Merodon chalybeus

28 At least upper half of eyes with black hairs. Basoflagellomere reddish to dark-brown, legs dark except knees, both ends of tibiae and tarsi in part, that can be paler; male genitalia as in Figs 126-129. . . . . . . . . Merodon pumilus

Eyes completely pale haired, rarely with few black hairs on upper corner. Basoflagellomere reddish to dark-brown, legs dark except knees, both ends of tibiae and part of tarsi, which can be paler; male genitalia as in Figs 220-222 . . . . . . . . . . . . . . . . . . . . . . . . . Merodon unicolor

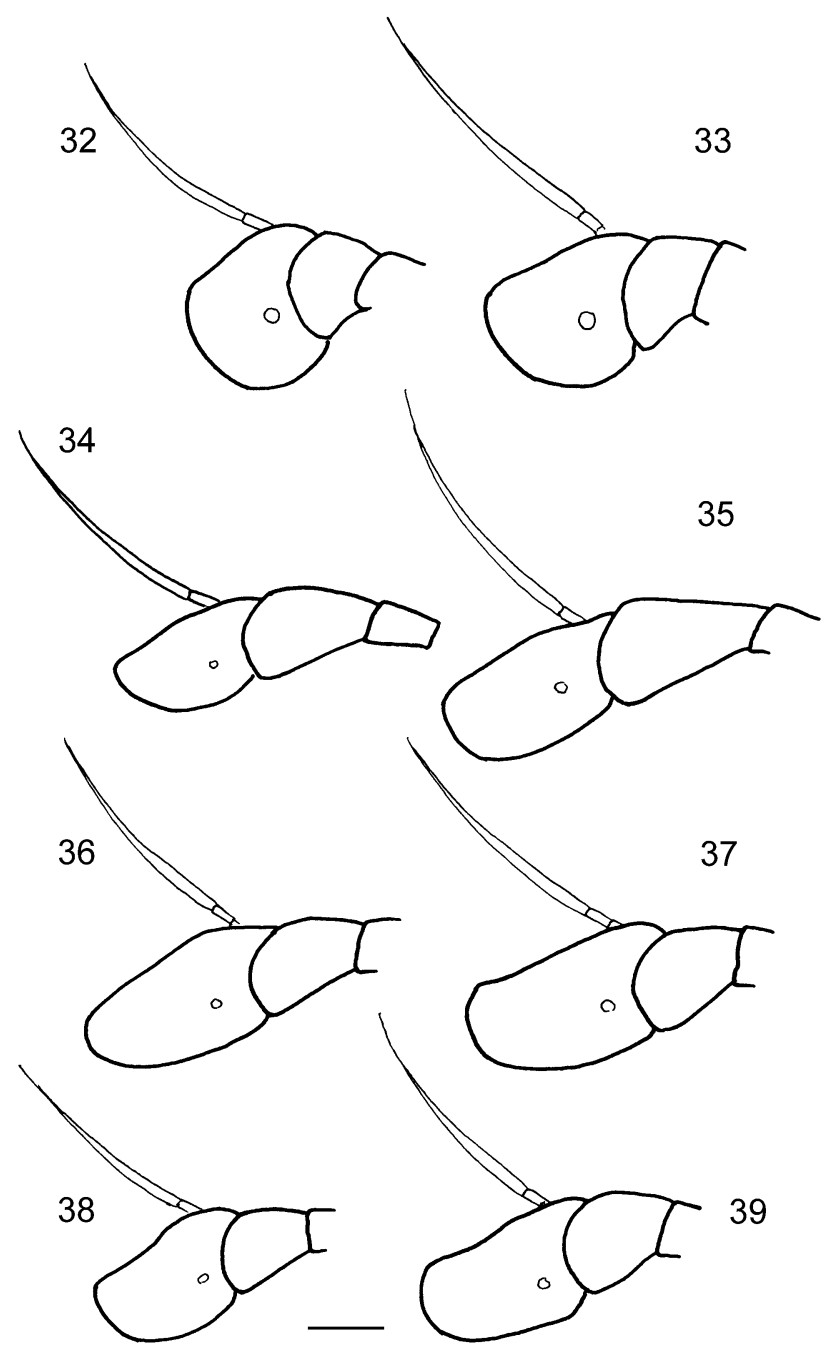

Figs 32-39. Right antenna, inner view (basoflagellomere and pedicel). 32, 33. Merodon cabanerensis sp. n.; 34, 35. M. funestus; 36, 37. M. legionensis sp. n.; 38, 39. M. quercetorum sp. n.; $32,34,36,38$ - males; 33, 35, 37, 39 - females. Scale $0.2 \mathrm{~mm}$.

29 Tergites II-IV with clear whitish pollinose stripes; scutum with golden tomentum and covered with yellow hairs; hind femora pale haired. . . . . . . . . . . . . . 30

- Only tergites II, III (or only tergite II) with clear whitish pollinose stripes (Figs 55, 56); scutum dark with whitegreyish hairs; hind femora with black hairs on apical part. Eye hairs whitish on central part, dark-grey and black on the upper (and usually on lower) part. This species can be very variable in size $(4-11 \mathrm{~mm})$, pollinose areas on tergites: from pollinose areas present on all tergites (Fig. 55) to shiny tergites, except small pollinose spots on tergite II (Fig. 56), length and density of body hair. ...... Merodon chalybeus

30 At least upper $1 / 3$ of eyes with black hairs............

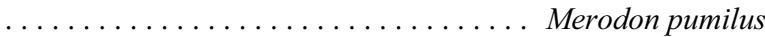

- Eyes completely pale haired, only a few black hairs may be present on upper corner. ............. Merodon unicolor

31 Humeri, postalar calli, antennae, tibiae and tarsi of fore and middle legs yellowish; male genitalia as in Figs 194-197. Large species with relatively short body hairs, small basoflagellomere (Figs 74, 77); whitish hairs on frons and face, pollinose stripes on mesoscutum, red-yellow lateral spots on tergite II and pair of pollinose stripes on tergites II-IV . . . . . . $\ldots \ldots \ldots \ldots \ldots$ Merodon luteihumerus sp. $\mathrm{n}$. 


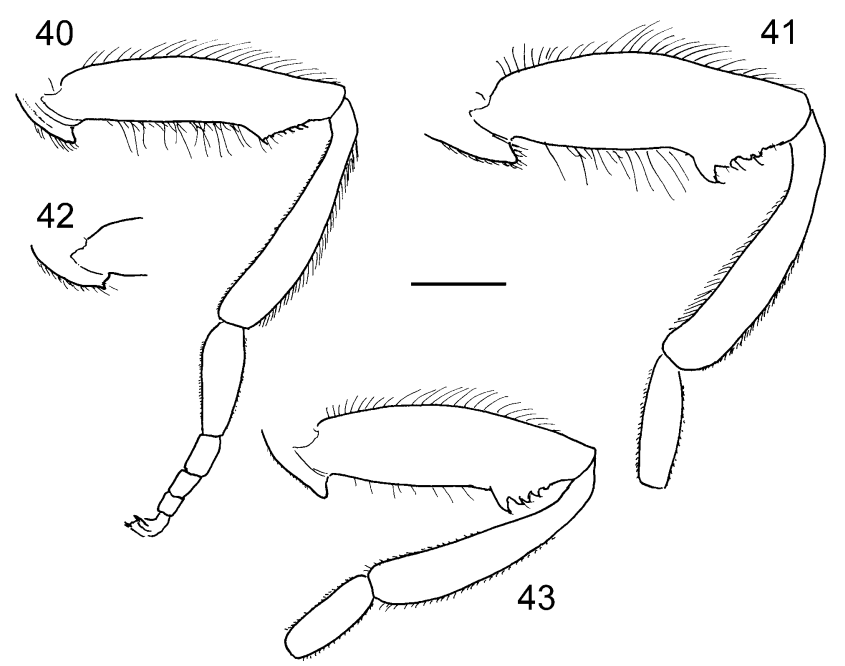

44
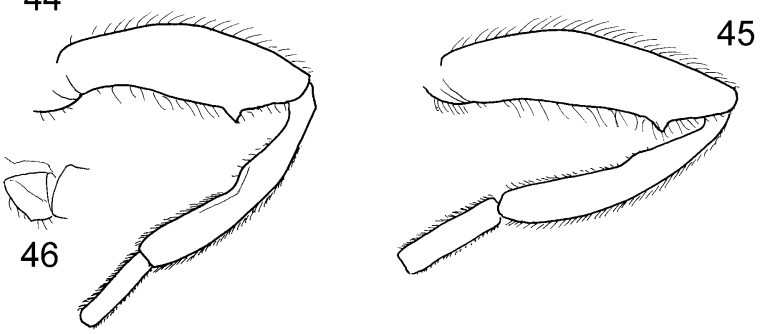

Figs 40-46. Left hind leg. 42, 46 - hind trochanter; 40-45lateral view; 46 - posterior view; 40 - Merodon unicolor; 41 M. legionensis sp. n.; $42-$ M. unguicornis, hind trochanter; $43-$ M. quercetorum sp. n.; 44-46-M. cabanerensis sp. n.; 40-44, 46 - males; 45 - female. Scale $1 \mathrm{~mm}$.
Humeri and postalar calli dark. . . . . . . . . . 32

32 Male................................ 33

- Female.......................... 48

33 Hind tibiae with long apico-medial prolongation (Figs 57, 58); big, bumblebee-like species. . . . . . . . . . . 34

Hind tibiae without such long prolongation. ........ 35

34 Apical prolongation of hind tibiae long and curled (Fig. 57); hind tibiae with large central bulge; male genitalia as in Figs 155-158. Body hairs can be variable, from almost completely pale to specimens with black haired posterior half of scutum and tergite III (a few varieties were described based on this variation). . . . . . . . . . . Merodon equestris

- Apical prolongation of hind tibiae shorter (Fig. 58); bulge on hind tibiae small or absent; male genitalia as in Figs 165-169. . . . . . . . . . . . . . . . . . . Merodon flavus

35 Hind femora with ventral bulge on basal fifth (Fig. 59); hind trochanter with clear rounded projection (Fig. 59); male genitalia as in Figs 235-238. .... Merodon trochantericus

- Hind femora without basal bulge. . . . . . . . . . . 36

36 Hind trochanter with blunt thorn, usually covered with hairtuft (geniculatus species group and sometimes teruelensis) (Figs 60-63) . . . . . . . . . . . . . . . . 37

- Hind trochanter without this type of processes....... 41

37 Hind trochanter with very long projection (Fig. 60); basotarsomere of hind leg with medial incision on central part (Fig. 64); hind femora swollen, curved basally (Fig. 60); male genitalia as in Figs 186-189. Basoflagellomere (Fig. 66) reddish; eyes pale haired; tibiae pale with dark central part; tarsi pale, except two darkened tarsomeres; body hairs pale; tergites black; tergite II with reddish lateral spots; tergites III, IV with pollinose stripes. ... Merodon longispinus sp. $\mathrm{n}$. - Hind trochanter with shorter prolongation.......... 38
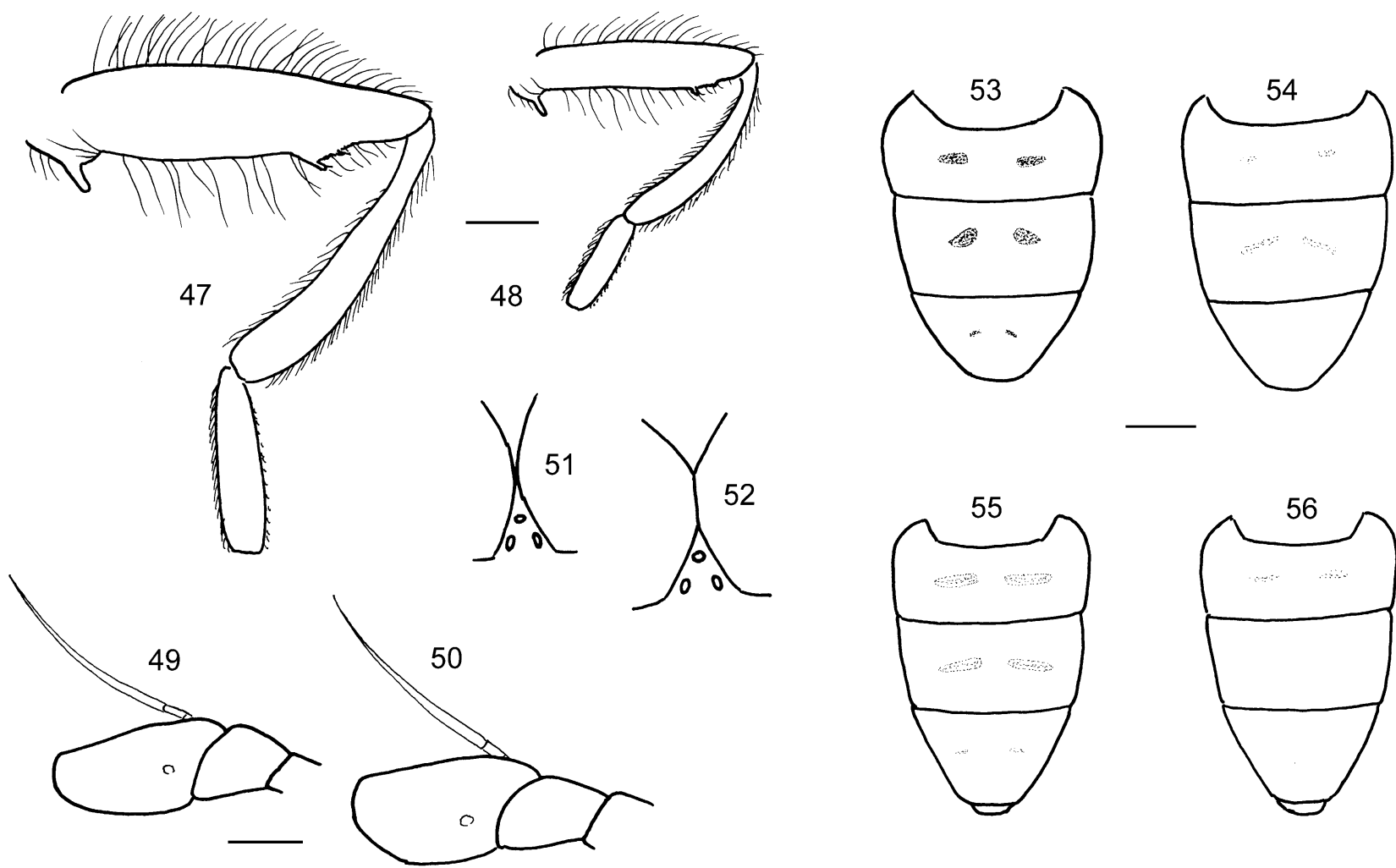

Figs 47-56. Merodon chalybeus. 47, 48 - left hind leg, lateral view. Scale $0.5 \mathrm{~mm} ; 49,50$ - right antenna, inner view (basoflagellomere and pedicel); 51, 52 - eye contiguity, dorsal view. Scale $0.2 \mathrm{~mm} ; 53-56$ - tergites II-IV, dorsal view; 47-49, 51-54 - males; $50,55,56$ - females. Scale $1 \mathrm{~mm}$. 

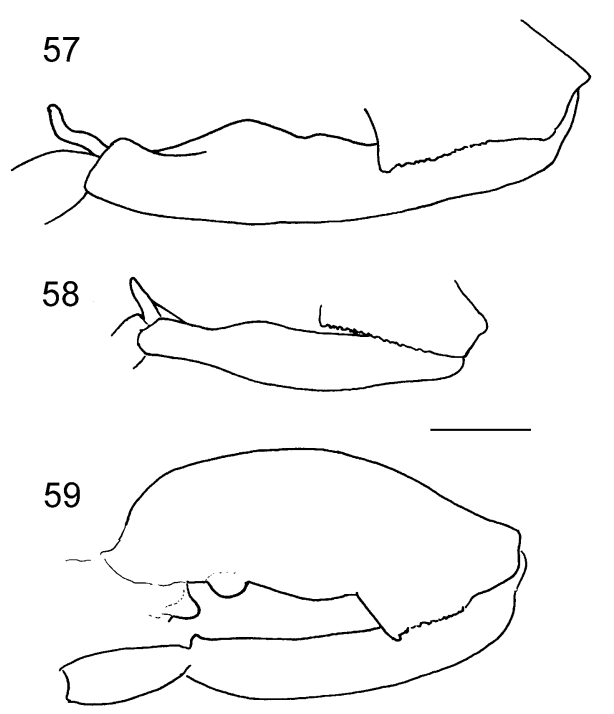

Figs 57-59. Legs, males. 57-58 - left hind tibia, dorso-lateral view; 59 - left hind leg, lateral view; 57 - Merodon equestris; 58 - M. flavus; 59 - M. trochantericus. Scale $1 \mathrm{~mm}$.

38 Scutum with stripe of black hairs between wing bases. Hind tibia with apico-medial spur (Fig. 62); cercus has two distinct prolongations, posterior more expressed (Fig. 73). ..... .................... Merodon crypticus sp. n.

- Scutum pale haired, exceptionally with few black hairs near

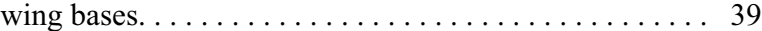

39 Basoflagellomere elongated, distance between tip of antenna and antennal pit six times longer than distance between antennal pit and pedicel (Figs 67, 68); hind tibia with apicomedial spur; top of hind tibia reaches the base of hind femur; hind femur without ventral bulge at basal 1/4 (Fig. 61 ); cercus with distinct apical prolongations (Figs 71, 72). . 40

- Basoflagellomere shorter, distance between top of antenna and antennal pit about three times longer than distance between antennal pit and pedicel (Fig. 65); hind tibia without apico-medial spur; hind tibia short, ending before the base of hind femora; hind femur with small ventral bulge (Fig. 63); male genitalia in Figs 174-177: cercus with only small anterior prolongation (Fig. 70). Medium sized species (9-11 mm); scutum with unpollinose shiny parts, especially on posterior half; spur on trochanter small (Fig. 63); hind basotarsomere usually partly pale dorsally; tergites II-IV with pollinose stripes. . . . . . . . . Merodon geniculatus

40 Cercus with strongly developed anterior prolongation (Fig. 72); scutum completely pale haired. . . . . . . . . . . ....................... Merodon antonioi $\mathrm{sp.} \mathrm{n}$. - Cercus with two strong, anterior and posterior prolongations (Fig. 71); scutum usually with a few black hairs near wing bases. .......................

41 Anterior surstyle lobe without clear thorns or extensions (Figs 198, 199, 227, 228)................. 42

- Anterior surstyle lobe with thorns or extensions (as in Figs $112,113) \ldots \ldots \ldots \ldots \ldots \ldots \ldots \ldots \ldots \ldots \ldots \ldots \ldots$

42 Anterior and posterior surstyle lobes well separated, L-shaped (Fig. 198); basoflagellomere shorter (bf $=1.8$ ) (Fig. 75); tergites II-IV with clear white pollinose stripe. ...

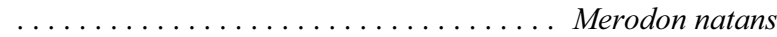

- Anterior margin of surstyle more or less straight (Fig. 227); basoflagellomere longer $(\mathrm{bf}=2.0)$ (Fig. 76); tergite IV (and usually tergite III) unpollinose. . . . . . . . Merodon segetum

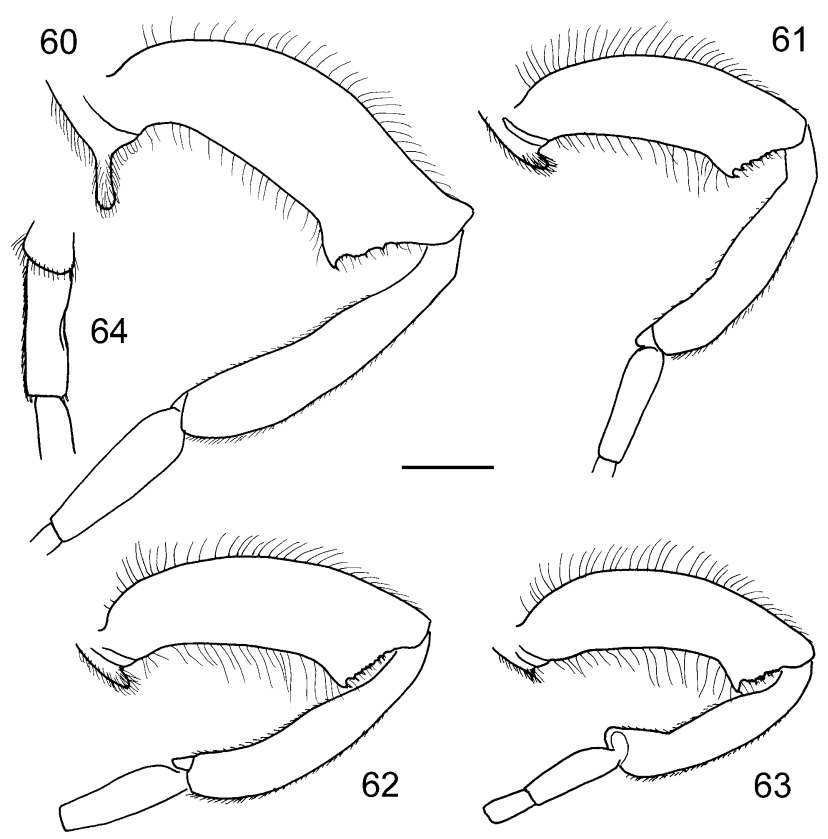

Figs 60-64. Left hind leg, males. 64 - hind basitarsomere, dorsal view; 60, 64 - Merodon longispinus sp. n.; $61-$ M. escorialensis; $62-$ M. crypticus sp. n.; $63-$ M. geniculatus. Scale 1 $\mathrm{mm}$.

43 Species with black body ground-colour, without clear pollinose stripes on scutum and small or no pollinose stripe on tergites III, IV; scutum usually with stripe of black hairs between wing bases; trochanter without or with clear hump (Fig. 80); legs with long hairs; tergite II with small brownish lateral spots; male genitalia as in Figs $231-234 \ldots \ldots \ldots \ldots$. . . . . . . . . . . . . . . . . . . . . . Merodon teruelensis

- At glance species with more brownish, olive or bluish ground colour. . . . . . . . . . . . . . . . . 44

44 Species with stocky abdomen; only tergite II with clear reddish lateral spots (Fig. 83); male genitalia as in Figs 215-219.................... Merodon parietum

- Species with more elongated abdomen (as in Fig. 84) and different male genitalia. . . . . . . . . . . . . . 45

45 Posterior surstyle lobe with notch before apex (Figs 122, 205)........................ 46

- Posterior surstyle lobe without notch (as in Fig. 112). . . 47

46 Body covered with dense, reddish hairs, erect on tergites; tergites III, IV with narrow greyish pollinose stripes; male genitalia as in Figs 122-125. ... . Merodon arundanus sp. n.

- Pale body hairs, more yellowish and greyish; on central part of tergites III, IV short, adpressed and mixed black and pale hairs; tergites III, IV with white pollinose stripes (Fig. 84); male genitalia as in Figs 205-210. . Merodon obscuritarsis

47 Tergites III, IV with large pollinose stripes, stripe on tergite IV at least $1 / 4$ of tergite's length (Fig. 86); hind trochanter with clear angular hump (Fig. 81); male genitalia as in Figs 178-181................. Merodon hurkmansi sp. n.

- Tergites III, IV with narrower pollinose stripes, stripe on tergites IV less than 1/5 of tergite's length (Fig. 85); hind trochanter with only very small hump (Fig. 82); male genitalia as in Figs 112-115........... Merodon albifrons

48 Species without pollinose stripes on tergites and with long erect hairs on tergites III, IV . . . . . . . . . . . . . . . . 49

- Species with at least slightly pollinose tergites. . . . . . . 51

49 Hind tibia black haired; tergites II-IV shiny black; legs black. . . . . . . . . . . . . . . . . . . . . . . . . 50 


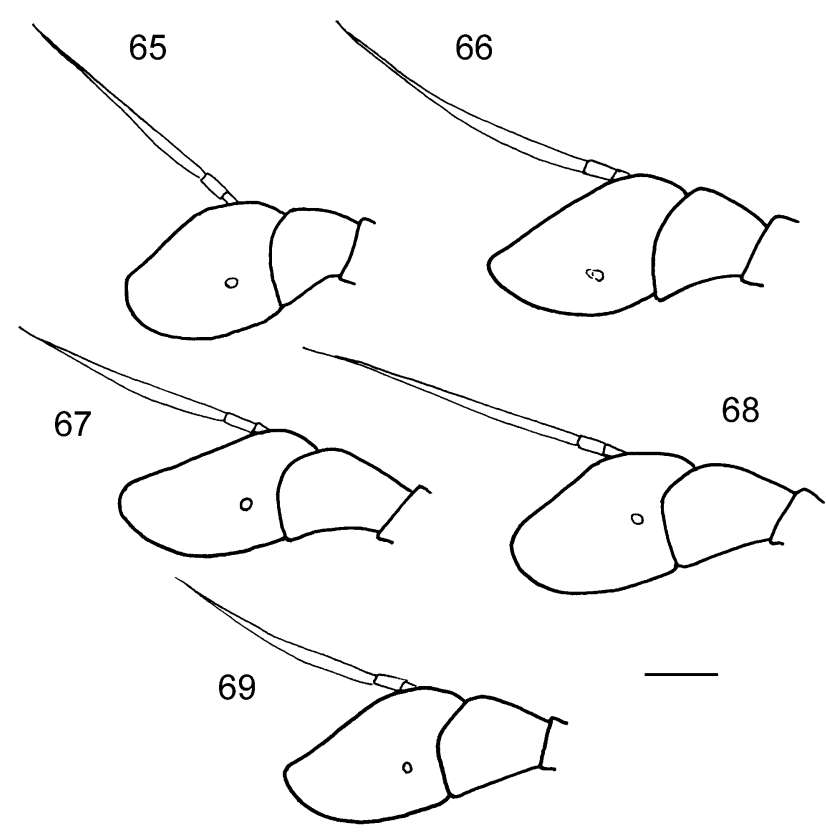

Figs 65-69. Right antenna, inner view (basoflagellomere and pedicel), males; 65 - Merodon geniculatus; $66-M$. longispinus sp. n.; $67-M$. antonioi sp. n.; $68-$ M. escorialensis; $69-M$. crypticus $\mathrm{sp} . \mathrm{n}$. Scale $0.2 \mathrm{~mm}$.

- Hind tibia pale haired; tergites II-IV dull brown; tibiae and tarsi partly pale............... Merodon teruelensis

50 Hind femora on ventral side with long hairs (long as width of femur) (Fig. 94); tergites III, IV with long semi adpressed and erect hairs................. Merodon equestris

- Hind femora without such long hairs on ventral side (Fig. 95); tergites III, IV predominantly covered with adpressed hairs mixed with a few erect. .......... Merodon flavus

51 Hind femora with small ventral hump, near base (Fig. 96). . ................... Merodon trochantericus Hind femora without ventral hump. . . . . . . . . . . 52

52 Basoflagellomere longer $(\mathrm{bf}=1.8$ and more) $($ Figs 78,79$) \ldots$ .............................. 53 Basoflagellomere shorter $(\mathrm{bf}=1.5$ and less) (Figs 97-99). . . ........................... 54

53 Large species (about $15 \mathrm{~mm}$ ); tergites III, IV without or with very narrow pollinose stripes; basoflagellomere more than twice longer than wide (Fig. 79); scutum with two patches of black hairs anteriorly of transversal suture.

Medium sized species (about $10 \mathrm{~mm}$ ); tergites II-IV with broad white pollinose stripes; basoflagellomere less than twice longer than wide (Fig. 78); scutum pale haired (few intermixed black hairs may appear on posterior half). .

54 Posterior margin of at least tergite IV with clear whitish

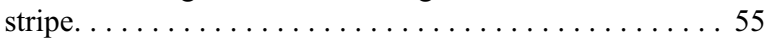

- Tergites dark, without pale posterior margin. Only tergite II with reddish lateral spots; pale haired scutum usually with few black hairs, especially between wing bases.......... . . . . . . . . . . . . . . . . . . Merodon teruelensis

55 Hind tibiae short, ended on the apical $1 / 3$ of hind trochanter (Fig. 100); basoflagellomere short, distance between antennal pit and top of basoflagellomere less than three times longer than distance between antennal pit and pedicel (Fig. 105). . . . . . . . . . . . . . Merodon geniculatus Hind tibiae longer (Figs 101-104). . . . . . . . . . 56
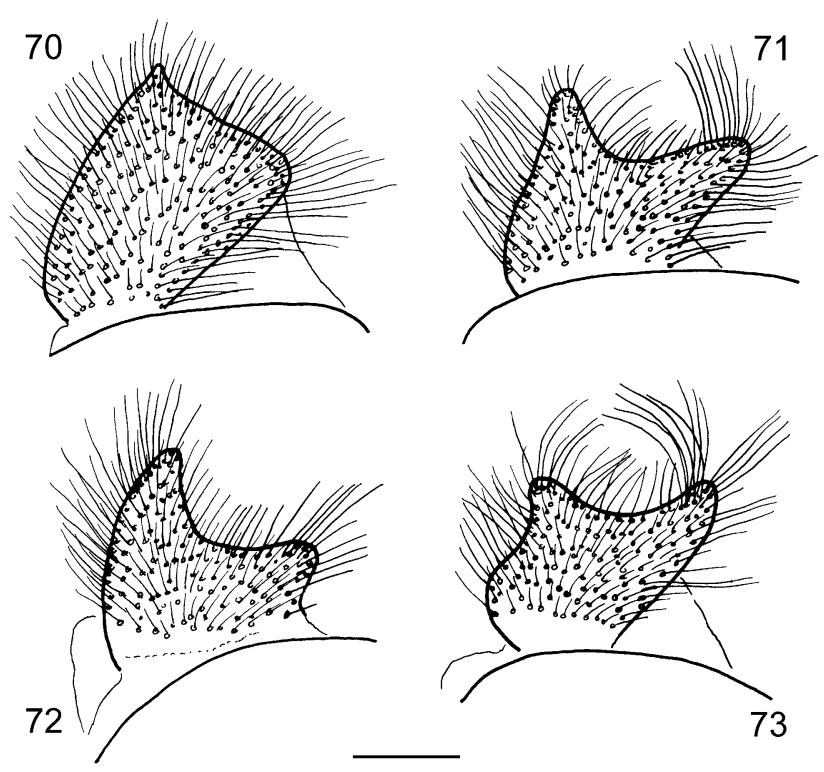

Figs 70-73. Male genitalia, left cercus, lateral view. $70-$ Merodon geniculatus; $71-$ M. escorialensis; $72-$ M. antonioi sp. n.; $73-$ M. crypticus sp. n. Scale $0.2 \mathrm{~mm}$.

56 Scutum with stripe of black hairs between wing bases...... ....................... Merodon crypticus sp. n.

- Scutum pale haired, only few black hairs can occur near

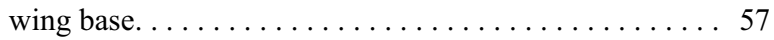

57 Apical $1 / 3$ of hind tibia arcuate ventrally direction (Figs

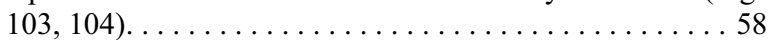

- Hind tibia with more or less straight ventral margin (Figs 101, 102) . . . . . . . . . . . . . . . . . . . . . . 59

58 Tarsi with at least a few black bristly hairs........... ....................... Merodon escorialensis Tarsi with only pale bristly hairs... Merodon antonioi $\mathrm{sp.} \mathrm{n}$.

59 Tergites dark, only tergite II with reddish lateral spots; tergite IV with dense yellowish-white hairs especially in posterior half and laterally; hind legs predominantly black, except base of tibiae and tarsi on ventral side that may be paler. ....

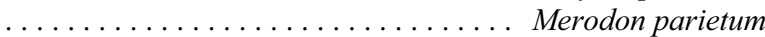

- Tergite IV with sparser hairs; hind legs partly yellow, at least tibiae at both ends and basotarsomere pale. . . . . 60

60 Stripes on tergites broader; tergite IV with white pollinose stripes occupying $1 / 3-1 / 4$ of tergite's length (Fig. 86). . . . . $\ldots \ldots \ldots \ldots$............... Merodon hurkmansi sp. n.

- Stripes on tergites narrower. ................ 61

61 Tergites III-V mainly reddish and predominantly pale

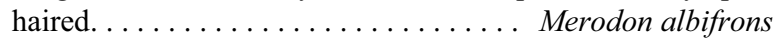

- Tergites III-V mainly black, predominantly black haired, except lateral sides and pollinose parts covered with pale hairs. . . ................ Merodon obscuritarsis

\section{TAXONOMY}

\section{Merodon aberrans Egger, 1860}

Figs 7, 14, 23, 27, 109-111

Merodon aberrans Egger, 1860: 664.

Diagnosis. Species with bare cx and reduced hairs on pa; big (12-15 $\mathrm{mm}$ ) but slender species with dark tergites, black legs, dark antennae; scutum with bluish black stripe between wing bases of wings covered with black hairs; basoflagellomere short ( $b f=1.1)$, arista long (Figs 7, 27); tergite II dark; hind femora narrow and slender (Figs 14, 


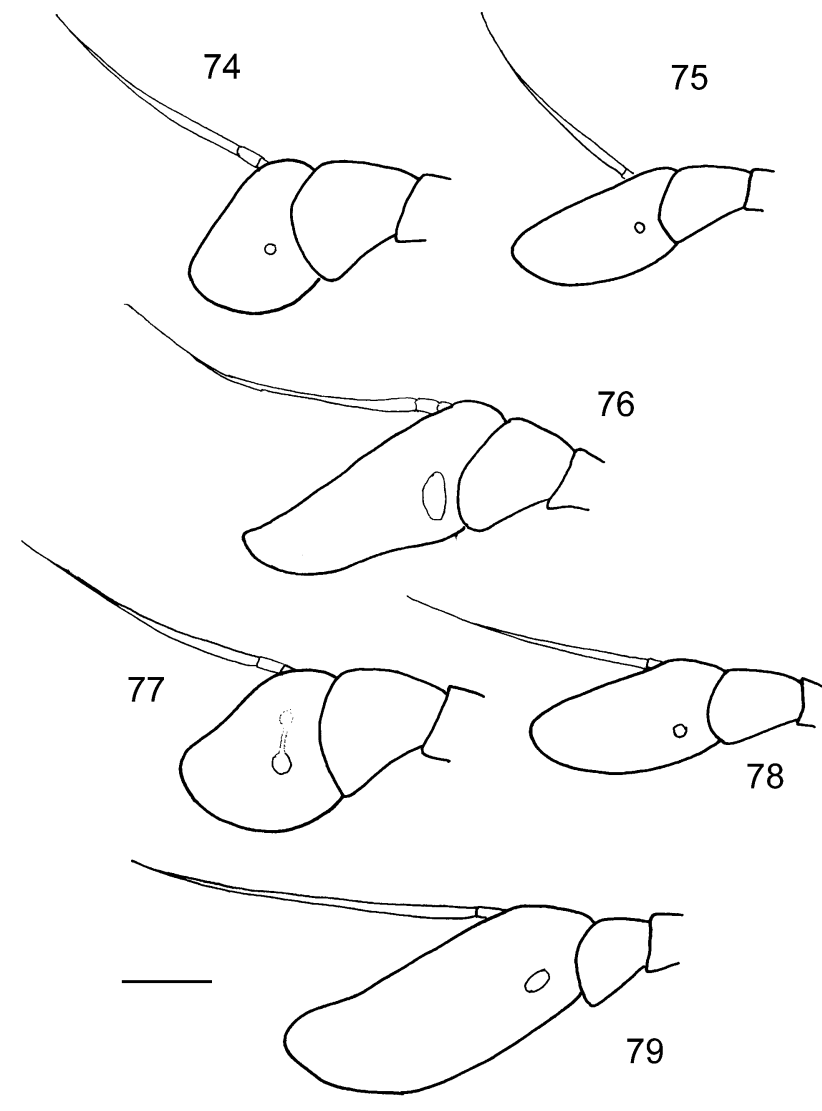

Figs 74-79. Right antenna, inner view (basoflagellomere and pedicel). 74, 77 - Merodon luteihumerus sp. n.; 75, $78-M$. natans; 76, 79 - M. segetum; 74-76 - males; 77-79 - females. Scale $0.3 \mathrm{~mm}$.

23); male genitalia: AL large, covered with dense short hairs; interior accessory lobe of PL well-developed, covered with strong bristles; L very long, S elongated (Figs 109-111).

Published records. Peck, 1988; Dirickx, 1994.

Biology. Preferred environment: Unimproved, calcareous montane grassland and patchily-vegetated, herbrich open areas within the Abies forest zone. Flowers visited: Apiaceae. Period of flight: May/July and August at higher altitudes.

Iberian distribution. Sistema Central of Spain (Fig. 244).

Range. through central Europe from Germany, the Czech Republic and the Alps (France, Switzerland, Austria) to Hungary and Romania and on to the Ukraine and southern Russia; in southern Europe from mountainous parts of Portugal and Spain eastwards to Italy, Albania, the former Yugoslavia and Greece and on to Turkey and round the Mediterranean (Lebanon) into North Africa (Morocco), including Mediterranean islands e.g. Crete.

\section{Merodon albifrons Meigen, 1822}

Figs 1, 2, 82, 85, 87, 91, 97, 101, 112-115

Merodon albifrons Meigen, 1822: 359.

Merodon spinipes grossus Gil Collado, 1930: 254 syn. n.

Merodon albifrons was described from an unspecified number of females. Lectotype (designated here): female "M. albifrons m. Gallia / Galia Merid. Coll. Winthem /
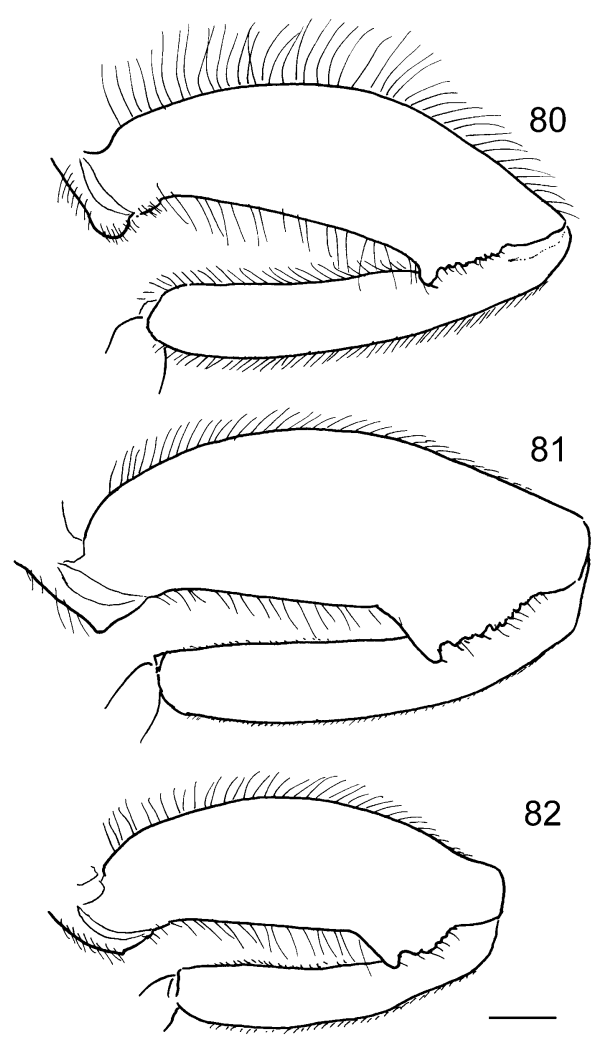

Figs 80-82. Left hind leg, lateral view, males. $80-$ Merodon teruelensis; $81-$ M. hurkmansi sp. n.; $82-$ M. albifrons. Scale $0.5 \mathrm{~mm}$.

Typus / albifrons det. Sack" (NHMW). Paralectotype female "albifrons / 1918 40" (MNHN, Meigen collection). There were two type specimens (syntypes) found in two Museums; the designation of lectotype was based on more comprehensive data on specimen in NHMW collection.

Merodon grossus (as var. of spinipes): Lectotype (designated here): male "spinipes v. grossus / Valvidriera" (Barcelona, Spain) (IEE). Paralectotype: male "spinipes v. grossus / Tiermas" (IEE) [there are two more syntypes preserved in IEE, but are currently on loan; the identity of these specimens is unclear]. Identity: available name, a junior synonym of $M$. albifrons.

Diagnosis. Species with hairy cx and reduced hairs on pa; medium sized $(10.6-12.6 \mathrm{~mm})$, short haired species with reddish abdomen; bf = male 1.1, female 1.2 (Figs 91, 97); male genitalia: PL rounded; surstyle margin with strong marginal thorn; AL with well-developed apical extension; S hammer-like (Figs 112-115). M. albifrons is fairly similar to $M$. hurkmansi sp. n. but can be distinguished by their pollinose abdominal stripes, wider in $M$. hurkmansi sp. n. (Fig. 86) than in M. albifrons (Fig. 85); hind trochanter with a clear angular hump in M. hurkmansi sp. n. (Fig. 81) very small in M. albifrons (Fig. 80).

Type material examined. Lectotype: Gil Collado, 1930 as Merodon spinipes var. grossus: Spain, Barcelona: $10^{\text {t }}$ "Valvidriera" (IEE). Paralectotype: Gil Collado, 1930 as Merodon spinipes var. grossus: Spain: Zaragoza: 10 , “Tiermas” (IEE). 


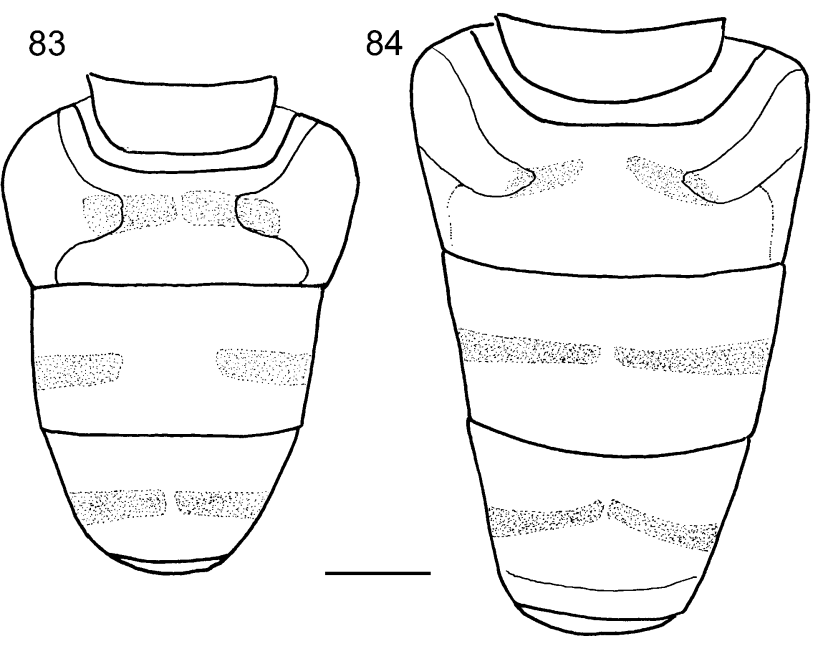

Figs 83-84. Abdomen, dorsal view, males. 83 - Merodon parietum; $84-$ M. obscuritarsis. Scale $1 \mathrm{~mm}$.

Other material examined. Unpublished material: Spain, Albacete: Riopar; Viveros; Alicante: Caveta del Buitre, Xixona; El Menetjador, Alcoi; Foia Ampla, Agres; Font Retura, Agres; Font Roja, Alcoi (CEUA \& NSEC); Mas de Cano, Xixona; Mas de St. Ignaci, Xixona; Venta Carrasqueta, Xixona; Barcelona: La Garriga; Granada: Hazas de Plan Diezma; Murcia: Yecla; Valencia: Chelva; Mas del Parral, Bocairent; Utiel; Zaragoza: Los Monegros.

Additional published records. Czerny \& Strobl (1909); Arias (1912); Andreu (1926); Gil-Collado (1930); Peris (1958); Van der Goot \& Lucas (1967); Marcos-García (2000).

Biology. Preferred environment: open ground; stoney, unimproved, non-calcareous dry grassland and open, tallherb areas in Quercus pubescens and Q. ilex forest on calcareous substrates. Flowers visited: Chrysanthemum sp., Euphorbia sp., Helianthemum sp., Ranunculus sp., Senecio sp. Period of flight: April to September.

Iberian distribution: Sistema Ibérico (East of Spain), Pyrenees and mountains of the Centre of Portugal (Fig. 244).

Range. From central France south to the Mediterranean and North of Africa; from western Spain eastwards through central (Switzerland, Austria) and southern Europe (Corsica, Sardinia, Sicily, Italy, former Yugoslavia, Greece, Bulgaria, Romania) to the Crimea and Azerbaijan.

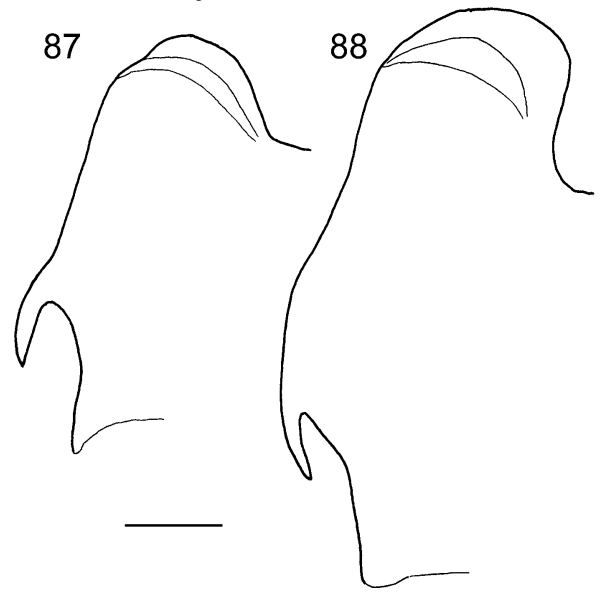

Figs 87,88 . Male genitalia, left surstylus, lateral view. $87-$ Merodon albifrons; $88-$ M. hurkmansi sp. n. Scale $0.2 \mathrm{~mm}$.
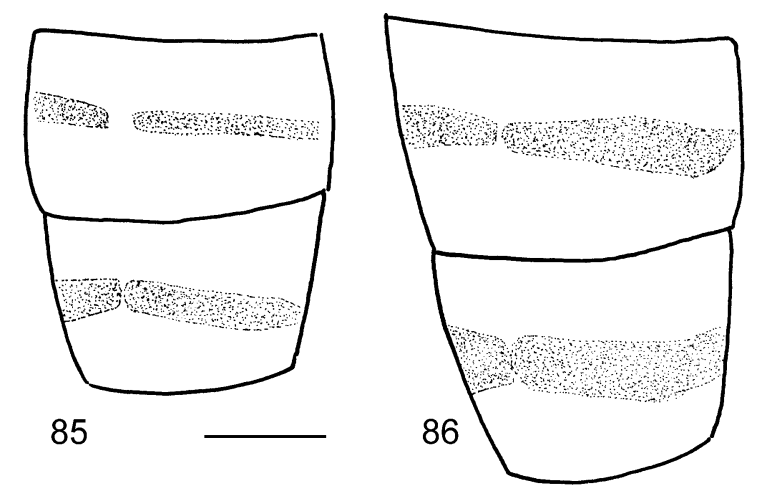

Figs 85, 86. Tergites III-IV, dorso-lateral view. 85 Merodon albifrons; $86-M$. hurkmansi sp. n. Scale $1 \mathrm{~mm}$.

\section{Merodon antonioi sp. $\mathbf{n}$.}

Figs 67, 72, 104, 107, 161

Male

Head. Antennae dark brown; basoflagellomere 1.5 times as long as wide; dorsal margin plain, apex acute; basoflagellomere and pedicel with some red ventral colouration. Face and frons shiny black covered with dense white pubescence and yellowish-white hairs. Oral margin bare and black lustrous. Vertical triangle isosceles, twice as long as eye contiguity distance, shiny black with white pubescence and red hairs. Ocellar triangle isosceles. Eyes with white hairs.

Thorax. Mesonotum and scutellum dark-green with metallic luster and covered with erect red hairs; five longitudinal lines of pubescence only visible under microscope. Posterior anepisternum, anepimeron and dorsal part of katepisternum with yellow long hairs. Wings palegreyish with dark veins. Dorsal and ventral calypters pale-yellow. Halteres yellow. Femora dark-brown with pale apical part. Fore and mid tibiae yellow in basal part

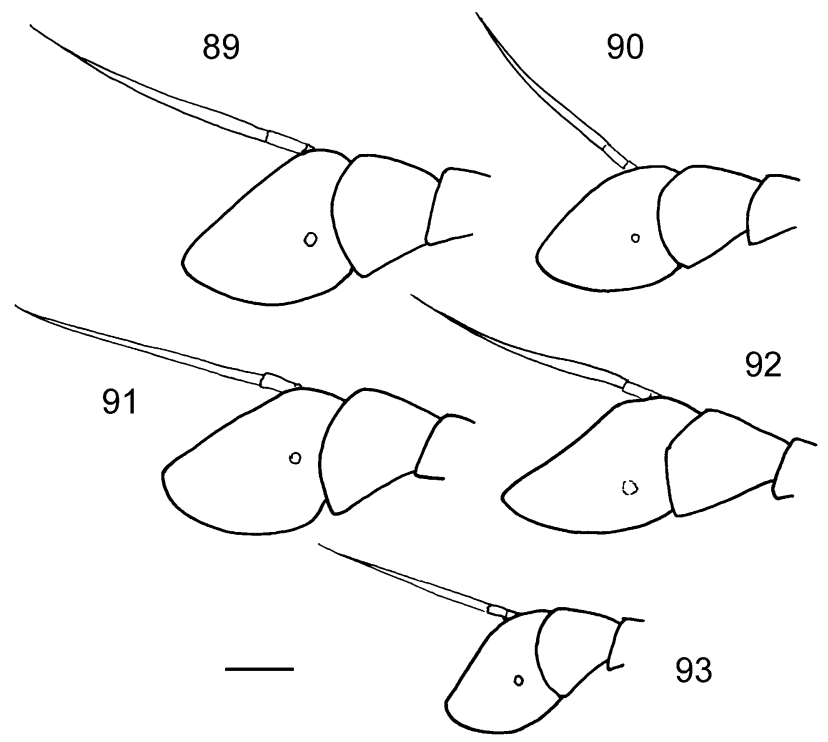

Figs 89-93. Right antenna, inner view (basoflagellomere and pedicel), males; 89 - Merodon arundanus sp. n.; $90-M$. obscuritarsis; $91-M$. albifrons; $92-M$. hurkmnasi sp. n.; $93-M$. parietum. Scale $0.2 \mathrm{~mm}$. 


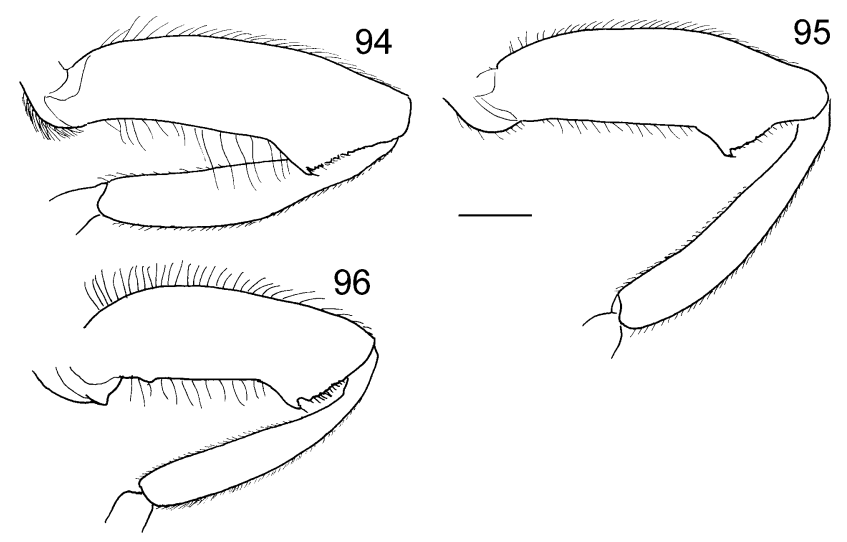

Figs 94-96. Left hind leg, lateral view, females; $94-$ Merodon equestris; 95 - M. flavus; 96 - M. trochantericus. Scale $1 \mathrm{~mm}$.

and black distal part, covered with yellow hairs. Hind tibiae yellow with dark median band, slightly sinuous in ventral part and with a blunt apicomedial process. Tarsi dark, occasionally with basal tarsomeres partly pale. Hind trochanter with a distinct thorn covered with dense, red hairs. All legs with red bristles and hairs.

Abdomen. Dark, oval and longer than mesonotum. Tergites II-IV black with white pruinose transverse band interrupted in the middle on tergites II and III; posterior margin of tergites pale; tergite II with red antero-lateral margin; tergites covered with black adpressed hairs except on the transversal lines which are yellow. Sternites, anterior corner of the tergite II and lateral margins of all tergites covered with long pale hairs. Sternite I dark anteriorly and pale posteriorly; sternite II and III pale; sternite IV and posterior ones dark brown.

Male genitalia. PL dorsally acute (Fig. 161). Surstyle margin clearly convex. C concave with one distinct apical prominence (Fig. 72). Hypandrium with folded thecal ridge.

Female

Similar to the male except for the following characteristics: Basoflageromellere and pedicel with more extended red ventral colouration. Ocellar triangle equilateral. Frons shiny, white dusted laterally and covered with yellowishwhite hairs anteriorly reclined. Mesonotum and scutellum with white hairs. Hind tibia without apical process.

Diagnosis. Species with hairy cx and reduced hairs on $\mathrm{pa}$, it belongs to the geniculatus group characterized by a hind trochanter with a blunt thorn, usually covered with hair-tuft (as in Fig. 61); bf $=1.5$; medium sized (12.6-14.0 mm) species; thorax covered with pale hairs. M. antonioi $\mathrm{sp}$. $\mathrm{n}$. is fairly similar to M. crypticus $\mathrm{sp} . \mathrm{n}$. and $M$. escorialensis but can be easily distinguished by the following morphological characteristics: pilosity of the vertical triangle completely white in $M$. escorialensis and $M$. antonioi sp. n. and with a tuft of dark hairs in $M$. crypticus sp. n.; mesonotum with uniform yellowishwhite hairs on dorsal surface in M. escorialensis and $M$. antonioi sp. n. and with one trasverse band of black pilosity at the level of wing insertion in M. crypticus sp.

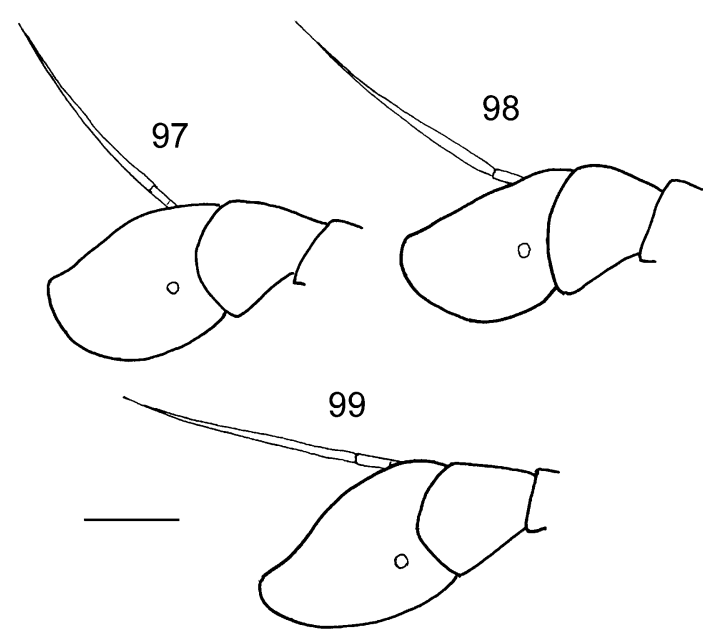

Figs 97-99. Right antenna, inner view (basoflagellomere and pedicel), females. 97 - Merodon albifrons; 98 - M. obscuritarsis; 99 - M. hurkmansi sp. n. Scale $0.3 \mathrm{~mm}$.

n.; hind tibia with a blunt apico-lateral process in $M$. escorialensis (Fig. 61) and M. antonioi sp. n. and sharp processes in M. crypticus sp. n. (Fig. 62); posterior surstyle lobe rounded in M. crypticus sp. n. (Fig. 162) and acute in M. escorialensis (Fig. 159) and M. antonioi sp. n. (Fig. 161); C in M. escorialensis with two apical prominences of similar size (Fig. 71), with a strongly developed anterior prominence in M. antonioi sp. n. (Fig. 72) and a much developed the posterior one in M. cryticus sp. n. (Fig. 73).

Variability. The colour of legs can vary from almost all tarsi pale to predominantly dark tarsi, especially dorsally.

Type material. Holotype: Spain, Ciudad Real: 10, P.N. Cabañeros, Fresneda 11.ix.2004, Leg. A. Ricarte (CEUA). Paratype: Spain, Ciudad Real: 2 $\widehat{0}$, P.N. Cabañeros, Fresneda 11.ix.2004, Leg. A. Ricarte (CEUA); 10 , P.N. Cabañeros, Fresneda 11.ix.2004, Leg. A. Ricarte (MNMS); $1 \delta^{\star}$, P.N. Cabañeros, Fresneda 11.ix.2004, Leg. A. Ricarte (NSEC); 1ㅇ, P.N. Cabañeros, Fresneda 02.x.2004, Leg. A. Ricarte (CEUA).

Etymology. The name antonioi refers to the first name of the collector of the type serie specimens, Antonio Ricarte.

Biology. Preferred environment: Open areas with Fraxinus angustifolia close to seasonal rivers. Adults were caught resting on the rocks of a dry river bed. Period of flight: September.

Iberian distribution. Cabañeros National Park (Montes de Toledo) in the Centre of Spain. Adults have been caught in the valley of the river Gargantilla (Fig. 244).

Range. Spain.

\section{Merodon arundanus sp. $\mathbf{n}$.}

Figs 89, 122-125

Male

Head. Antennae dark brown; basoflagellomere 1.1 times longer than wide; apex acute. Face and frons black, white dusted and with yellowish-white hairs. Oral margin bare and shiny black. Vertical triangle big, isosceles with yellow hairs in anterior and posterior part and with a tuft 


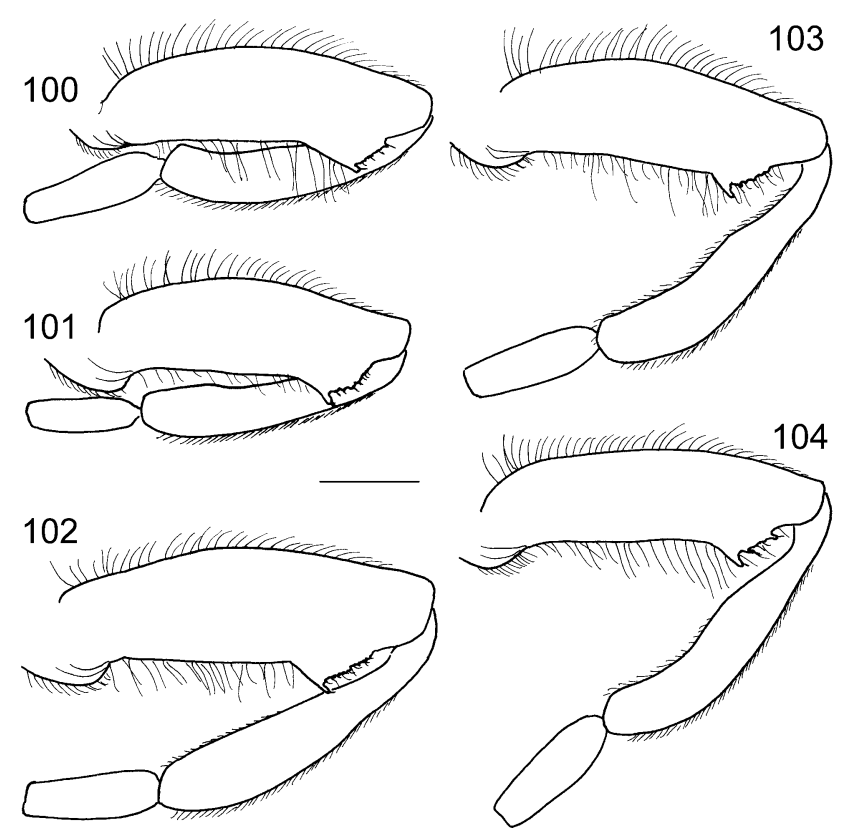

Figs 100-104. Left hind leg, lateral view, females. $100-$ Merodon geniculatus; $101-$ M. albifrons; $102-$ M. obscuritarsis; $103-$ M. escorialensis; $104-$ M. antonioi sp. n. Scale 1 $\mathrm{mm}$.

of black hairs on the ocellar triangle surface. Occiput black with yellow hairs.

Thorax. Mesonotum and scutellum dark-green with metallic luster and covered with erect reddish hairs. Five longitudinal dusted bands can be distinguished from posterior view. Posterior anepisternum, anepimeron and dorsal part of katepisternum with yellowish hairs. Wings pale-greyish with dark veins. Dorsal and ventral calypters pale yellow. Halteres with yellow pedicel and dark capitulum. Legs black (only the basal part of tibia pale), covered by yellow hairs.

Abdomen. Dark, oval and longer than mesonotum. Tergite II with two reddish lateral spots; tergites II-IV with a dusted transversal band. Sternites entirely black. Abdomen completely covered with dense, long reddish hairs.

Male genitalia. PL rounded in lateral view, with a small notch on upper margin (Fig. 122). Surstyle margin straight till the elevation of the long and strong marginal thorn (Figs 122, 123). AL with a wide excavated circular area limited by a very long sickle-shaped thorn and apical prominence twisted and pointed medially (Fig. 123). C convex, without prominences (Fig. 122). Hypandrium with thecal ridge strongly folded (Fig. 124).

Female

Unknown.

Diagnosis. Big (14.5-16.5 mm), stocky species with hairy $\mathrm{cx}$ and reduced hairs on pa; $\mathrm{bf}=1.1$; body covered with dense, reddish hairs, erect on tergites; tergites III, IV with narrow greyish pollinose stripes. This species is fairly similar to $M$. tricinctus but can be easily distinguished by the long, erect, reddish hairs on tergites,

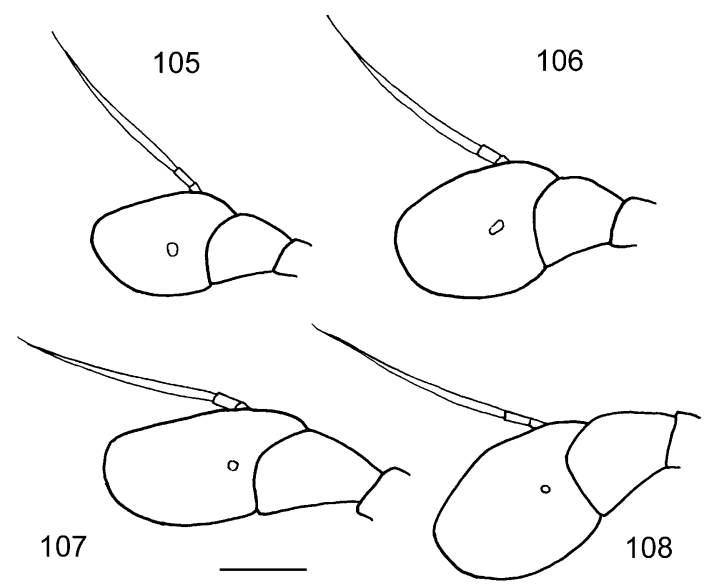

Figs 105-108. Right antenna, inner view (basoflagellomere and pedicel), females. 105 - Merodon geniculatus; $106-M$. crypticus sp. n.; $107-$ M. antonioi sp. n.; $108-M$. escorialensis. Scale $0.3 \mathrm{~mm}$.

strongly folded theca and the extremely long thorn on the surstyle margin of the genitalia.

Type material. Holotype: Spain, Cádiz: 10 , Coros, Sierra de Grazalema (Natural Park) 1331 m. $36^{\circ} 47^{\prime} \mathrm{N}, \quad 5^{\circ} 22^{\prime} \mathrm{W}$, 20.iv.2002, Leg. W. Van Steenis \& E.S. Bakker (CEUA). Paratype: Spain, Cádiz: 20, Coros, Sierra de Grazalema (Natural Park) $1331 \mathrm{~m}, 36^{\circ} 47^{\prime} \mathrm{N}, 5^{\circ} 22^{\prime} \mathrm{W}, 20$. iv.2002, Leg. W. Van Steenis \& E.S. Bakker (deposited in the W. Van Steenis collection and CEUA).

Etymology. The name arundanus is derived from Arunda, the Latin name of the mountains range of the Sierra de Grazalema and Ronda (Spain) where the type specimens were collected.

Biology. Preferred environment: Open area at the top of Abies pinsapo forest. Period of flight: April.

Iberian distribution. Grazalema National Park, mountainous area in the South of the Iberian Peninsula with the highest level of annual precipitation (2,132 mm) in Spain (Fig. 245).

Range. Spain.

\section{Merodon avidus (Rossi, 1790)}

Figs 12, 29, 130-132

Syrphus avidus Rossi, 1790: 292.

M. avidus (Rossi, 1790) is the most frequent and widely distributed of a group of closely related species (Speight, 2006). This group has been the subject of taxonomic debates due to its great morphological variation, resulting in up to 24 known synonyms for M. avidus (Hurkmans, 1993). There is no key in which all known European members of this group of species are included and females, in particular, can be extremely difficult to separate. In a recent study of allozyme and morphological variability in populations of the M. avidus taxon, two cryptic taxa were identified, Mediterranean Merodon avidus A and mountainous Merodon avidus B species based on the diagnostic species-specific alleles at $I d h-2$ and Aat loci and diagnostic morphological characters (Milankov et al., 2001).

There are specimens published as $M$. avidus before 2001 , that were not posible to examine or were unavail- 


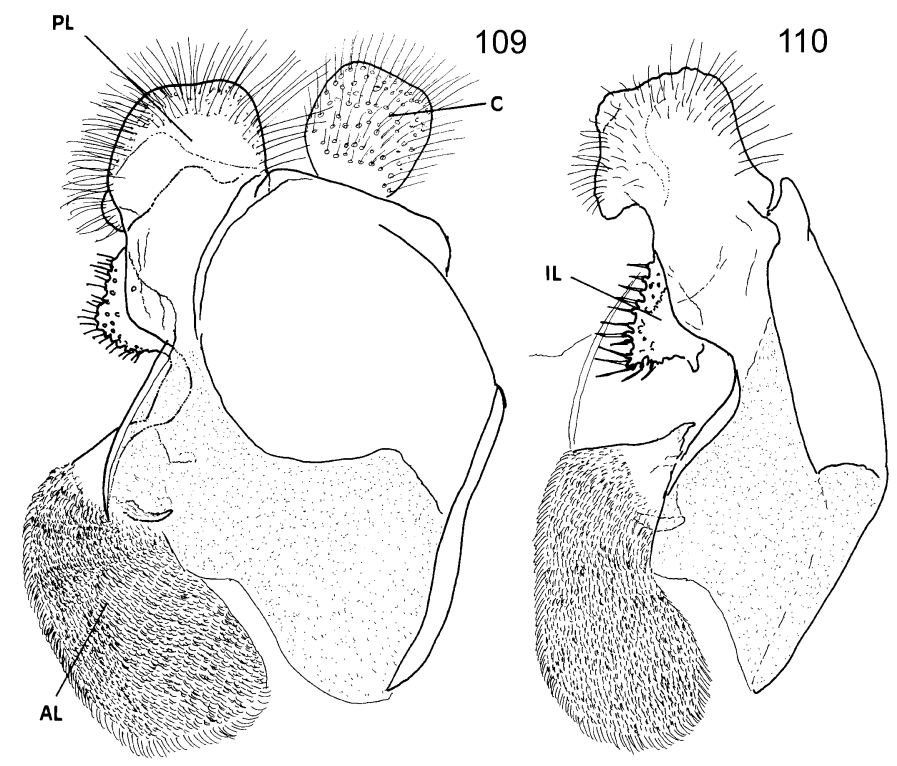

Figs 109-111. Merodon aberrans, male genitalia. 109 - epandrium, lateral view; 110 - left surstyle, anterior view; 111 - hypandrium, lateral view; $\mathrm{AL}$ - anterior surstyle lobe; $\mathrm{C}$ - cercus; $\mathrm{EA}$ - ejaculatory apodeme; $\mathrm{IL}$ - interior accessory lobe of posterior surstyle lobe; L - lingula; P - aedeagus; PL - posterior surstyle lobe; $\mathrm{S}$ - lateral sclerite of aedeagus; $\mathrm{T}$ - ctenidium. Scale $0.2 \mathrm{~mm}$.

able for our study. We keep the name M. avidus (Rossi, 1790) for this material, which is detailed below.

Published records. Spain: Czerny \& Strobl, 1909 as M. serrulatus; Czerny \& Strobl, 1909 as M. spinipes; Czerny \& Strobl, 1909 as M. spinipes var. obscuritarsis; Arias, 1912 as Merodon serrulatus; Arias, 1912 as M. spinipes; Arias, 1912 as M. spinipes var. obscuritarsis; Andreu, 1926 as M. spinipes; Andreu, 1926 as M. spinipes var. obscuritarsis; Gil-Collado, 1930 as M. spinipes; Gil-Collado, 1930 as M. spinipes var.
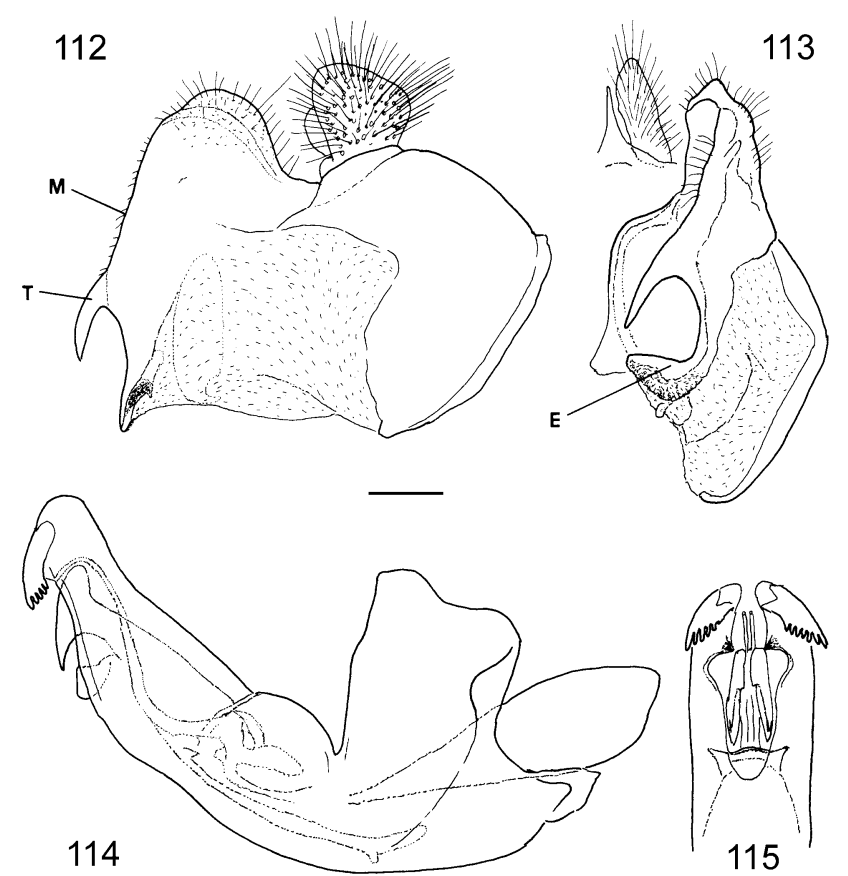

Figs 112-115. Merodon albifrons, male genitalia; 112 - epandrium, lateral view; 113 - left surstyle, anterior view; 114 hypandrium, lateral view; 115 - apical part of hypandrium, anterior view; $\mathrm{E}$ - apical extension of anterior surstyle lobe; $\mathrm{M}$ - surstyle margin; $\mathrm{T}$ - marginal thorn. Scale $0.2 \mathrm{~mm}$. avidus; Gil-Collado, 1930 as M. spinipes var. bicolor; GilCollado, 1930 as M. spinipes var. nigritarsis; Gil-Collado, 1930 as M. spinipes var. obscuritarsis; Gil-Collado, 1930 as $M$. spinipes var. serrulatus; Leclercq, 1971; Peck, 1988 as $M$. spinipes var. bicolor; Marcos-García, 1985a as M. avidus; Marcos-García, 1990b as M. avidus; Marcos-García \& Louis, 2000 as M. avidus. Portugal: Peck, 1988 as M. serrulatus; Hurkmans, 1993 as M. serrulatus.

\section{Merodon avidus A sensu Milankov et al., 2001}

Figs 17, 20, 21

Diagnosis. Medium sized (12.3-14.6 mm), slender species with relatively short body hairs, olive-brown groundcolour; cx bare and pa with reduced hairs; tergites III, IV always with whitish pollinose stripes; colour of tergites III, IV very variable, from dark, to almost completely red (avidus group); basoflagellomere elongated, bf $=1.4$ (Fig. 17); tergite II always with a pair of whitish pollinose spots, from clear to almost indistinct (Fig. 21); tibiae usually pale; tergites II, III usually with reddish lateral spots; male genitalia: PL square-form; AL oval; small hairy protuberance between surstyle lobes; hypandrium with L, apical part narrow; S elongated (Figs 130-132).

Material examined. Unpublished material: Spain, Ávila: 19 , Zapardiel de la Ribera 900 m, 23.vi.1961; Girona: 1 으, Massanas 26.viii.1976, Leg. M. Carles-Torlà.

\section{Merodon avidus B sensu Milankov et al., 2001}

Figs 16, 19, 22

Diagnosis. Extremely similar to previous species, except basoflagellomere slightly less elongated, $\mathrm{fm}=1.3$ (Fig. 16); tergite II shiny, unpollinose (Fig. 22); hind tibiae partly dark; tergite III usually without reddish lateral spots; no established differences in male genitalia characters between these two taxa.

Material examined. Unpublished material: Spain, Albacete: Puerto de las Crucetillas; Riopar; Ávila: Piedralaves; Cantabria: 


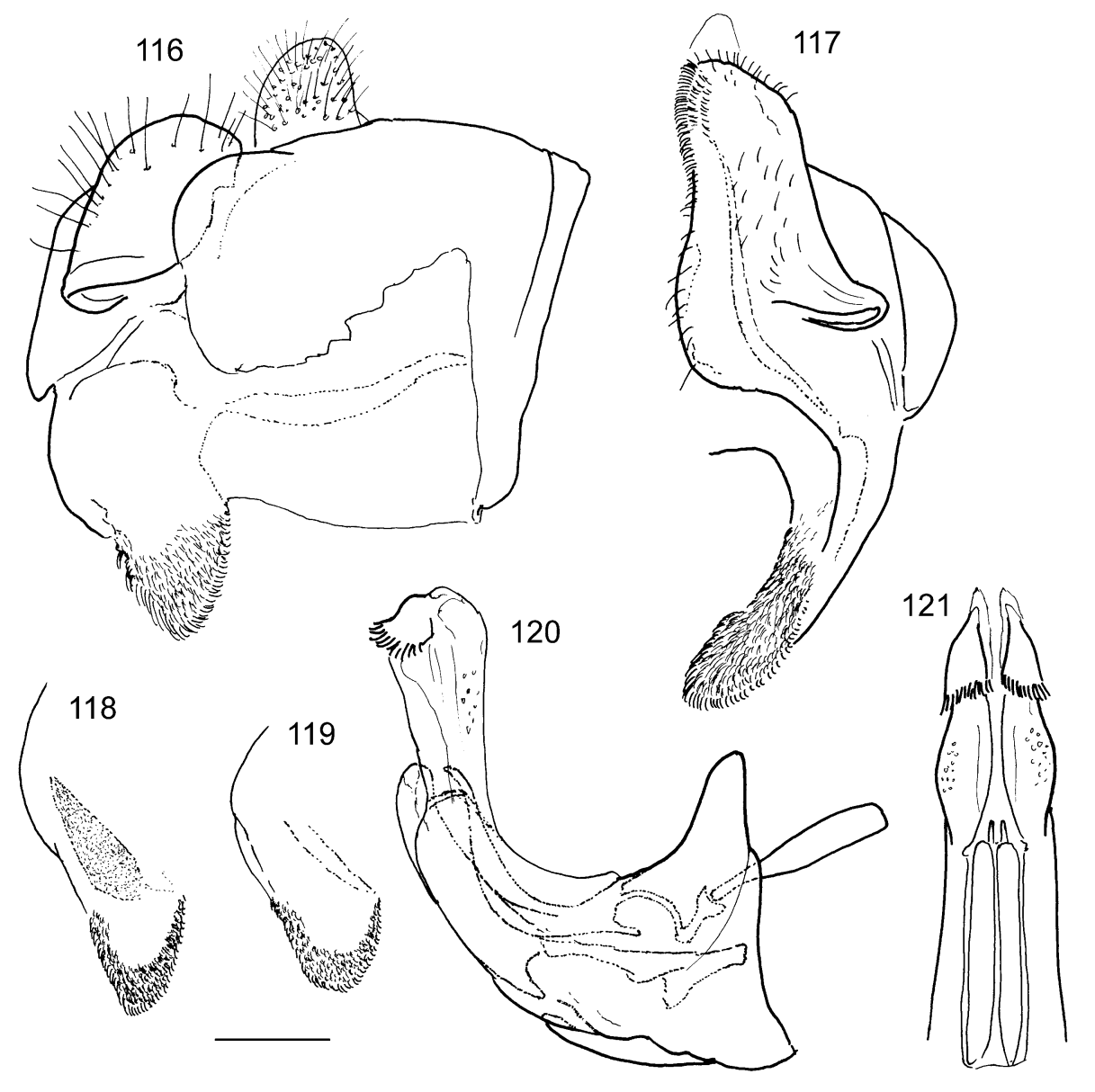

Figs 116-121. Merodon serrulatus, male genitalia. 116 - epandrium, lateral view; 117 - left surstyle, anterior view; 118, 119 anterior surstyle lobe, lateral view; 120 - hypandrium, lateral view; 121 - apical part of hypandrium, anterior view. Scale $0.2 \mathrm{~mm}$.

Santander; Ciudad Real: P.N. Cabañeros; León: Lavelilla de Valdoré; Lleida: Pont de Suert; Sant Guim; Salamanca: Albergueria de Argañán; Tremedal de Tormes; Villaseco de los Gamitos; Tarragona: Espluga de Fran.

Additional published records. Marcos-García (1985a) as $M$. avidus; Marcos-García (1985b) as M. spinipes; Marcos-García (1990b) as M. avidus.

Biology. Preferred environment for $\mathrm{A}$ and $\mathrm{B}$ : Forest/open ground; humid Fagus/Picea forest, thermophilous Quercus forest. Evergreen Quercus forest ( $Q$. ilex); dry, pasture, old almond, cherry and olive orchards. Flowers visited: Apiaceae, Achillea sp., Euphorbia sp., and Muscari sp. Period of flight: June-July in northern parts, but also a second generation, August-September, further south.

Range. From Southern Scandinavia to the Mediterranean and North Africa; from Spain through most of central and southern Europe to Turkey and European parts of Russia.

Iberian distribution M. avidus A. Sistema Central and Sierra Montseny (Northeast of Spain) (Fig. 245).

Iberian distribution M. avidus B. Widespread in the Peninsula (Cantabrian mountain range, Pyrenees, Sistema Central, and Portugal) (Fig. 245).

\section{Merodon cabanerensis sp. $\mathbf{n}$.}

Figs 32, 33, 44-46, 133-136

\section{Male}

Head. Antennae black; basoflagellomere rounded, approximately as long as wide and as long as scape and pedicel together; distance between antennal pit and top of basoflagellomere twice as long as the distance between pit and base of basoflagellomere. Front and occiput dull black, face covered with long grey hairs reclined to the medium line on face. Vertical triangle isosceles, black with long pale hairs, except some black ones on the ocellar area. Eyes with white hairs; ocellar triangle equilateral. Length of eye contiguity line similar to the distance between two ocelli.

Thorax. Mesonotum and scutellum dark with metallic luster and covered with erect red-yellowish hairs. Posterior anepisternum, anepimeron and dorsal part of katepisternum with yellow hairs. Wings pale-greyish with dark veins. Dorsal and ventral calypters pale yellow with dark margins. Halteres with pale pedicel and yellow and dark capitulum. Legs completely dark and covered with yellow hairs. Hind tibiae slightly nicked in the ventral part. Hind trochanter without thorn. Ventral part of tarsi with dense red hairs.

Abdomen. Oval, with the widest part in the second tergite. Black with metallic luster. Tergites II-IV with unclear marks of pubescence; covered with yellowish hairs except posterior half of second and third tergites 

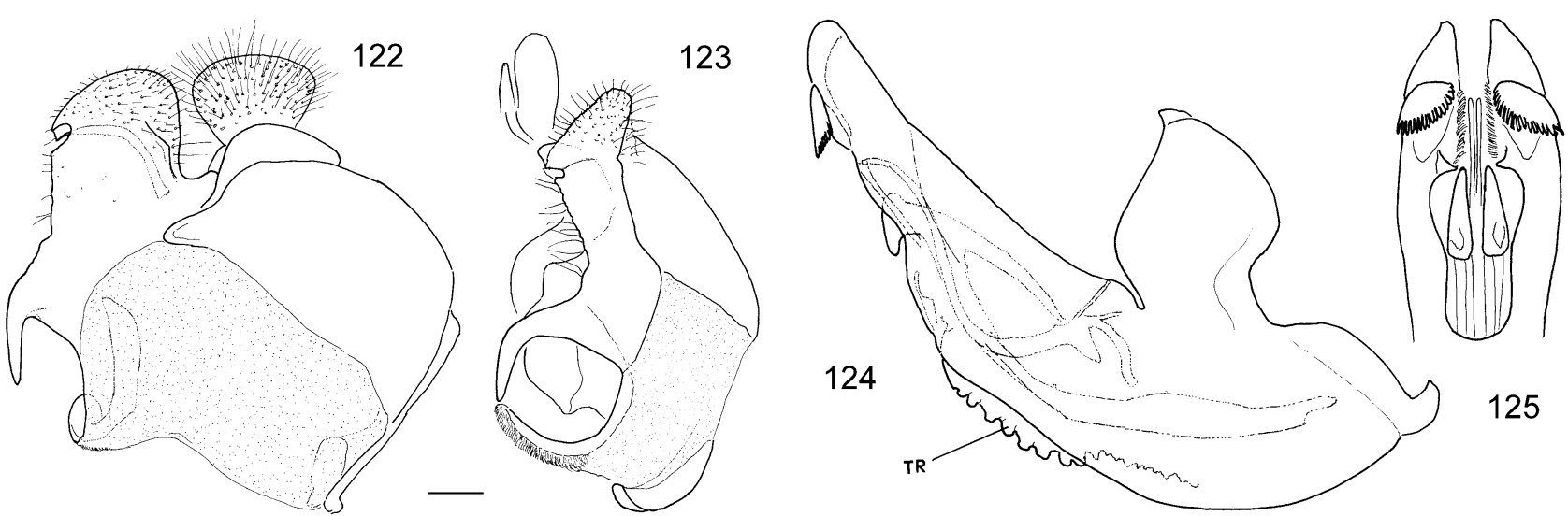

Figs 122-125. Merodon arundanus sp.n, male genitalia. 122 - epandrium, lateral view; 123 - left surstyle, anterior view; 124 hypandrium, lateral view; 125 - apical part of hypandrium, anterior view; TR - thecal ridge. Scale $0.2 \mathrm{~mm}$.

with black adpressed hairs. Sternites black with erect, yellowish hairs.

Male genitalia. AL not visible in lateral view, but developed and containing a medially pointed prolongation covered with dense short hairs (Fig. 134). PL very narrow on the apical half. $\mathrm{T}$ in characteristic shape (Figs 135, 136). EA large (Fig. 135). S curved posteriorly (Fig. 135).

\section{Female}

Similar to the male except for sexual dimorphism and the following characteristics: frons black, dull, covered with yellowish hairs, anteriorly reclined and with a median longitudinal groove from anterior ocellus to lunule. Vertical triangle black with long, black hairs. Ocellar triangle equilateral. Transversal abdominal lines of pubescence inconspicuous.

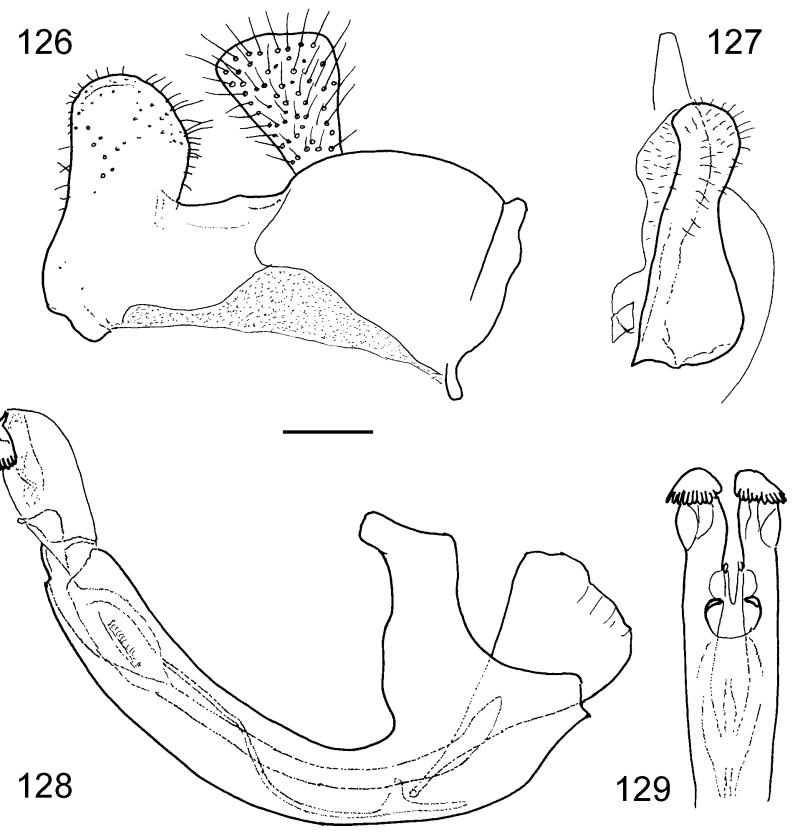

Figs 126-129. Merodon pumilus, male genitalia; 126 - epandrium, lateral view; 127 - left surstyle, anterior view; 128 hypandrium, lateral view; 129 - apical part of hypandrium, anterior view. Scale $0.2 \mathrm{~mm}$.
Diagnosis. Small species (8.6-10.5 mm ) with hairy cx and pa; dark, unpollinose, medium haired; antenna (Figs 32,33 ) short, basoflagellomere rounded (bf: 1.0); hind tibia with central nick (Figs 44, 45); hind trochanter in male without thorn (Fig. 46); male genitalia with welldeveloped surstyle lobes (Figs 133, 134); female with the bare central stripe occupying about $1 / 3$ of face; tergites shiny, unpollinose (in some specimens tergite III with very narrow and small pollinose stripes).

Type material. Holotype: Spain, Ciudad Real: 10, Canalejas. P.N. de Cabañeros. 19.iii.2004, Leg. A. Ricarte (CEUA). Paratype: Spain, Ciudad Real: $10,1 \%$, Canalejas, P.N. de Cabañeros 19.iii.2004, Leg. A. Ricarte (CEUA); 10 , Canalejas, P.N. de Cabañeros 19.iii.2004, Leg. A. Ricarte

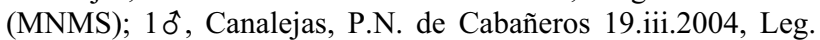
A. Ricarte (NSEC).

Etymology. The name cabanerensis is derived from Cabañeros, the name of the Spanish National Park where the type specimens were collected.

Biology. Preferred environment: Open ground areas in thermophilous Quercus faginea Lam. and Fraxinus angustifolia L. (Tolman \& Lewington, 1997) forest. Adults were caught resting or flying near the ground. Period of flight: March.

Iberian distribution. Cabañeros National Park (Montes de Toledo) in the Centre of Spain (Fig. 244).

Range. Spain.

\section{Merodon chalybeus Wiedemann in Meigen, 1822}

Figs 47-56, 137-144

Merodon chalybeus Wiedemann in Meigen, 1822: 365.

Merodon spicatus Becker, 1907: 251 syn. n.

Merodon chalybeus was described from a single specimen. In the Meigen collection there is one specimen with original name label and corresponding data. We accept this specimen as the holotype: female "var. chalybea / Lusitania / Hoffmannsegg S. / Type" (Portugal) (MFNB).

M. spicatus was described from an unspecified number of males and females. There are two type specimens (syntypes) found in two Museums; the designation of lectotype was based on more comprehensive data on specimen in KBIN collection. Lectotype (designated here): male 


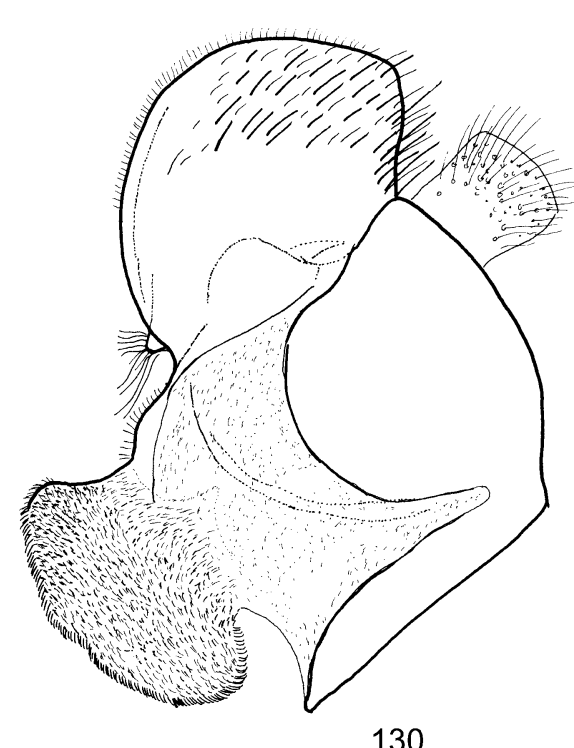

130
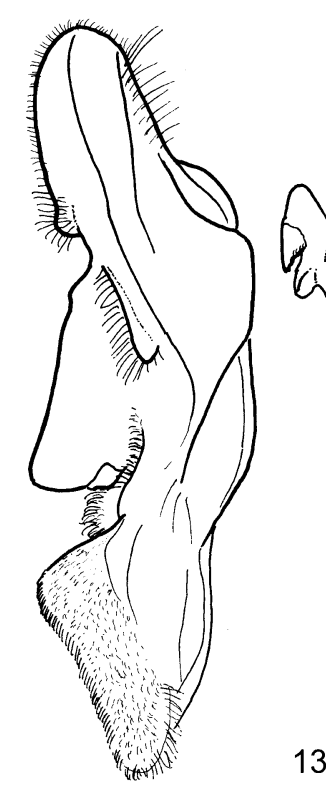

131

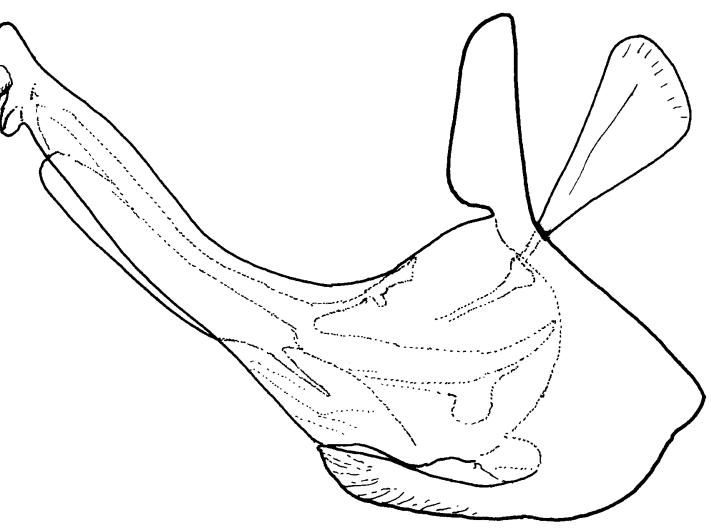

132

Figs 130-132. Merodon avidus, male genitalia. 130 - epandrium, lateral view; 131 - left surstyle, anterior view; 132 - hypandrium, lateral view. Scale $0.2 \mathrm{~mm}$.

"spicatus det. Becker / Tunisie 17.4.98 / Coll. J. Villeneuve Lampetia spicata R.M.H.N. Belg." (KBIN). Paralectotype: female "Tunis" (Becker collection, MFNB) [two females exist in the Becker collection under the name of Merodon spicatus; one from Algeria is labeled by Becker; this second one has no determination label, but locality data fits to the original description].

Diagnosis. Small $(6.6-8.0 \mathrm{~mm})$ species with hairy cx and many hairs on pa, thorn on hind trochanter in male (aureus group); basoflagellomere reddish to brown; upper (and lower) part of eyes dark haired; body hairs not so dense as in other species in the aureus group, hairs whitish-grey to yellowish-grey; mesonotum usually at least near wing bases with black hairs; mesonotum and tergites with dark-olive tegument; tergite II on posterior $1 / 3$ and central parts of tergite III (except pale stripes on the middle) black haired; tergites II, III with small pollinose stripes; legs dark, tibiae at both ends and tarsi in part can be paler; apical part of hind femora with black hairs; male genitalia similar to $M$. aureus: AL undeveloped with straight ventral margin; PL rounded apically; hypandrium narrow, elongated and sickle-shaped; S reduced (Figs 137-144).

Variability. This species can be very variable in size (4-11 mm) (Figs 61, 62), length of eye contiguity line in males (Figs 63, 64), pollen on tergites (Figs 65-68): from pollinose areas present on all tergites (Fig. 65) to shiny tergites, except small pollinose spots on tergite II (Fig. 68), length and density of body hairs; and shape of PL of male genitalia (Figs 137-139).

Type material examined. Holotype: Wiedemann in Meigen, 1822 as Merodon chalybeus: 1 $\$$, "Lusitania / Hoffmannsegg S." (Portugal) (MFNB).

Other material examined. Unpublished material: Spain. Cáceres: Embalse de Guadiloba; Jarandilla; Cádiz: Puerto de Santa Maria; León: Valdoré; Salamanca: Lagunilla. Published material: Spain: Gil-Collado (1930) as M. aeneus chalybeus; Gil-Collado (1930) as M. spinipes var. obscuritarsis; MarcosGarcía (1981) as L. aenea; Marcos-García (1985a) as M. aeneus (CEUA \& NSEC); Peck (1988) as M. spinipes var.

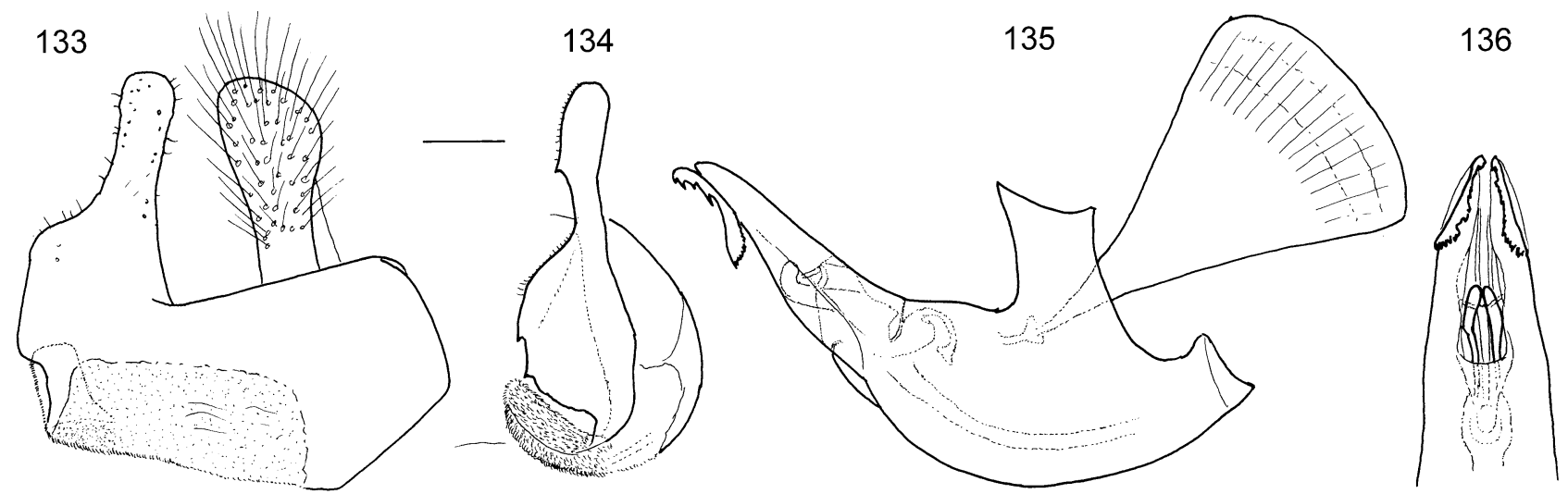

Figs 133-136. Merodon cabanerensis sp. n., male genitalia. 133 - epandrium, lateral view; 134 - left surstyle, anterior view; 135 - hypandrium, lateral view; 136 - apical part of hypandrium, anterior view. Scale $0.2 \mathrm{~mm}$. 


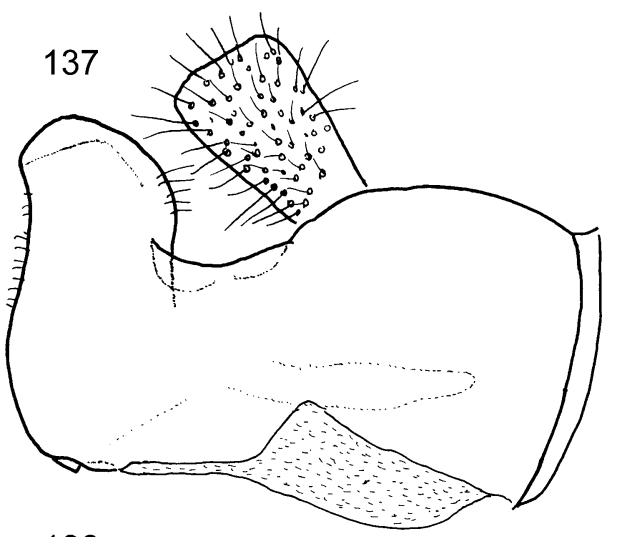

138

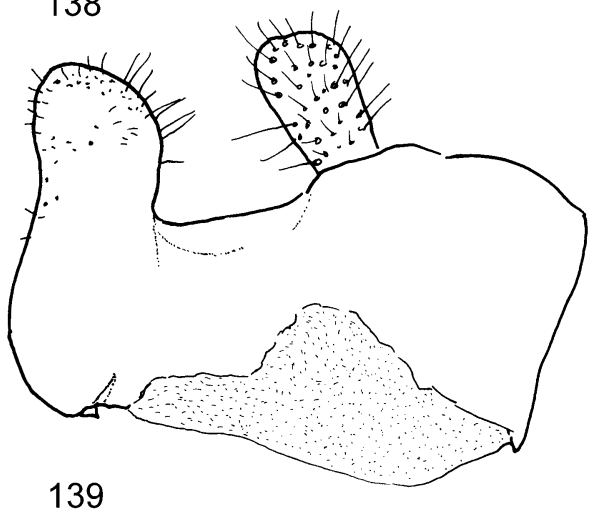

139

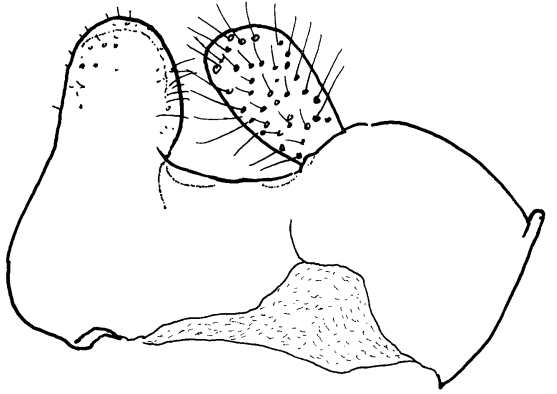

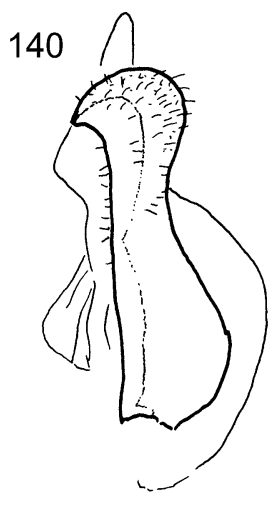
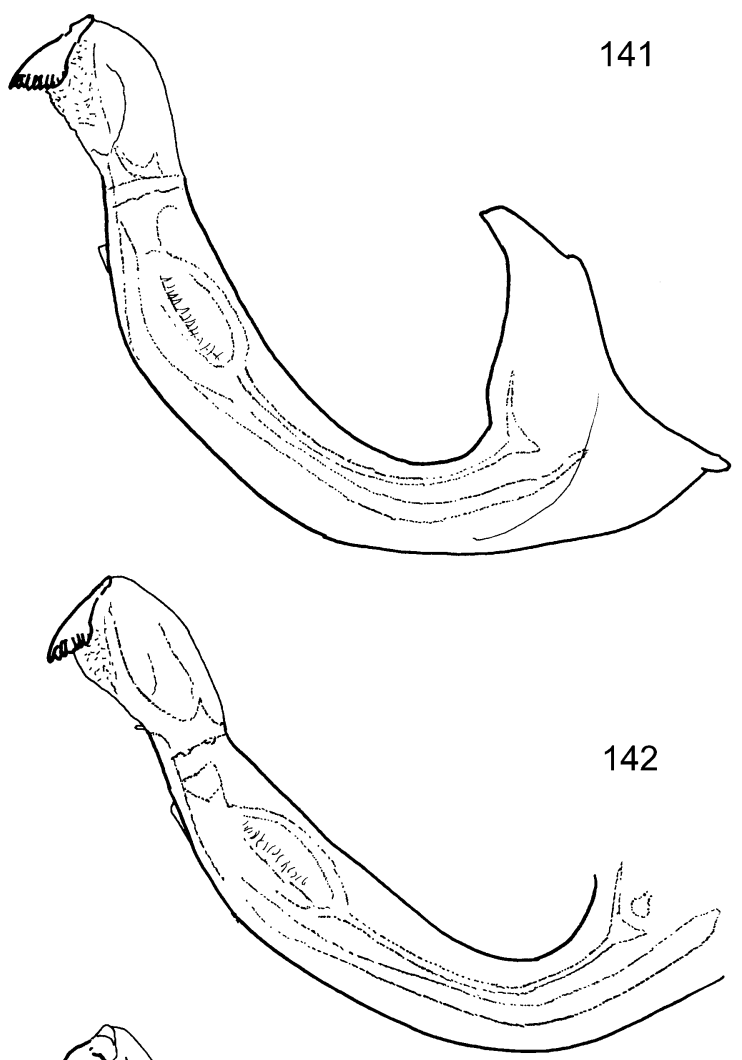

144
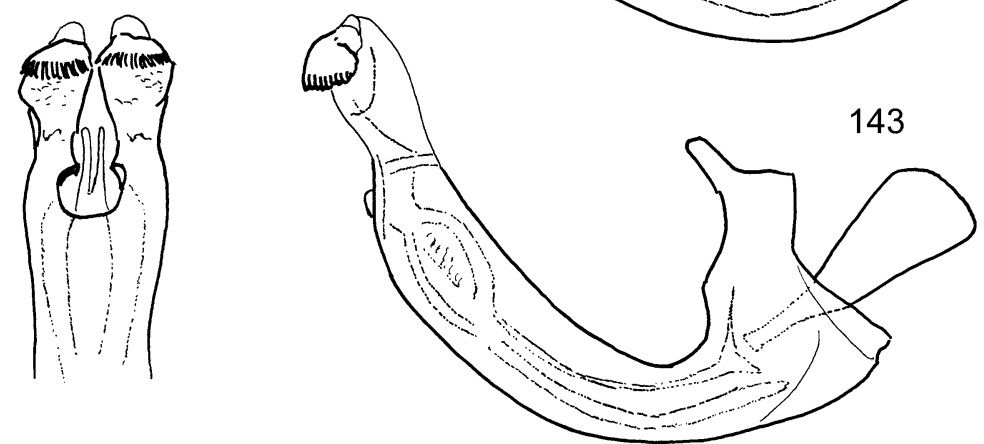

Figs 137-144. Merodon chalybeus, male genitalia. 137-139 - epandrium, lateral view; 140 - left surstyle, anterior view; 141-143 - hypandrium, lateral view; 144 - apical part of hypandrium, anterior view. Scale $0.2 \mathrm{~mm}$.

obscuritarsis; Marcos-García (1990b) as M. aeneus. Portugal: Arias (1912).

Additional published records. Gil-Collado (1930) as $M$. aeneus chalybeus; Pedersen (1971) as M. spicatus.

Biology. Preferred environment: forest/open ground; open areas in evergreen oak maquis and more open, almost bare ground in semi-arid conditions. Period of flight: April-September.

Iberian distribution. Mountains of the Sistema Central of Spain (Fig. 246).

Range. Spain, Portugal and southern France round the Mediterranean to parts of the former Yugoslavia and on to North Africa (Morocco).

\section{Merodon clavipes (Fabricius, 1781)}

Figs 6, 145-147

Syrphus clavipes Fabricius, 1781: 427.

Diagnosis. Big (17-23 mm), bumble bee-like species with long and dense body hairs; cx bare, pa with reduced hairs; hind femora thickened; bf $=1.8$ (Fig. 6); usually yellowish-white haired species with stripe of black hairs between wing basis, and red-yellow hairs on tergites III, IV; tergites with pollinose stripes covered with hairs; legs black; male genitalia: PL square-shape, with small lateral bulge; AL large, extensively covered with dense short hairs; hypandrium with small L; S elongated (Figs 145-147).

Variability. The colour of hairs on body can be variable; based on that fact few varieties were described (for more see: Hurkmans, 1993).

Material examined. Published material: Marcos-García [1985a, b, 1990b (NSEC), 2000].

Additional published records. Arias (1912); Andreu (1926); De la Fuente (1926); Gil-Collado (1930); Gil-Collado (1930) as Merodon clavipes var. senilis; Peris (1958); Pedersen (1971); Peck (1988) as Merodon sacki; Hurkmans (1993) as M. sacki.

Biology. Preferred environment: Open ground, sparsely vegetated, semi-arid, stony pasturage and open, grassy areas within thermophilous Quercus forest. Flowers vis- 

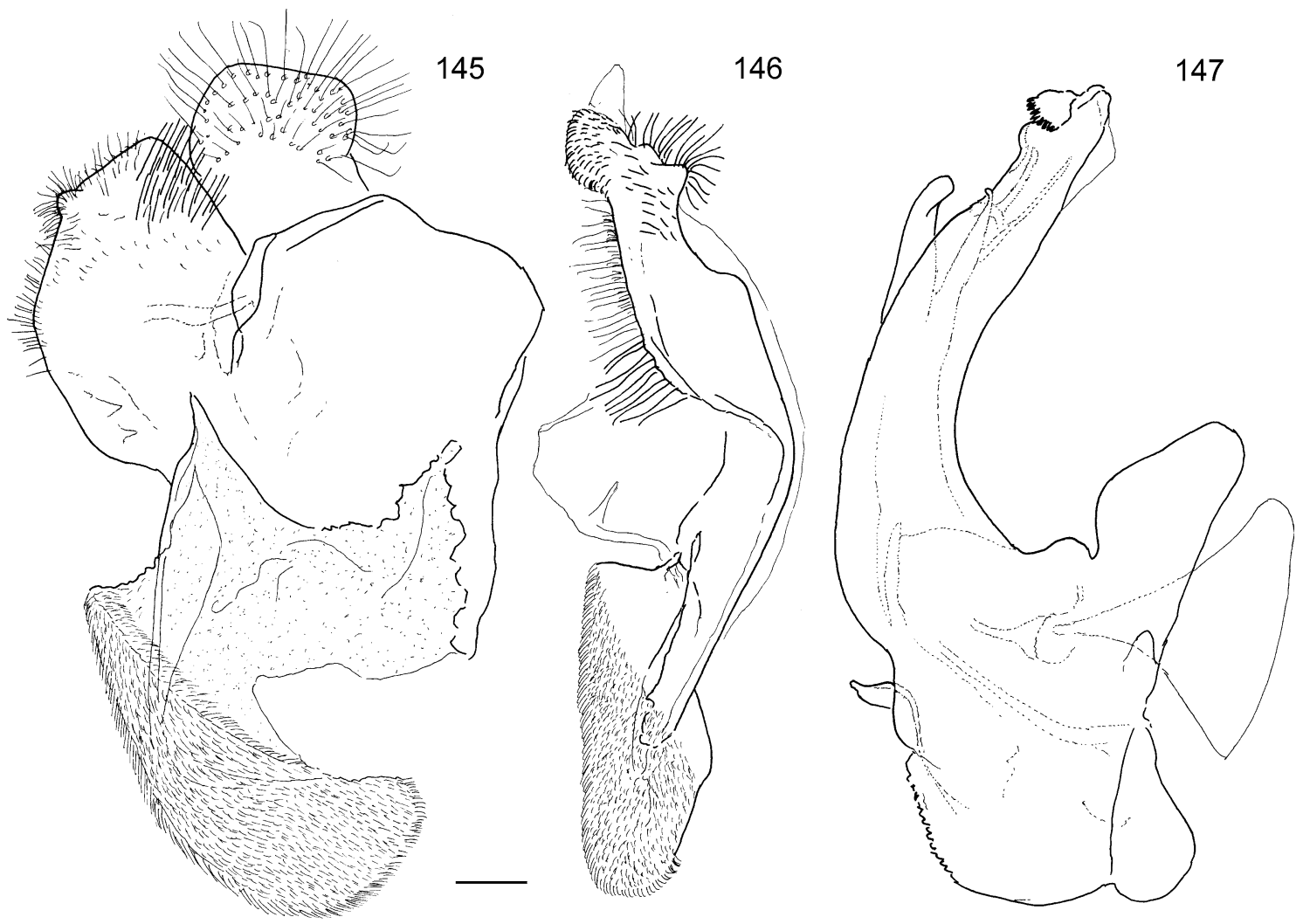

Figs 145-147. Merodon clavipes, male genitalia. 145 - epandrium, lateral view; 146 - left surstyle, anterior view; 147 - hypandrium, lateral view. Scale $0.2 \mathrm{~mm}$.

ited: Apiaceae, Euphorbia sp., Leontodon sp. and Solidago sp. Period of flight: April-August.

Iberian distribution. Widespread in mountainous areas of the Peninsula (Fig. 247).

Range. From northern France to the Mediterranean (including Corsica, Sardinia, Sicily and Crete) and North Africa; from Portugal and Spain through central and southern Europe to Greece, Romania, Ukraine and Turkey.

\section{Merodon clunipes Sack, 1913}

Figs 9, 10, 25, 148-151

Merodon clunipes Sack, 1913: 444.
Diagnosis. Medium sized (11.3-14.00 mm), dark species with hairy cx and reduced hairs on pa; scutum with stripe of black hairs between wing bases and five longitudinal whitish pollinose stripes; antennae dark to brownish, hind femora extremely thick (Figs 9, 10, 25); fore and mid tibiae with large dark ring, tarsi darkened dorsally; tergite II dark without pale lateral spots; tergites II-IV with broad whitish pollinose stripes; male genitalia: PL squared, with posterior hump; AL small, rounded; L medium sized; S elongated; EA large, triangular (Figs 148-151).
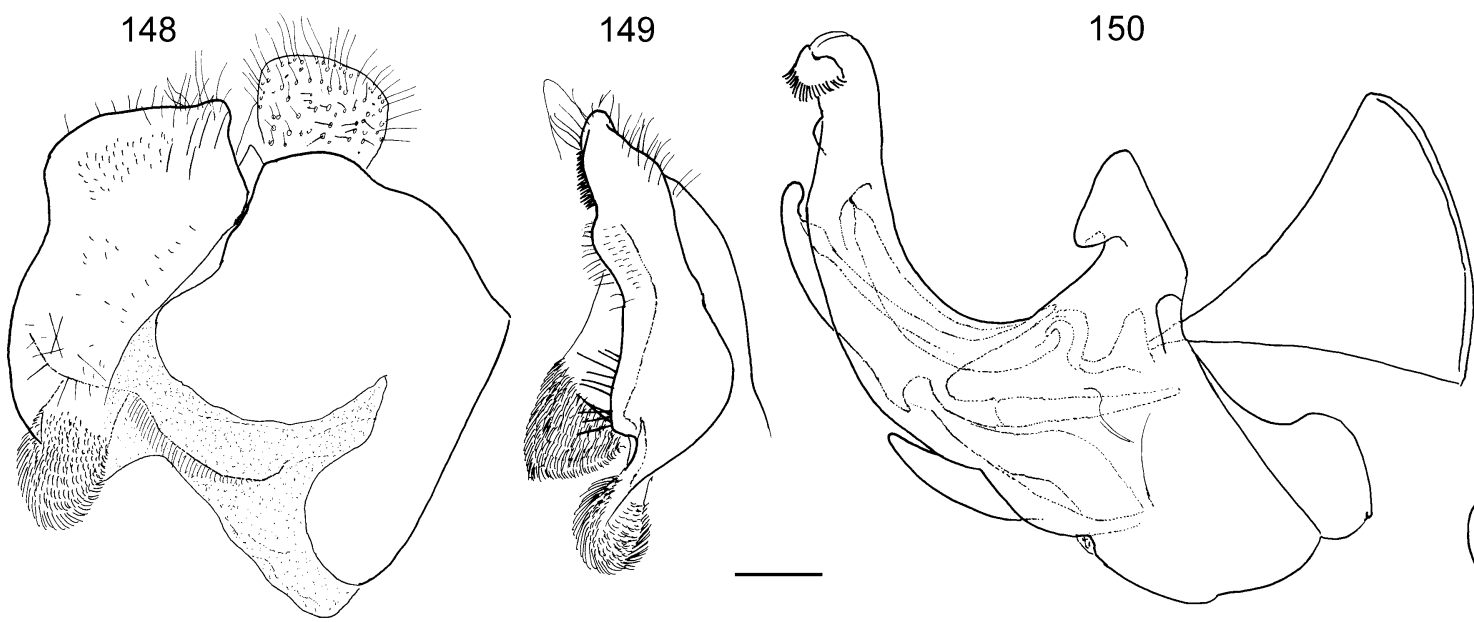

151

Figs 148-151. Merodon clunipes, male genitalia. 148 - epandrium, lateral view; 149 - left surstyle, anterior view; 150 - hypandrium, lateral view; 151 - apical part of hypandrium, anterior view. Scale $0.2 \mathrm{~mm}$. 


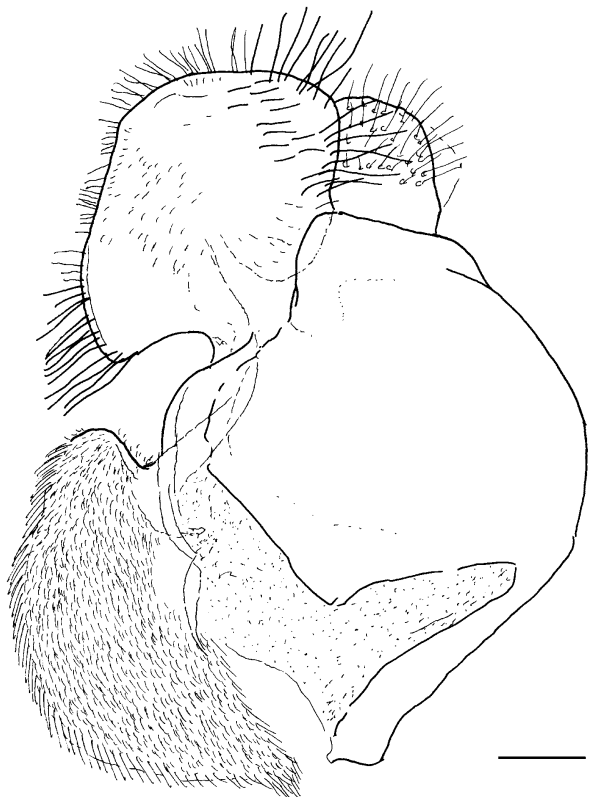

152
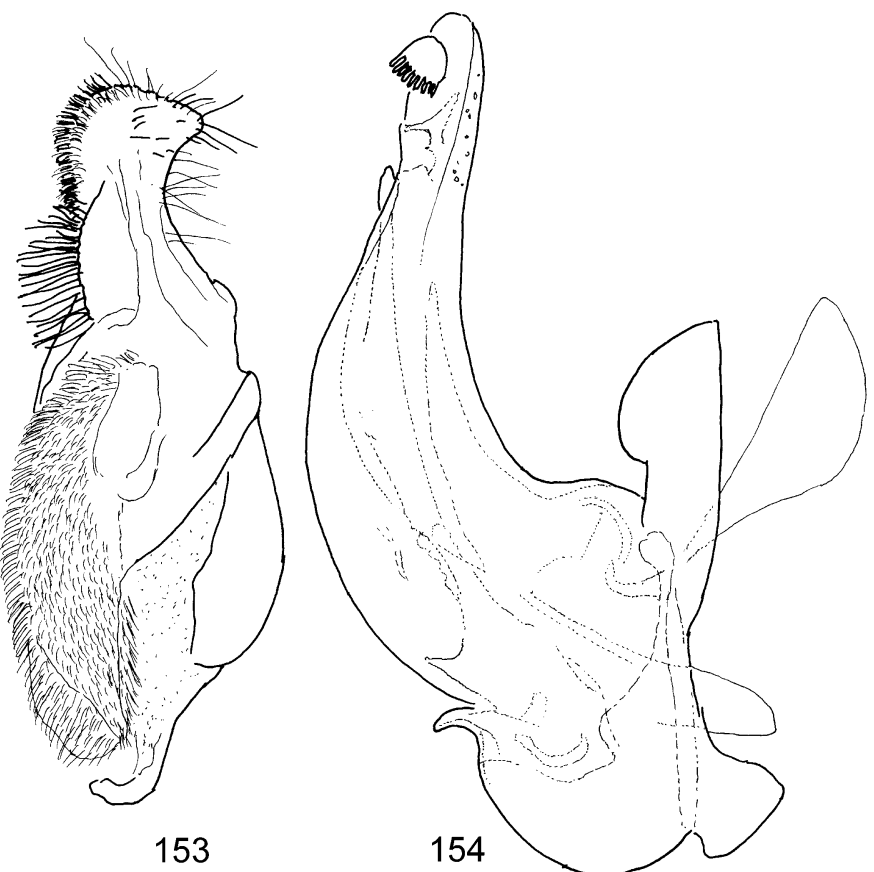

Figs 152-154. Merodon elegans, male genitalia. 152 - epandrium, lateral view; 153 - left surstyle, anterior view; 154 - hypandrium, lateral view. Scale $0.2 \mathrm{~mm}$.

Published records. Hurkmans (1993) (RMNH).

Biology. Preferred environment: deciduous forest; Fagus and thermophilous oak forest. Period of flight: June-July.

Iberian distribution. Sistema Central of Spain (Fig. 246).

Range. Spain, southern France, Switzerland, Austria, Hungary, Italy (and Sicily), parts of the former Yugoslavia, Greece, Bulgaria, Cyprus, Turkey and the Lebanon.

\section{Merodon crypticus sp. $\mathbf{n}$.}

Figs 62, 69, 73, 106, 162

\section{Male}

Head. Antennae dark brown; basoflagellomere 1.2 times as long as wide, upper margin slightly concave, apex acute. Face, frons and occiput black covered by dense white pubescence and long white hairs. Oral

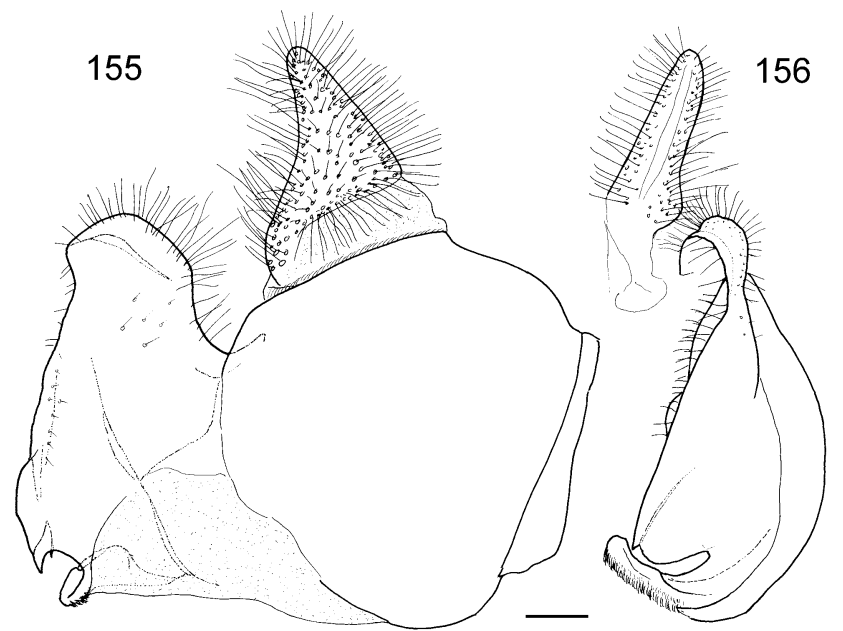

margin bare and lustrous black. Ocellar and vertical triangles isosceles. Eyes with white hairs; vertical triangle with white and black erect hairs.

Thorax. Mesonotum and scutellum dark green with metallic luster and covered with erect pale-yellow hairs and one transverse band of black hairs at the level of wing insertion. Posterior anepisternum, anepimeron and dorsal part of katepisternum with yellowish-white hairs. Wings pale-greyish with dark veins. Dorsal and ventral calypters pale yellow. Halteres with yellow capitulum and pedicel. Femora dark brown with pale apical part. Fore and mid tibiae yellow in basal part, with distal dark top; hind tibiae yellow with dark median band and with a sharp apico-medial process. Tarsi dark, with black bristles and some black tarsomeres, partly pale. Hind trochanter with a distinct rounded thorn covered with long, dense hairs. Legs with pale hairs except some black reclined

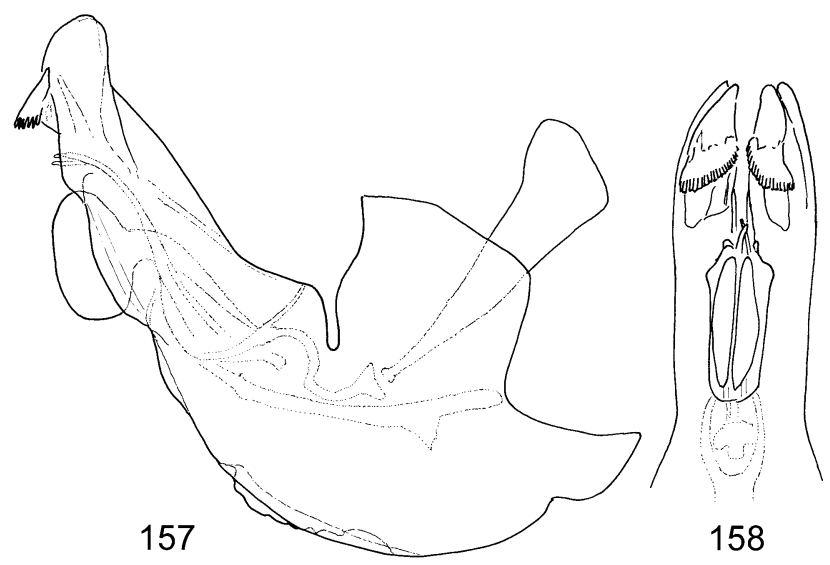

Figs 155-158. Merodon equestris, male genitalia. 155 - epandrium, lateral view; 156 - left surstyle, anterior view; 157 - hypandrium, lateral view; 158 - apical part of hypandrium, anterior view. Scale $0.2 \mathrm{~mm}$. 

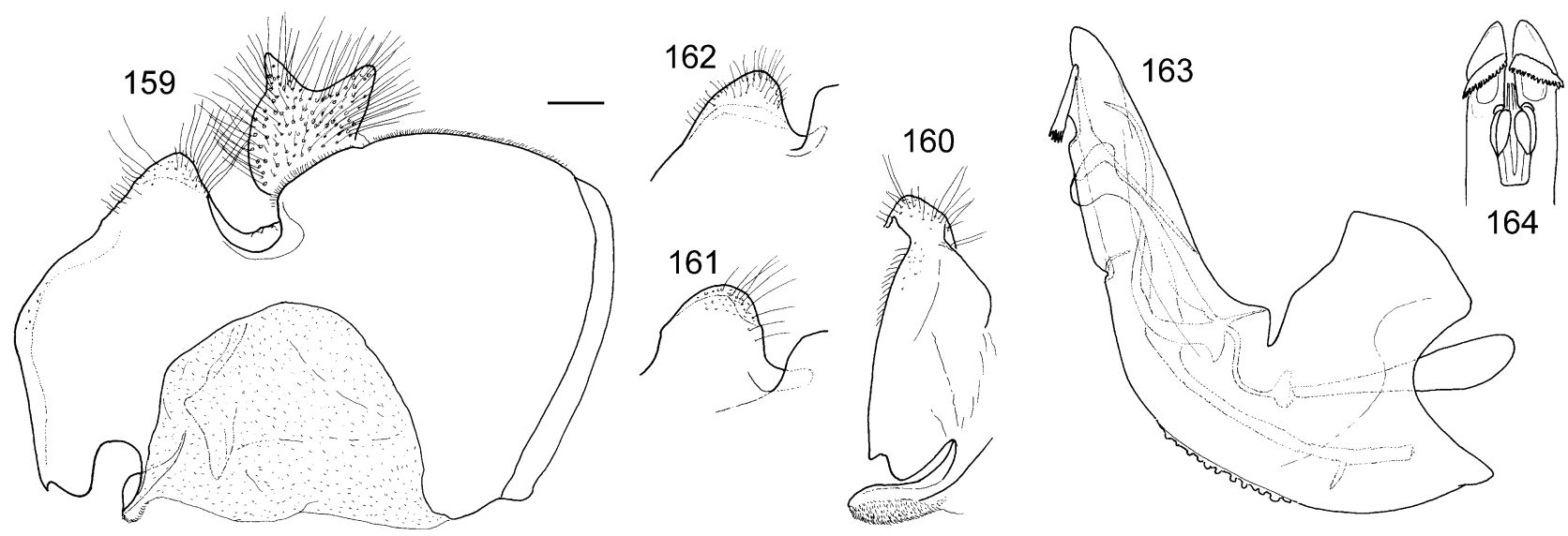

Figs 159-164. Male genitalia. 159, 160, 163, 164 - Merodon escorialensis; 161 - M. antonioi sp. n.; 162 - M. crypticus sp. n.; 159 - epandrium, lateral view; 160 - left surstyle, anterior view; 161, 162 - apical part of posterior surstyle lobe, lateral view; 163 hypandrium, lateral view; 164 - apical part of hypandrium, anterior view. Scale $0.2 \mathrm{~mm}$.

ones on dorso-apical part of fore femora and some black hairs on tarsomeres.

Abdomen. Dark, oval and longer than mesonotum. Tergites II-IV black with white pruinose transverse bands interrupted in the middle on tergites II and III; posterior margin of tergites pale; tergite II with pale antero-lateral margin; tergites covered with adpressed hairs of the same colour as the tegument. Sternites, pale spots of tergite II and lateral margin of all tergites covered with long pale hairs. Sternite I dark anteriorly and pale posteriorly; sternites II and III pale; sternite IV and posterior ones dark brown.

Male genitalia. PL dorsally rounded (Fig. 154). Surstyle margin obviously convex. C concave with two distinct apical prominences (Fig. 73). Hypandrium with folded thecal ridge.

\section{Female}

Similar to the male except for the following characteristics: Antennae brown with pale ventral surface. Frons shiny, white dusted laterally and covered with yellowishwhite hairs anteriorly reclined. Ocellar triangle equilateral, covered with black hairs. Hind tibia without apical process.
Diagnosis. Species with hairy cx and reduced hairs on pa, hind trochanter with blunt thorn, usually covered with tuft of hairs (Fig. 62) (geniculatus group); bf $=1.1-1.2$ (Figs 69, 106); medium sized (10.6-14.0 mm) species, with a stripe of black hairs between wing bases; hind tibia with apico-medial spur (Fig. 60); C with two distinct apical prolongations (Fig. 70). For more details, see diagnosis of $M$. antonioi $\mathrm{sp} . \mathrm{n}$.

Type material. M. crypticus: Holotype: Spain. León: 10 , Pto. de las Señales $1625 \mathrm{~m}, 30 \mathrm{TUN} 1771$, 12.ix.87. Leg. Marcos-García (CEUA). Published as M. escorialensis in Marcos-García, 1990b. Paratype: Spain: Asturias: 19 , Laguna de Arbás 1690 m; 29TQH0963, 10.ix.87, Leg. Marcos-García; Cantabria: 10ิ, Vejo $1000 \mathrm{~m}$; 30TUN6072, 13.ix.87, Leg. Marcos-García; Huesca: $1 \%$, Siresa 925 m; 13.vii.81, Leg. E. Galante; León: 10, Aralla 10.ix.87, Leg. Marcos-García (NSEC); 1 ㅇ, Cofiñal 9.ix.87, Leg. Marcos-García; $1 \hat{0}$, Cofiñal 12.ix.87, Leg. Marcos-García; 1 đo, $1 \%$, Pto. de las Señales, Cofiñal 1625 m; 30TUN1771, 12.ix.87, Leg. Marcos-García; 1 o , 1 ㅇ, Hayedo de Pandetrave 1562 m; 30TUN4874, 13.ix.87, Leg. Marcos-García; 1으, Hayedo de Pandetrave $1562 \mathrm{~m}$; 30TUN4874, 13.ix.87, Leg. Marcos-García (NSEC); 10, Pto. Leitariegos $1550 \mathrm{~m}$; 29TQH1162, 10.ix.87, Leg. Marcos-García; 10, Pto. San Glorio 1609 m; 30TUN5669, 13.ix.87, Leg. Marcos-García; 10, Pto. San Glorio 1609 m; 30TUN5669, 13.ix.87, Leg. Marcos-García (MNMS); Palencia: 1 , Sierra Braña; Refugio Golobar 2000 m, 22.viii.1995, Leg.
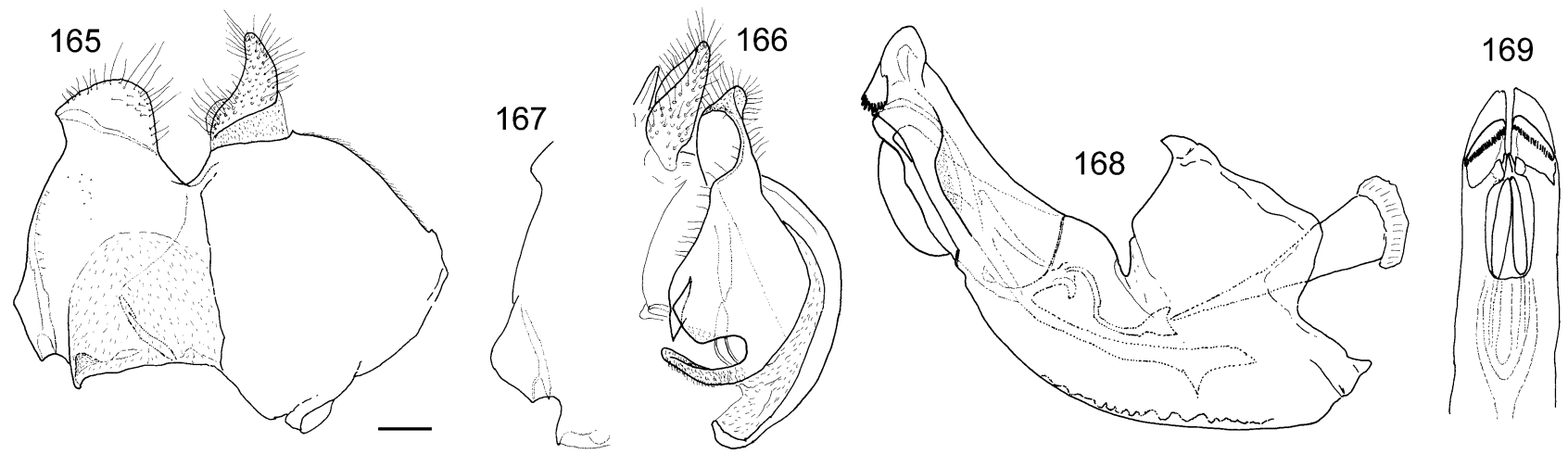

Figs 165-169. Merodon flavus, male genitalia. 165 - epandrium, lateral view; 166 - left surstyle, anterior view; 167 - surstyle margin; 168 - hypandrium, lateral view; 169 - apical part of hypandrium, anterior view. Scale $0.2 \mathrm{~mm}$. 


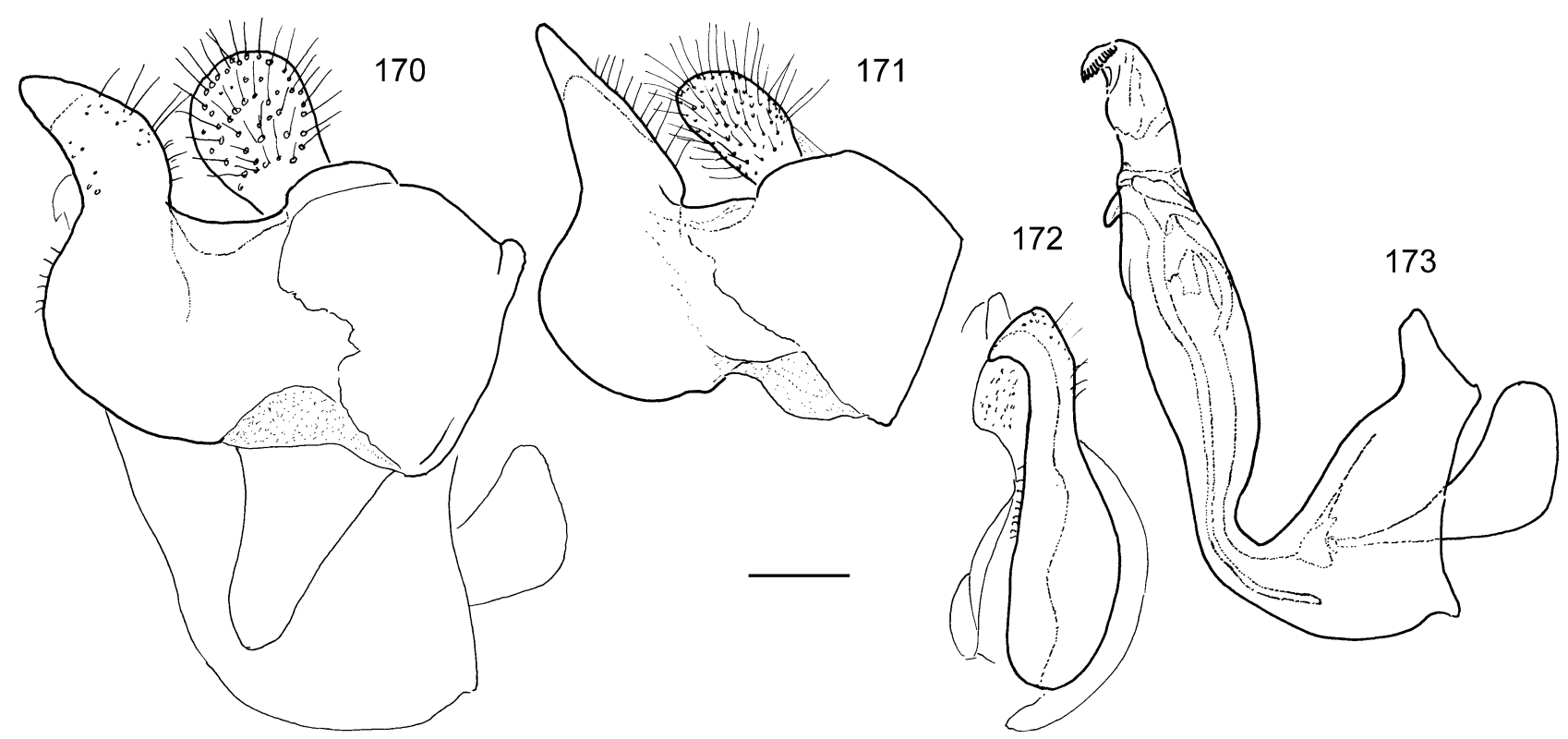

Figs 170-173. Merodon funestus, male genitalia. 170, 171 - epandrium, lateral view; 172 - left surstyle, anterior view; 173 hypandrium, lateral view. Scale $0.2 \mathrm{~mm}$.

Marcos-García; 1 \% , Sierra Braña, Refugio Golobar 2000 m, 22.viii.1995, Leg. Marcos-García (MNMS); 2 \%, Sierra Braña, Refugio Golobar 2096 m, 19.viii.1995, Leg. Marcos-García. Material from León, Asturias, Cantabria and Huesca was published as M. escorialensis in Marcos-García, 1990b.

Etymology. The name crypticus is derived from the same Latin word that refers to the newly discovered cryptic species among M. escorialensis specimens.

Biology. Preferred environment: Open ground areas of the high mountains belonging to the Spanish Eurosiberian region. Period of flight: July-September.

Iberian distribution. North of Spain, Orocantabric mountain range and West Pyrenees (Fig. 248).

Range. Spain.

\section{Merodon elegans Hurkmans, 1993}

Figs 11, 28, 152-154

Merodon elegans Hurkmans, 1993: 195.

Diagnosis. Medium sized (11.0-14.3 mm), slender species with relatively short body hairs, olive-brown ground-

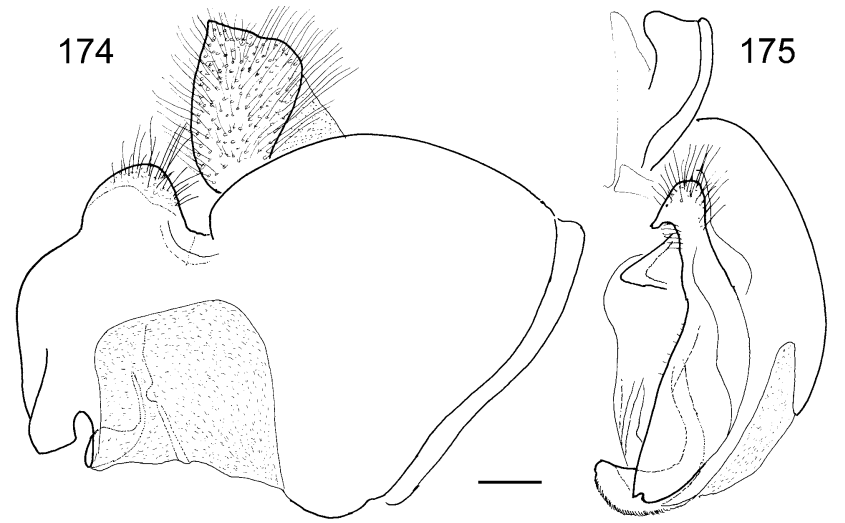

colour; cx bare and hairs on pa reduced; tergites III, IV always with whitish pollinose stripes (avidus group); hind femora very thick, covered with long pale hairs on ventral margin (Figs 11, 28); scutum with stripe of black hairs between wing bases; tergite II with clear reddish lateral spots; tergites III, IV with whitish pollinose semicircular stripes, slightly interrupted in the middle; species with reddish antennae, predominantly pale fore and mid tibiae, pale tarsi; male genitalia: PL square-shaped, margin with very long hairs; AL large, covered with dense short hairs; hypandrium with small L; S elongated (Figs 152-154).

Variability. Black hairy stripe on scutum can be absent; basoflagellomere can be from orange to darkbrown; tibiae and tarsi are usually orange, but tibiae can have dark parts and tarsi can be darkened dorsally. Colour of tergites III, IV is very variable, from dark, to almost completely reddish.

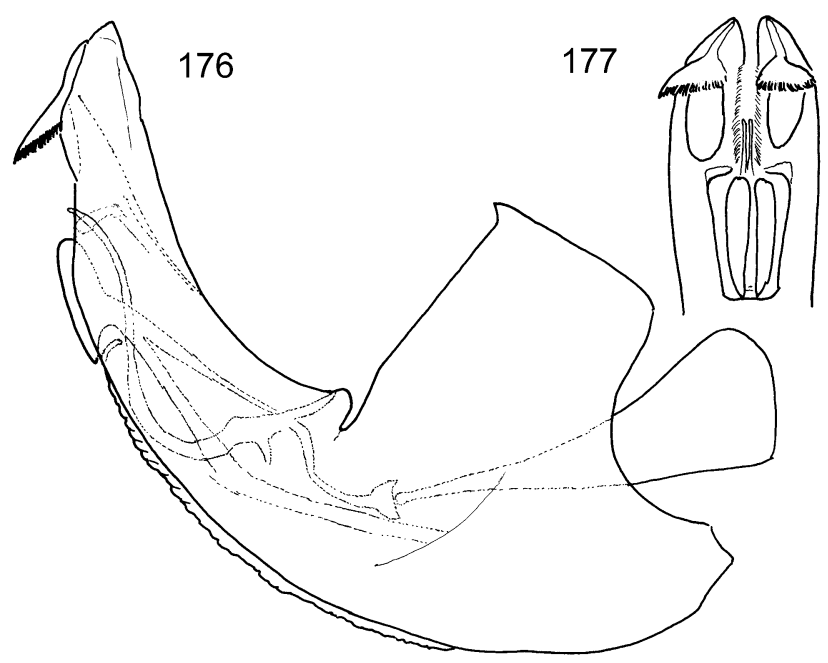

Figs 174-177. Merodon geniculatus, male genitalia. 174 - epandrium, lateral view; 175 - left surstyle, anterior view; 176 hypandrium, lateral view; 177 - apical part of hypandrium, anterior view. Scale $0.2 \mathrm{~mm}$. 

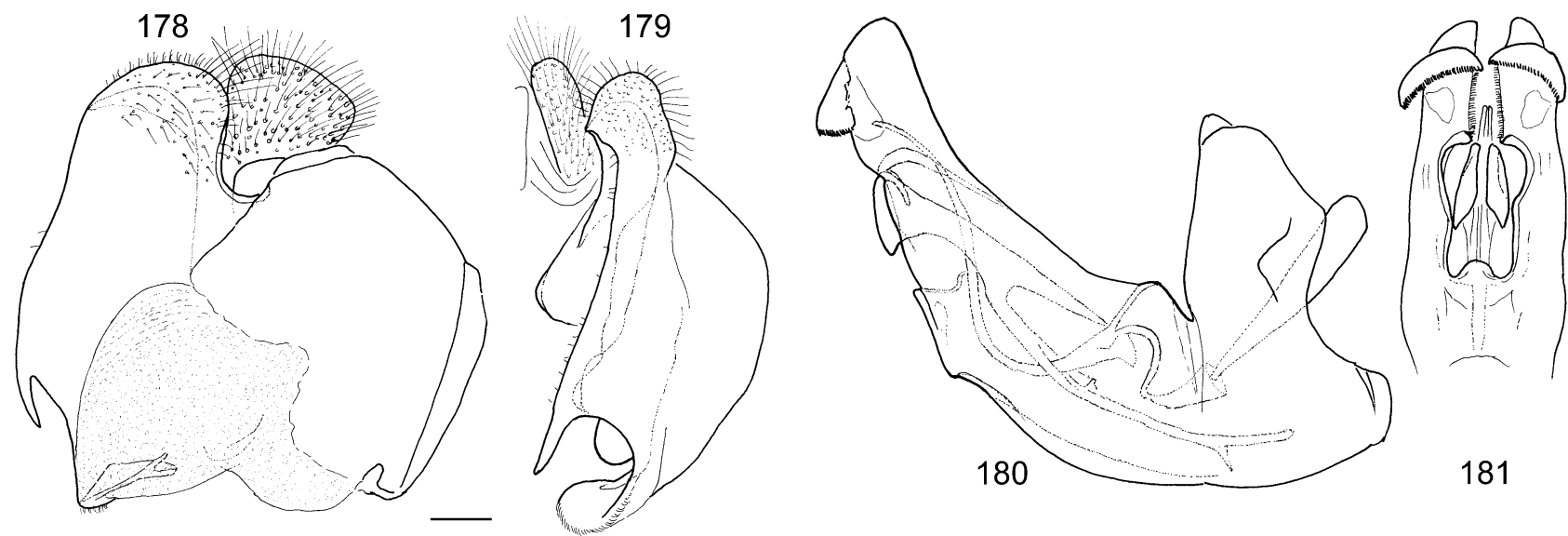

Figs 178-181. Merodon hurkmansi sp. n., male genitalia. 178 - epandrium, lateral view; 179 - left surstyle, anterior view; 180 hypandrium, lateral view; 181 - apical part of hypandrium, anterior view. Scale $0.2 \mathrm{~mm}$.

Materail examined. Unpublished material: Spain. Alicante: El Menetjador, Alcoi; Foia Ampla, Agres; Font Roja, Alcoi (CEUA \& NSEC); Mas de Cano, Xixona; Mas de St. Ignaci, Xixona; Venta Carrasqueta, Alcoi; Salamanca: Lagunilla; Peña de Francia; Valencia: Chelva; Mas del Parral, Bocairent; Utiel (NSEC). Published material: Marcos-García (1985a) as $M$. avidus; Marcos-García (1990b).

Additional published records. Hurkmans (1993).

Biology. Preferred environment: scrub/open ground. This species has been found on low-lying, sandy, herbrich grassland containing abundant wild onion flowers (Allium sp.), scattered clumps of sedge and occasional stems of Arundo, at the edge of Mediterranean salt-marsh, where the fluctuating ground-water levels would, during the winter, bring the water level very close to the ground surface. It has also been found in open dry Pinus forest ( $P$. halepensis) on largely bare, stoney ground and in open areas within Quercus ilex forest, garrigue and matorral. Flowers visited: Calystegia sp. and Cistus sp. Period of flight: April-September.

Iberian distribution. Widespread in the Iberian Peninsula: Cantabrian mountains (North of Spain), Iberian mountain range (East of Spain), and Sistema Central (Fig. 248).

Range. Spain, southern France (and Corsica), southern Italy (and Sicily); Northwest Africa (Algeria, Morocco); western Mediterranean species.

\section{Merodon equestris (Fabricius, 1794)}

Figs 57, 94, 155-158

Syrphus equestris Fabricius, 1794: 292.

Diagnosis. Big (17-23 mm), bumble bee-like species with long and dense body hairs; cx hairy, pa with reduced hairs; apical prolongation of hind tibiae long and curled (Fig. 57); hind tibiae with large central bulge (Fig. 57); male genitalia: PL with rounded top; surstyle margin more or less straight, until the marginal thorn; marginal thorn small, bifid; AL with long apical extension pointed medially; C large, triangular; hypandrium with folded thecal ridge; $\mathrm{S}$ with large, oval apical part (Figs 155-158).

Variability. Body hairs can be very variable, from specimens with almost completely pale hairs to specimens with black haired posterior half of scutum and tergite III; some varieties were described based on this polymorphism.

Material examined. Unpublished material: Spain, Lleida: Bosque de Bonabé, Valle de Arán. Published material: MarcosGarcía (1985a, b, 1990b), as M. equestris nobilis (CEUA \& NSEC); Marcos-García (2000).

Additional published records. Czerny \& Strobl (1909); Czerny \& Strobl (1909) as M. equestris narcissi; Czerny \& Strobl (1909) as M. equestris nobilis; Arias (1912); Arias (1912)
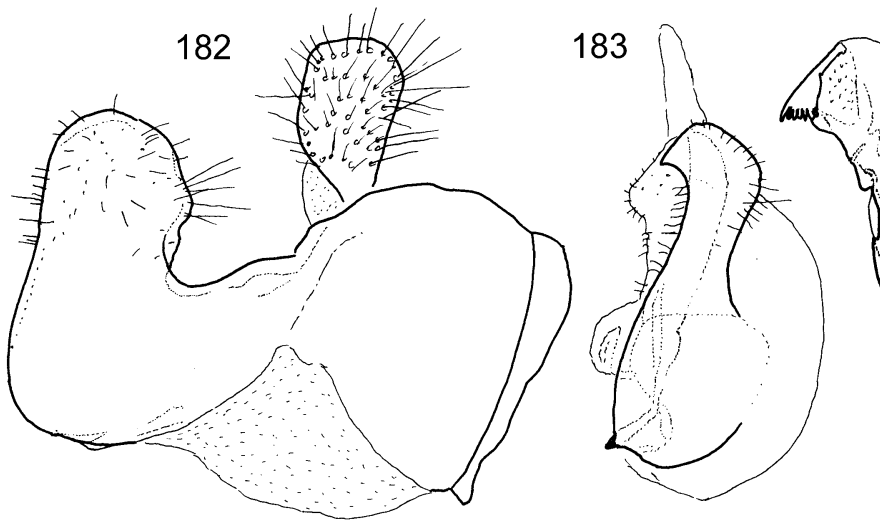

184

Figs 182-185. Merodon legionensis sp. n., male genitalia. 182 - epandrium, lateral view; 183 - left surstyle, anterior view; 184 hypandrium, lateral view; 185 - apical part of hypandrium, anterior view. Scale $0.2 \mathrm{~mm}$. 

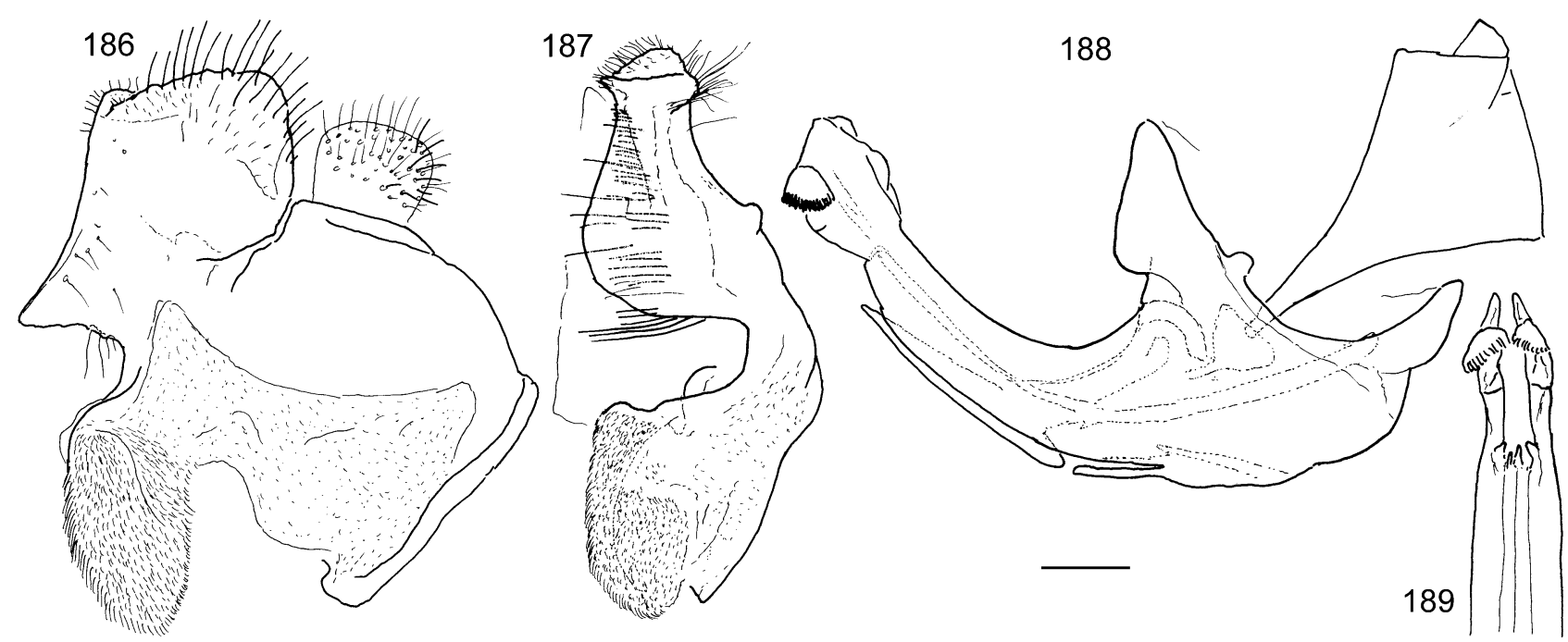

Figs 186-189. Merodon longicornis, male genitalia. 186 - epandrium, lateral view; 197 - left surstyle, anterior view; 188 hypandrium, lateral view; 189 - apical part of hypandrium, anterior view. Scale $0.2 \mathrm{~mm}$.

as M. equestris narcissi; Arias (1912) as M. equestris nobilis; Andreu (1926); Andreu (1926) as M. equestris narcissi; GilCollado (1930); Gil-Collado (1930) as M. equestris narcissi; Gil-Collado (1930) as M. equestris nobilis; Séguy (1934) as Lampetia equestris var. narcissi; Peris (1958); Séguy (1961) as L. equestris; Pedersen (1971) as M. equestris narcissi; Pedersen (1971) as M. equestris nobilis. Andorra: Van der Goot (1958) as M. equestris nobilis: Andorra la Vella. 100-1300 m, 24-25.vii.1955.

Biology. Preferred environment: deciduous forest, significantly anthropophilic, occurring also in suburban gardens and on horticultural land; in the Alps abundant in unimproved, montane and alpine pasture. Flowers visited: Umbellifers; Ajuga sp., Aster sp., Cirsium sp., Crepis sp., Eschscholzia californica, Hieracium sp., Knautia arvensis, Meconopsis cambrica, Papaver sp., Ranunculus sp., Rubus idaeus, and Senecio sp. Period of flight: May-July (plus April in southern Europe and August at higher altitudes).

Iberian distribution. Mountainous areas of the Eurosiberian region and Sistema Central of Spain (Fig. 257).

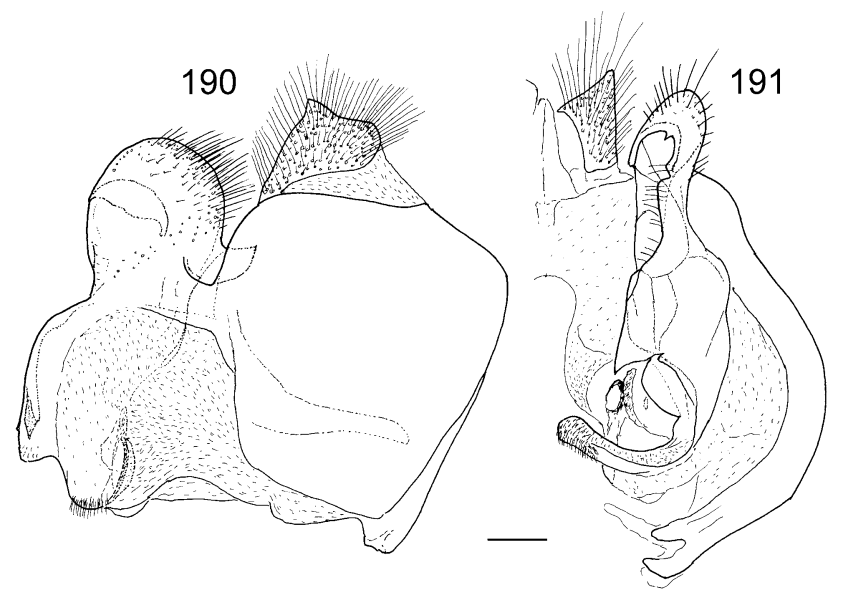

Range. Fennoscandia south to Iberia and the Mediterranean, including N Africa; from Ireland eastwards through much of Europe into European parts of Russia; also in Japan; in North America from British Colombia south to California. Human activities have resulted in the introduction of this species to parts of the world outside its natural range, including New Zealand. Within Europe its range has almost certainly been expanded due to human activity and it is doubtful, for instance, that this species reached either Britain or Ireland unaided by man (Speight, 2006).

\section{Merodon escorialensis Strobl in Czerny \& Strobl, 1909}

Figs 61, 68, 71, 103, 108, 159, 160, 163, 164

Merodon geniculatus escorialensis Strobl in Czerny \& Strobl, 1909: 203.

M. escorialensis was described from the three syntypes, as variety of M. geniculatus. Marcos-García (1989) concluded that it must be considered as a distinct species. But the designation of neotype (Marcos-García, 1989) was incorrect, because of currently recognised syntypes from the Strobl collection. In this paper we designate the lectotype. Lectotype (designated here): male "geniculatus v. escorialensis / Escorial, Rd” (Spain) (NMBA). Paralecto-

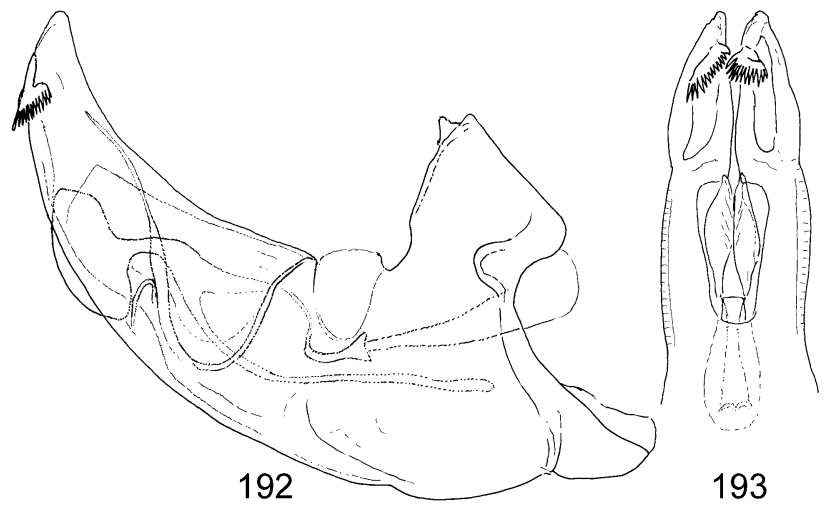

Figs 190-193. Merodon longispinus sp. n., male genitalia. 190 - epandrium, lateral view; 191 - left surstyle, anterior view; $192-$ hypandrium, lateral view; 193 - apical part of hypandrium, anterior view. Scale $0.2 \mathrm{~mm}$. 

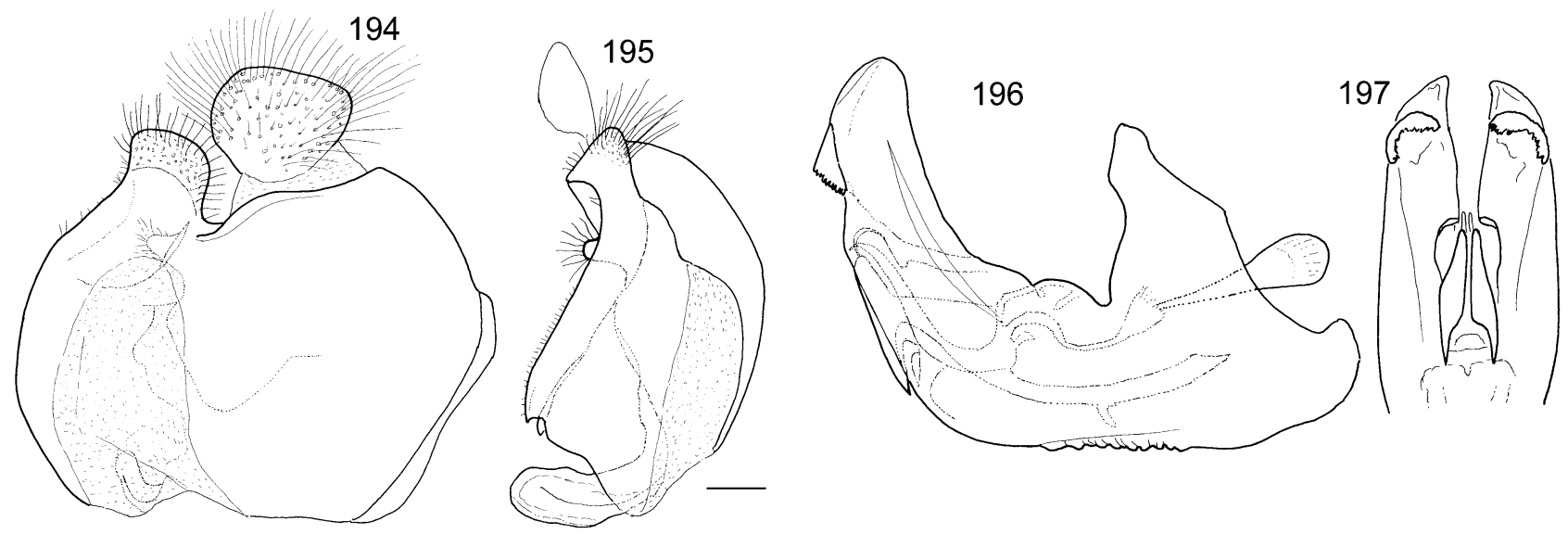

Figs 194-197. Merodon luteihumerus sp. n., male genitalia. 194 - epandrium, lateral view; 195 - left surstyle, anterior view; 196 - hypandrium, lateral view; 197 - apical part of hypandrium, anterior view. Scale $0.2 \mathrm{~mm}$.

types: female on the same pin together with lectotype (in copula) [conspecific with lectotype]; female "Chinchon, Dusmet" (Spain) [identity: M. geniculatus Rondani, 1845] (NMBA).

This species is re-described because previous descriptions contain characters from three cryptic species $(M$. antonioi sp. n., M. crypticus sp. n. and nominated species).

\section{Male}

Head. Antennae brown; basoflagellomere 1.2 times as long as pedicel, upper margin slightly concave, apex acute. Face, frons and occiput black covered by dense white pubescence and long white hairs. Oral margin bare and lustrous black. Ocellar triangle isosceles. Eyes with white hairs; vertical triangle with white erect pilosity.

Thorax. Mesonotum and scutellum dark green with metallic luster and covered with erect pale-yellow hairs. Some specimens have a group of black setae at wings base. Five dusted longitudinal stripes can be visible from posterior view. Posterior anepisternum, anepimeron and dorsal part of katepisternum with yellowish-white hairs. Wings pale-greyish with dark veins. Dorsal and ventral calypters pale-yellow. Halteres with yellow capitulum and pale-brown pedicel. Femora dark-brown with pale apical part. Fore and mid tibiae yellow in basal part in a variable extension with distal dark end; hind tibiae yellow with dark median band and with a blunt apico-medial process. Tarsi dark, with the two first tarsomeres partly pale. Hind trochanter with a distinct rounded thorn covered with long, dense hairs. Legs with pale hairs except some black adpressed ones on the dorso-apical part of the hind femora.

Abdomen. Dark, oval and longer than mesonotum. Tergites II-IV black with white pruinose transverse band interrupted in the middle on tergites II and III; posterior margin of tergites III and IV pale; tergite II with pale antero-lateral spots. Tergites covered with adpressed hairs of the same colour as the tegument; long pale hairs on sternites, on pale spots of tergite II and on lateral margin of all tergites. Sternite I dark anteriorly and pale posteri- orly; sternites II and III pale; sternite IV and posterior ones dark brown.

Male genitalia. PL dorsally acute (Fig. 191). Anterior margin of the surstyle clearly convex. C concave with two distinct apical prominences (Fig. 71); Hypandrium with folded thecal ridge (Fig. 163).

Female

Similar to the male except for the following characteristics: Antennae brown with pale ventral surface. Frons shiny, white dusted laterally and covered with yellowishwhite hairs anteriorly reclined. Ocellar triangle equilateral, covered with black pilosity.

Diagnosis. Species with hairy cx and reduced hairs on pa, hind trochanter with blunt thorn, usually covered with tuft of hairs (Fig. 61) (geniculatus group); bf $=1.2$ (Figs $68,108)$; medium sized $(11.0-13.3 \mathrm{~mm})$ species, with pale haired scutum, usually with few black bristles near wing bases; hind tibia with apico-medial spur (Fig. 61); C with two distinct apical prolongations (Fig. 71). Fore more details see diagnosis of $M$. antonioi sp. $\mathrm{n}$.

Type material examined. M. escorialensis: Lectotype: Strobl in Czerny \& Strobl (1909) as M. geniculatus var. escorialensis: Spain, Madrid: 10, El Escorial (NMBA). Paralectotype: Strobl in Czerny \& Strobl (1909) as M. geniculatus var. escorialensis: Spain, Madrid: 1ㅇ, El Escorial (NMBA). Neotype: MarcosGarcía (1990b) as M. escorialensis: Spain, León: 20ત, Candín 875 m, 29TPH8642, 9.ix.1987, Leg: Marcos-García (MNMS).

Other material examined. Unpublished material: Spain, Albacete: Riopar (van Steenis collection); Batan del Puerto (van Steenis collection); Sierra de Alcaraz (van Steenis collection); Ávila: Sierra Candelario; Barcelona: Barcelona; Cáceres: Hervás; Nuñomoral; Valverde del Fresno; Granada: Delphi; Jaén: Arroyo Aguaderillos, Cazorla (Natural Park); Málaga: Alhaurin El Grande; Salamanca: Escurial de la Sierra (NSEC); Fuente Gaspar, Batuecas; Las Batuecas; Peña de Francia (NSEC); Pto. de la Cruz, Béjar.

Additional published records. Arias (1912) as Merodon geniculatus var. escorialensis; Andreu (1926) as Merodon geniculatus var. escorialensis; Gil-Collado (1930) as M. geniculatus var. escorialensis; Marcos-García (1990b) as M. escorialensis; Marcos-García (2000). 

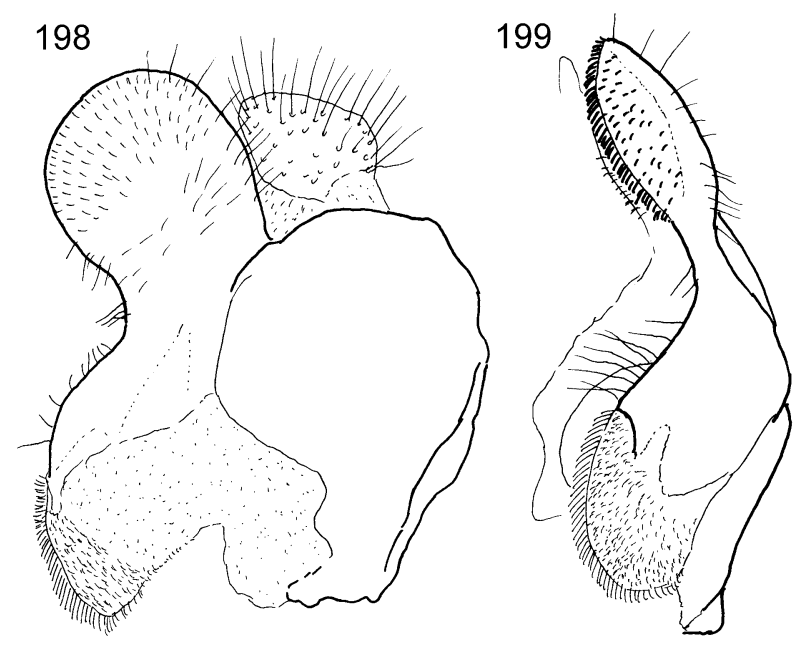

Figs 198-201. Merodon natans, male genitalia. 198 - epandrium, lateral view; 199 - left surstyle, anterior view; 200 - hypandrium, lateral view; 201 - apical part of hypandrium, anterior view. Scale $0.2 \mathrm{~mm}$.

Biology. Preferred environment: open ground; unimproved, non-calcareous, montane grassland and heath, from the level of Castanea forest up to $1800 \mathrm{~m}$ (MarcosGarcia, 1989b), all over Iberian Peninsula. Flowers visited: yellow composites; Calluna sp., Lavandula sp., Mentha sp., and Succisa sp. Period of flight: March-September.

Iberian distribution. Mountains of the Sistema Central (centre of Spain) and Parque Natural de Cazorla (South of the Iberian Peninsula) (Fig. 250).

Range. Spain (from Cantabrian mountains southwards into much of central Spain).

\section{Merodon flavus Sack, 1913}

Figs 58, 95, 165-169

Merodon flavus Sack, 1913: 429.

Diagnosis. Big (13.3-14.0 mm), bumble bee-like species related to $M$. equestris, with long and dense yellowish body hairs; cx hairy, pa with reduced hairs; apical prolongation of hind tibiae not so long and straight (Fig. 58); hind tibiae with small central bulge (Fig. 58); male genitalia similar to that of M. equestris: PL with rounded top and anterior acute excavation; surstyle margin slightly rounded (more or less straight in $M$. equestris); marginal thorn larger, with bigger inner tooth than in M. equestris; $\mathrm{AL}$ with long apical extension pointed medially; $\mathrm{C}$ triangular, but smaller than in $M$. equestris; hypandrium with folded thecal ridge; $\mathrm{S}$ with large, oval apical part (Figs 165-169).

Material examined. Unpublished material: Spain. Cáceres: 20, Gata 19.iv.1981, Leg. Marcos-García; Salamanca: 10, Pantano de la Almendra 28.iii.1982, Leg. Marcos-García. Published material: Marcos-García (1990b) as M. equestris narcissi (CEUA \& NSEC); Kehlmaier (2002).

Biology. Preferred environment: Open ground, montane grassland with stands of wild Narcissus. Period of flight: April to July.

Iberian distribution. Mountainous areas of the Eurosiberian region and Sistema Central of Spain (Fig. 249).
Range. Czech Republic; Spain, Causses (France), Alps (France, Switzerland, Italy); Hungary, Bulgaria.

\section{Merodon funestus (Fabricius, 1794)}

Figs 34, 35, 170-173

Syrphus funestus Fabricius, 1794: 302.

Diagnosis. Small (8.0-10.6) species with hairy cx and many hairs on pa, short rounded abdomen, and thorn on hind trochanter of male, related to aureus group; antennae usually dark, pedicel as long as basoflagellomere (Figs 34, 35); hairs on eyes from whitish to greyish; scutum punctured medially, usually with two narrow central and two broader lateral pollinose stripes; legs dark with pale knees, tibiae at both ends and tarsi (at least ventrally); tergites with very rough punctures, especially on tergites II, III, on dark haired parts; tergites II-IV with pale pollinose stripes covered with pale hairs; tergite IV with adpressed golden-greyish hairs in clear contrast to black haired central parts of tergite III (and II); male genitalia: PL pointed towards top; AL undeveloped; $\mathrm{C}$ rounded; hypandrium straightened on the central acute part; S small (Figs 170-173).

Material examined. Unpublished material: Spain, Albacete: Riopar; Sierra de Alcaraz; Alicante: Caveta del Buitre, Agres; El Menetjador, Alcoi; Font Roja, Alcoi; Barcelona: Montserrat; Sabadell; Girona: De Campodron a Setcases; Huesca: San Juan de la Peña, Jaca; Tarragona: Calafell; Pontevedra: Pontevedra; Valencia: Chelva; Requena; Utiel. Published material: GilCollado (1930); Séguy (1961) as L. funesta; Marcos-García (1985a, 1986, 2000).

Additional published records. Andreu (1926); Peris (1958); Leclercq (1971).

Biology. Preferred environment: Forest/open ground; open areas in Quercus ilex forest and tall-herb ruderal communities on sparsely-vegetated open ground, close to seasonal rivers and streams or drainage ditches. Flowers visited: tall yellow Composites; Adonis sp., Anacyclus sp., and Ranunculus sp. Period of flight: May-June and August-September. 

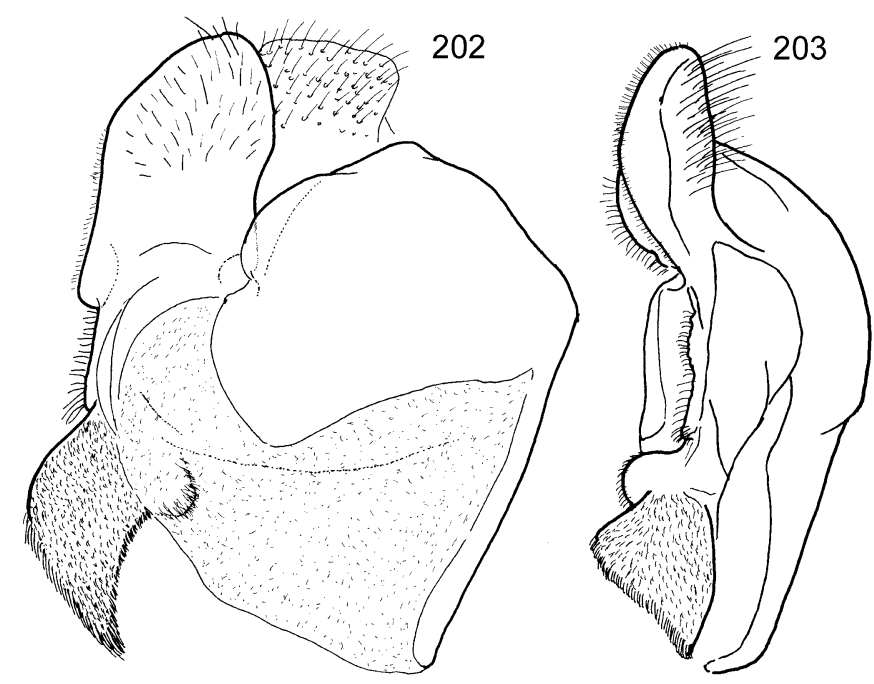

Figs 202-204. Merodon nigritarsis, male genitalia. 202 - epandrium, lateral view; 203 - left surstyle, anterior view; 204 - hypandrium, lateral view. Scale $0.2 \mathrm{~mm}$.

Iberian distribution. Pyrenees, Northwest of Spain and mountains of the Centre, East and South of Spain (Fig. 249).

Range. Spain and Mediterranean basin through southern France, Italy (inc. Sicily), parts of the former Yugoslavia, Albania and Turkey to Israel and Libya; known also from Bulgaria and Romania and, apparently, from Poland.

\section{Merodon geniculatus Strobl in Czerny \& Strobl, 1909}

Figs 30, 63, 65, 70, 100, 105, 174-177

Merodon geniculatus Strobl in Czerny \& Strobl, 1909: 203.

Diagnosis. Species with hairy cx and reduced hairs on pa, hind trochanter with blunt thorn, usually covered with tuft of hairs (as in Fig. 63) (geniculatus group); medium sized (9-11 mm) species; thorax covered with pale hairs; scutum with unpollinose shiny parts, especially on posterior half; basoflagellomere short ( $b f=1.1$ ), distance between top of antenna and antennal pit about three times longer than distance between antennal pit and pedicel (Figs 65, 105); spur on trochanter small (Fig. 63); hind tibia without apico-medial spur, short, ending before the base of hind femora; hind femur with small ventral bulge (Fig. 63); hind basotarsomere usually partly pale dorsally; pollinose stripes on tergites broad; male genitalia similar to that of $M$. antonioi sp. n., M. crypticus sp. n. and $M$. escorialensis: $\mathrm{C}$ with only small anterior protuberance (Figs 70, 174-177).

Type material examined. Lectotype: Strobl in Czerny \& Strobl (1909) as Merodon geniculatus: Spain, Andalucia: 1 , San Fernando (NMBA). Paralectotype: Strobl in Czerny \& Strobl (1909) as Merodon geniculatus: $3 \hat{0}, 3 \%$, same data as lectotype (NMBA). Strobl in Czerny \& Strobl (1909) as $M$. geniculatus var. escorialensis: Spain, Madrid: Chichón 1 , (NMBA).

Other material examined. Unpublished material: Spain, Alicante: Foia Ampla, Agres; Ciudad Real: N.P. Cabañeros; Valencia: Mas del Parral, Bocairent. Portugal, 10, 1․ Algarve, Castro Karin 18.iv.1985, Leg. J.A.W. Lucas. Published material: Gil-Collado (1930); Marcos-García (1985a); Vujic (1996); Marcos-García (2000). Gibraltar, Vujic (1996): Torre Guadiaro, Gibraltar 1.iv.1988.
Additional published records. Czerny \& Strobl (1909); Arias (1912); Andreu (1926); Gil-Collado (1930); Gil-Collado (1932); Compte (1958); Herrera (1988); Peck (1988).

Biology. Preferred environment: forest/open ground; unimproved montane grassland in southern Europe and open areas in mesophilous Fagus and Quercus ilex forests. Period of flight: March-April (Malta) and July to September, with a peak at end August-beginning September.

Iberian distribution. Widespread in the Iberian Peninsula except for the Eurosiberian region (Fig. 251).

Range. Southern France, Portugal, Spain, Italy, southern parts of the former Yugoslavia, Bulgaria, Turkey, Israel and N Africa (Algeria, Morocco); Mediterranean islands: Balearics, Corsica, Malta.

\section{Merodon hurkmansi sp. $\mathbf{n}$.}

Figs 81, 86, 88, 92, 99, 178-181

Male

Head. Antennae brown, pale in ventral part; basoflagellomere 1.4 times longer than wide, apex acute, dorsal margin straight. Face and frons black, white dusted and with yellowish-white hairs. Oral margin black lustrous, bare. Vertical triangle isosceles with yellow hairs. Ocellar triangle isosceles. Eye contiguity line in males as long as the distance between the anterior and posterior ocelli. Occiput black with yellow hairs.

Thorax. Mesonotum and scutellum dark-green with metallic luster and covered with erect yellow hairs and some black ones on wing bases. Posterior anepisternum, anepimeron and dorsal part of katepisternum with yellowish hairs. Five longitudinal dusted bands visible in posterior view. Wings pale-greyish with dark veins. Dorsal and ventral calypters pale yellow. Halteres yellow, slightly dark. Femora dark brown with pale apex. Fore and mid tibiae yellow in basal part with distal dark end; hind tibia yellow with dark median band and with a short and blunt apico-medial process; mid femora with ventral short black bristles. Tarsi darkened, except for three basal 

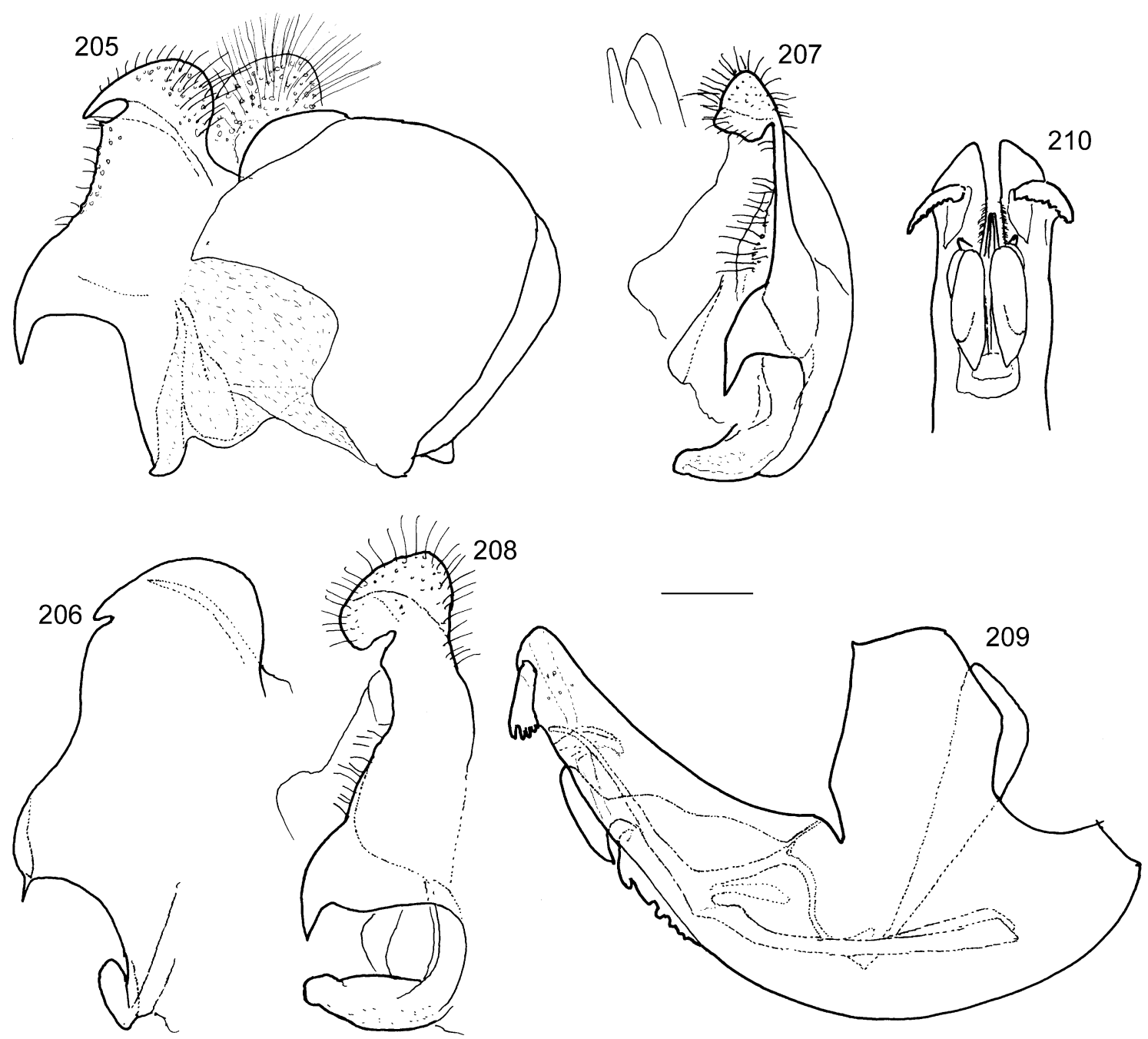

Figs 205-210. Merodon obscuritarsis, male genitalia. 205 - epandrium, lateral view; 206 - surstyle, lateral view; 207-208 - left surslyle, anterior view; 209 - hypandrium, lateral view; 210 - apical part of hypandrium, anterior view. Scale $0.2 \mathrm{~mm}$.

yellow tarsomeres of hind leg. Hind trochanter without a distinct thorn, but with a clear angular hump. Legs covered with pale hairs.

Abdomen. Dark, oval and longer than mesonotum. Tergite I completely black; tergite II with red antero-lateral spots; tergites III and IV black with large white pruinose transverse stripes interrupted in the middle; stripe on tergite IV at least one fourth of its length; all tergites covered with adpressed hairs of same colour than tegument. Sternites, anterior corner of tergite II and lateral margin of all tergites with long pale hairs. Sternites mainly dark brown.

Male genitalia. PL large and rounded; All with medium sized marginal thorn and large medial prolongation (Figs 178, 179). C rounded without prominences (Fig. 178). S hammer-like, curved anteriorly and with acute ventroapical extreme (Fig. 172).

Diagnosis. Species with hairy cx and reduced hairs on pa; medium sized (14.3 mm), short haired; bf $=1.4$ (Fig. 92); M. hurkmansi sp. n. is very similar to M. albifrons, but can be distinguished by pollinose abdominal stripes, wider in M. hurkmansi sp. n. (Fig. 86) than in M. albi- frons (Fig. 85); hind trochanter with a clear angular hump in M. hurkmansi sp. n. (Fig. 81), very small in M. albifrons (Fig. 80).

Type material. Holotype: Algeria: $1 \widehat{\delta}, \mathrm{W}$. Salda, Mercheria Dj. Antar 6.iv.1981, Leg. P.v.d. Hurk. (ZMAN). Paratype: Algeria: $1 \delta^{\star}$, Tlamcan, $20 \mathrm{~km} \mathrm{~N}$ de Maghnia, Bab Taza, 9.iv.1983, R.L. Leys \& P.v.d. Hurk (ZMAN).

Etymology. The name hurkmansi is dedicated to Willem Hurkmans in recognition of his long-term work on Merodon species.

Biology. Period of flight: April.

Range. Algeria.

\section{Merodon legionensis sp. $\mathbf{n}$.}

Figs 31, 36, 37, 41, 182-185

Male

Head. Antennae brown; basoflagellomere pale and 1.2 times as long as pedicel; upper margin straight; apex acute. Face and frons shiny black covered with long white-yellow hairs. Oral margin black lustrous, bare. Occiput covered by white pubescence and long white hairs. Vertical triangle equilateral and with white hairs. 

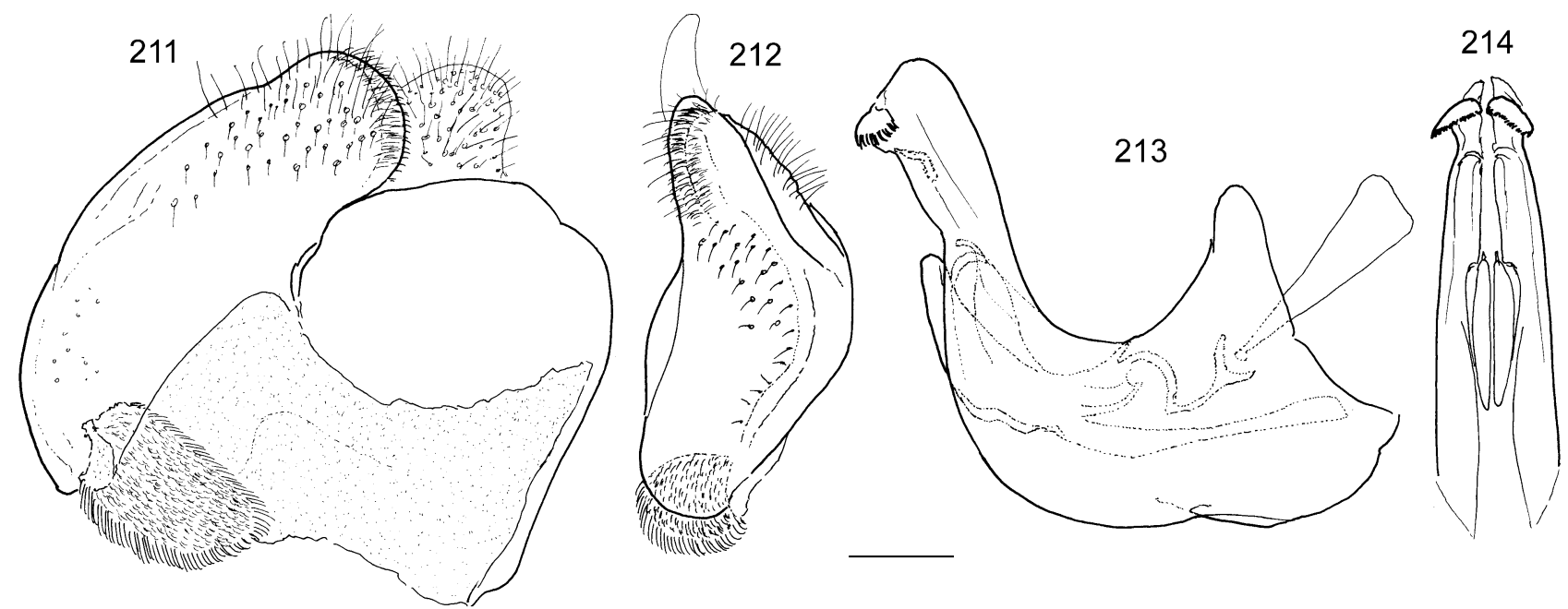

Figs 211-214. Merodon ottomanus, male genitalia. 211 - epandrium, lateral view; 212 - left surstyle, anterior view; 213 - hypandrium, lateral view; 214 - apical part of hypandrium, anterior view. Scale $0.2 \mathrm{~mm}$.

Eyes with white hairs on the low surface and black on the upper part.

Thorax. Mesonotum and scutellum dark green with metallic luster covered with erect yellow hairs. Posterior anepisternum, anepimeron and dorsal part of katepisternum with yellowish-white hairs. Wings pale-greyish with dark veins. Dorsal and ventral calypters pale yellow. Halteres with yellow pedicel and brown capitulum. Femora dark brown with pale colour apically and with long anterior white hairs and short posterior black reclined hairs. Tibiae yellow, occasionally with dark traces on the middle. Tarsi yellow except two last tarsomeres dark. Tibiae and tarsi with yellow hairs and some black ones. Hind trochanter with an inner bifid thorn.

Abdomen. Oval, approximately as long as mesonotum; dark green with metallic luster and covered with adpressed yellowish hairs. Second and third tergites bearing a pair of dusted transversal spots. Sternites black with long pale hairs.

Male genitalia. Similar to M. aureus. AL is undeveloped with straight ventral margin; PL is rounded on the apex with long hairs and parallel margins (Fig. 190). C elongated, without prominences. Hypandrium narrow, elongated and sickle-shaped; S reduced (Figs 182-185).

Female

Similar to the male except for the following characteristics: Frons shiny and covered with yellowish-white hairs; two narrow longitudinal bands of white pubescence near the eye margins. Ocellar triangle with black hairs. Hind trochanter without thorn. Abdomen shiny black with a pair of white dusted bands on the tergites II, III and IV. In the tergite II these spots are subparallel to the margins of the tergite and in the tergites III and IV are oblique.

Diagnosis. Small $(7.6-13.3 \mathrm{~mm})$ species with hairy cx and many hairs on pa; short rounded abdomen, and thorn on hind trochanter in male (aureus group); abdomen and mesonotum with dense, reddish-yellow hairs in male; female abdomen with shorter, mixed pale and black hairs, tergites II-IV with clear pollinose stripes; tegument of mesonotum and tergites with golden tomentum. $M$. legionensis sp. $\mathrm{n}$. is similar to M. aureus and M. pumilus but can be distinguished by the following characteristics: M. legionensis $\mathrm{sp}$. $\mathrm{n}$. has the upper quarter of eyes black haired, M. aureus has at least upper half of eyes black haired and M. pumilus has eyes completely pale haired. M. legionensis sp. $\mathrm{n}$. has dark brown femora pale apically; tibiae yellow, occasionally with dark traces on the middle; tarsi yellow except the two last dark tarsomeres, M. aureus and M. pumilus have dark legs except pale knees and ends of tibiae and tarsi.

Type material. Holotype: Spain. 10ิ, León: Murias de Paredes 9.ix.1987, Leg. Marcos-García (CEUA). Paratype: Spain. Alicante: 19 , Caveta del Buitre, Agres (Natural Park Mariola) 1200 m; 27.viii./10.ix.2002 (MT), Leg. X. Mengual (CEUA); 1 ㅇ, Font Roja, Alcoi (Natural Park) 21.ix.1993, Leg. P.M. Isidro (NSEC); 4 , Font Roja, Alcoi (Natural Park), Menetjador 22.ix.2004, Leg. A. Ricarte (CEUA); 1 \%, Font Roja, Alcoi (Natural Park), Menetjador 22.ix.2004, Leg. A. Ricarte (MNMS); León: 1 9 , Cofiñal 9.ix.1987, Leg. MarcosGarcía (CEUA); 19 , Pandetrave, Santa María de Baldeón 13.ix.1987, Leg. Marcos-García (CEUA); 1 을 Predosa del Rey 30TUN4054, 1100 m; 13.ix.1987, Leg. Marcos-García (published as M. aeneus in Marcos-García, 1990b) (CEUA); Valencia: 1 , Chelva 28.viii.1993, Leg. Pérez-Bañón (CEUA); 1 , Chelva 28.viii.1993, Leg. Pérez-Bañón (MNMS); 1 đิ, Utiel 6.ix.1994, Leg. Pérez-Bañón (CEUA); 1 đ̃, Utiel 6.ix.1994, Leg. Pérez-Bañón (NSEC).

Etymology. The name legionensis is derived from Legio VII, the Roman name of León, the Spanish province where the first specimens of this species were collected.

Biology. Preferred environment: High mountain grassland in the North of Spain and open areas with Mediterranean scrub in high mountains in the East of Spain. Flowers visited: Merendera montana. Period of flight: September.

Iberian distribution. Cantabrian range (North of Spain) and Iberian mountains (East of Spain) (Fig. 252).

Range. Spain. 


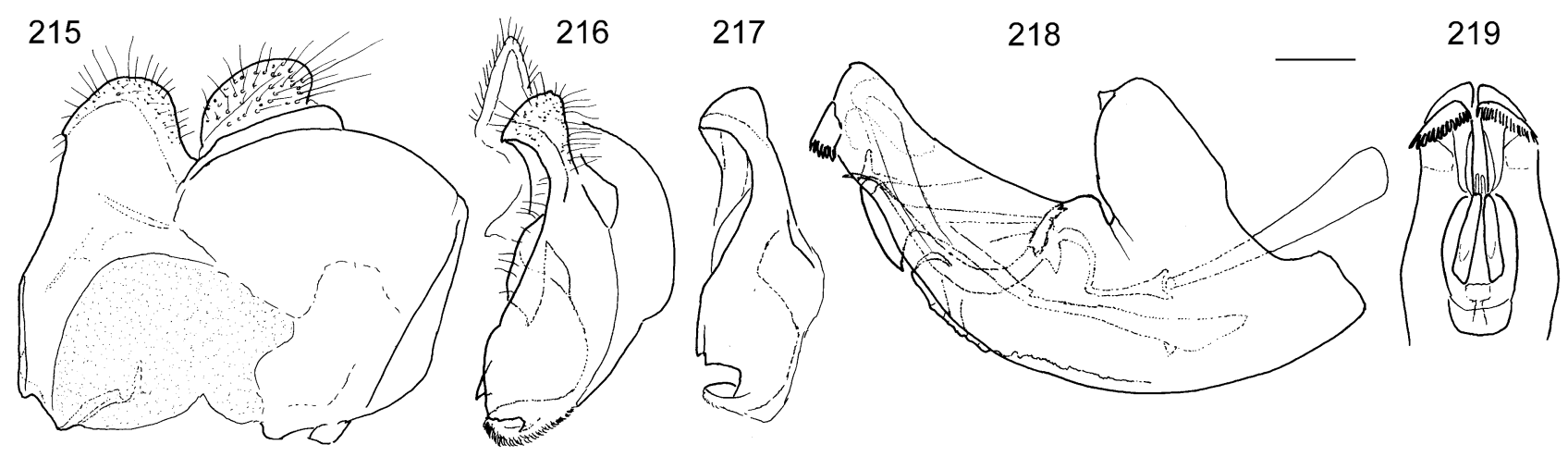

Figs 215-219. Merodon parietum, male genitalia. 215 - epandrium, lateral view; 216, 217 - left surstyle, anterior view; 218 hypandrium, lateral view; 219 - apical part of hypandrium, anterior view. Scale $0.2 \mathrm{~mm}$.

\section{Merodon longicornis Sack, 1913}

Figs 5, 186-189

Merodon longicornis Sack, 1913: 447.

Merodon affinis Gil Collado, 1930: 255 syn. $\mathrm{n}$.

Merodon affinis: holotype (original designation): female "Escorial" (Spain) (MNMS). [Holotype is slightly damaged, without antennae; fortunately the drawing of the head from the original description contains the shape of antenna, which fits M. longicornis Sack; this long antenna clearly separated this species from all others in the genus; the other morphological characters also fit $M$. longicornis].

Diagnosis. Medium sized to small (7.3-10.6 mm), slender species; cx bare and pa with reduced hairs; basoflagellomere very long, bf $=2.2$ (Fig. 5); face, pleurae and legs with whitish hairs, vertex (and frons in female) with black hairs; scutum with stripe of black hairs between wing bases and four pollinose longitudinal stripes; knee, tibiae at both ends and tarsi, at least ventrally, paler; tergites black in male, tergites II, III in female completely or partly red; tergites II-IV with clear white pollinose stripes; male genitalia: PL square-shaped, with ventral triangular prominent part, in lateral view; recess between surstyle lobes large and deep; AL medium sized, oval, covered with dense short hairs; hypandrium with small L; S elongated (Figs 186-189).

Variability. Frons in female with many or only a few black hairs; tergites II, III in female from partly to completely red.

Type material examined. Holotype: Gil Collado (1930) as Merodon affinis: Spain, Madrid: 1 , El Escorial (MNMS).

Other material examined. Unpublished material: Spain, Albacete: $1 \hat{\delta}$, Sierra de Alcaraz, Puerto de las Crucetillas 1200 m, $38^{\circ} 32^{\prime} \mathrm{N}, 2^{\circ} 24^{\prime} \mathrm{W}, 21 . v i .2003$, Leg. van Steenis.

Biology. Preferred environment: open/ground cultures, dry grassland and orchards. Flowers visited: Euphorbia sp. Period of flight: May-July.

Iberian distribution. Mountainous areas of the Centre and Southeast of Spain (Fig. 252).

Range. Former Yugoslavia, Greece, Turkey, Ukraine, southern Russia, Lebanon, North Africa. These are the first data from the Iberian Peninsula.

\section{Merodon longispinus sp. $\mathbf{n}$.}

Figs 60, 64, 66, 190-193

Male

Head. Antennae brown; basoflagellomere 1.2 times as long as wide; upper margin straight; apex acute. Face and frons shiny black, covered with long white-yellow hairs. Oral margin black lustrous, bare. Occiput covered with grey pubescence and long white hairs. Vertical triangle isosceles and with yellowish white hairs. Eyes covered with white hairs.

Thorax. Mesonotum dark, lustrous and covered with erect yellow hairs. Posterior anepisternum, anepimeron and dorsal part of katepisternum with yellowish-white hairs. Wings pale-greyish with darkened veins. Dorsal and ventral calypters pale yellow. Halteres yellowishbrown. Femora dark-brown, paler apically. Fore and mid tibiae yellow, with black apical third; hind tibiae yellow with a black central band. Fore tarsi with yellow basal tarsomeres and darker apical ones. Hind trochanter with a very long thorn, wider and rounded on its top. Femora with long white hairs.

Abdomen. Oval, approximately as long as mesonotum; dark lustrous and covered with long adpressed dark hairs. Tergites II-IV bearing a pair of dusted transversal spots. Tergite II with red antero-lateral spots. Sternites black covered with long pale hairs.

Male genitalia. PL spherical; surstyle margin with a central depression (Fig. 190). AL with an inner marginal thorn invisible in lateral view, and long medial prolongation (Figs 190, 191). C with anterior apical prominence (Fig. 190). S large and semi-spherical apically (Fig. 192).

Female

Unknown.

Diagnosis. Big species $(14 \mathrm{~mm})$ with hairy $\mathrm{cx}$ and reduced hairs on pa, hind trochanter with blunt thorn, usually covered with tuft of hairs (geniculatus group); $M$. longispinus sp. n. can be easily distinguished from other species of the geniculatus group by the extremely long thorn on the hind trochanter (Fig. 60); basotarsomere of hind leg with medial incision on central part (Fig. 64); hind femora swollen, curved basally (Fig. 60); basoflagellomere (Fig. 66) reddish (bf $=1.2$ ); eyes pale haired; 


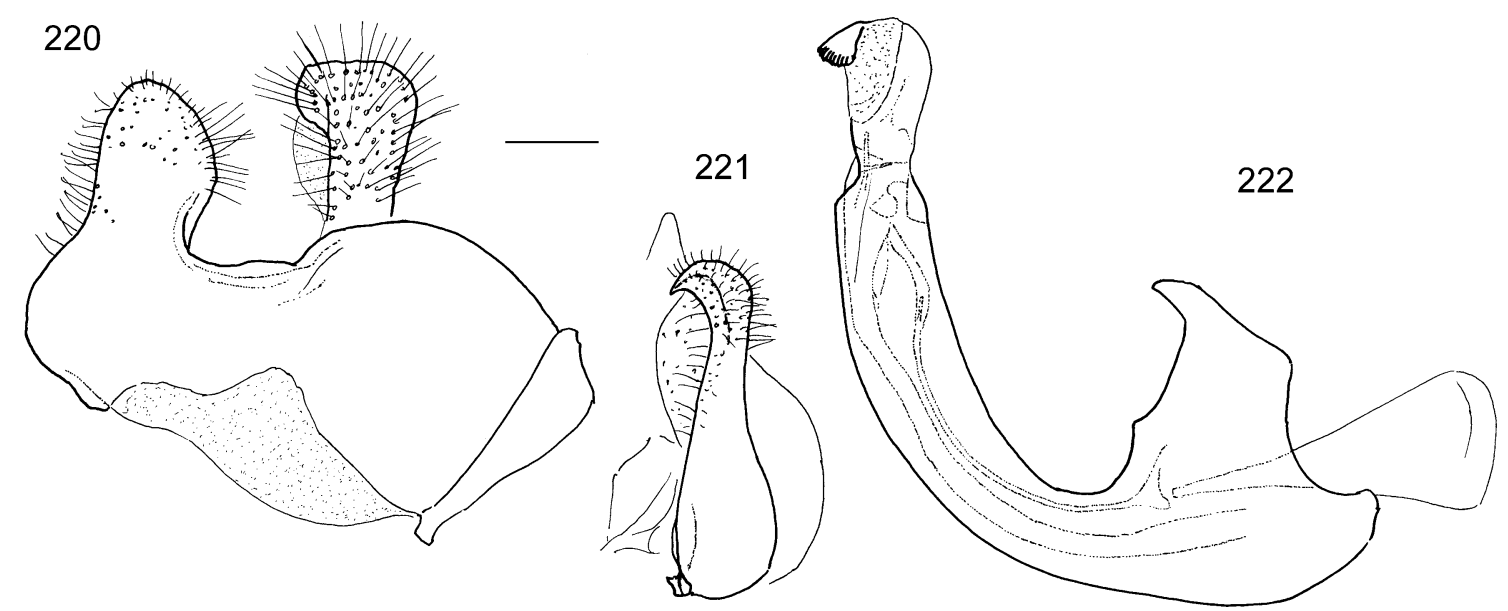

Figs 220-222. Merodon unicolor, male genitalia. 220 - epandrium, lateral view; 221 - left surstyle, anterior view; 222 - hypandrium, lateral view. Scale $0.2 \mathrm{~mm}$.

tibiae pale with dark central part; tarsi pale, except darkened two tarsomeres; body hairs pale; tergites black; tergite II with reddish lateral spots; tergites III, IV with pollinose stripes.

Type material. M. longispinus: Holotype: Spain, Jaén: 10, Arroyo Amarillo, Sierra de Cazorla 03.ix.1988, Leg. C.M. Herrera (CEUA).

Etymology. The name longispinus is derived from the very long tubercle on the hind tibia.

Biology. Preferred environment: Open ground close to rivers on mountains in the south of Spain. Flowers visited: Lavandula latifolia. Period of flight: September.

Iberian distribution. Sierra de Cazorla Natural Park (Fig. 252).

Range. Spain.

\section{Merodon luteihumerus sp. $\mathbf{n}$.}

Figs 74, 77, 194-197

\section{Male}

Head. Antennae short and completely yellow; basoflagellomere slightly longer than pedicel; apex rounded. Face and frons black, white dusted and with yellowish-white hairs. Oral margin yellowish and black, bare and lustrous. Vertical triangle isosceles with yellowish hairs; anterior angle with dense white pubescence and white hairs anteriorly reclined. Ocellar triangle isosceles. Eye contiguity line in males as long as the distance between the two posterior ocelli. Occiput black covered with white hairs.

Thorax. Mesonotum dark with metallic luster and covered with erect yellow hairs. Postpronotum (humeri) and postalar calli yellowish. Posterior anepisternum, anepimeron and dorsal part of katepisternum with yellow hairs. Five longitudinal dusted bands distinct. Wings palegreyish with dark veins. Dorsal and ventral calypters pale yellow. Halteres dark yellowish. Femora dark-brown with pale apical part, mainly in the ventral area. Fore and mid tarsi and tibiae yellow; hind tibiae yellow with dark median band and with short and blunt apical processes; hind tarsi dark. Mid femur without ventral short black bristles. Hind trochanter rounded, without thorn or angular hump. Legs covered with pale hairs.

Abdomen. Dark, oval and longer than mesonotum. Tergite I completely black; tergite II with red antero-lateral spots; tergites III and IV black with pale pruinose transversal stripes interrupted in the middle; all tergites covered with short adpressed hairs of the same colour than the tegument. Sternites, anterior corner of the tergite II and the lateral margin of all tergites with long pale hairs. Sternites mainly pale, brownish posteriorly.

Male genitalia. Apical part of PL small, quadrangular in lateral view; margin of surstyle distinctly convex (Fig. 194); medial prolongation of ventral surstyle lobe well developed but not visible in lateral view (Figs 194, 195). Hypandrium with thecal ridge strongly folded; apical part of $\mathrm{S}$ hammer-like, elongated in dorso-ventral direction (Fig. 196).

Female

Similar to the male except for the following characteristics: Ocellar triangle equilateral and covered with dark hairs. Frons black, completely covered with white pubescence except for a narrow shiny central line; yellowishwhite hairs anteriorly reclined on the lateral margins of frons.

Diagnosis. Very large species (14.0-18.6 mm) with hairy cx and reduced hairs on pa; differs from other European species by pale humeri and postalar calli; species with relatively short body hairs, short basoflagellomere, bf $=0.8-0.9$ (Figs 74, 77); whitish hairs on frons and face, pollinose stripes on mesoscutum, red-yellow lateral spots on tergite II and pair of pollinose stripes on tergites II-IV; antennae, tibiae and tarsi of fore and middle legs yellowish; similar in size and appearance to $M$. pruni Rossi, 1790 and $M$. clavipes but these two species do not have long hairs on the posterior side of mid coxae.

Type material. Holotype: Spain, Ciudad Real: $1 \delta^{\star}$, National Park Cabañeros 15.ix.2004, Leg. A. Ricarte (CEUA). Paratype: Spain: Ciudad Real: 2ð, 3 q, P.N. Cabañeros 12.ix.2004, Leg. A. Ricarte (CEUA); 1 đ, P.N. Cabañeros 12.ix.2004, Leg. A. Ricarte (MNMS); 1 đ, 1 \&, P.N. Cabañeros 14.ix.2004, Leg. A. 

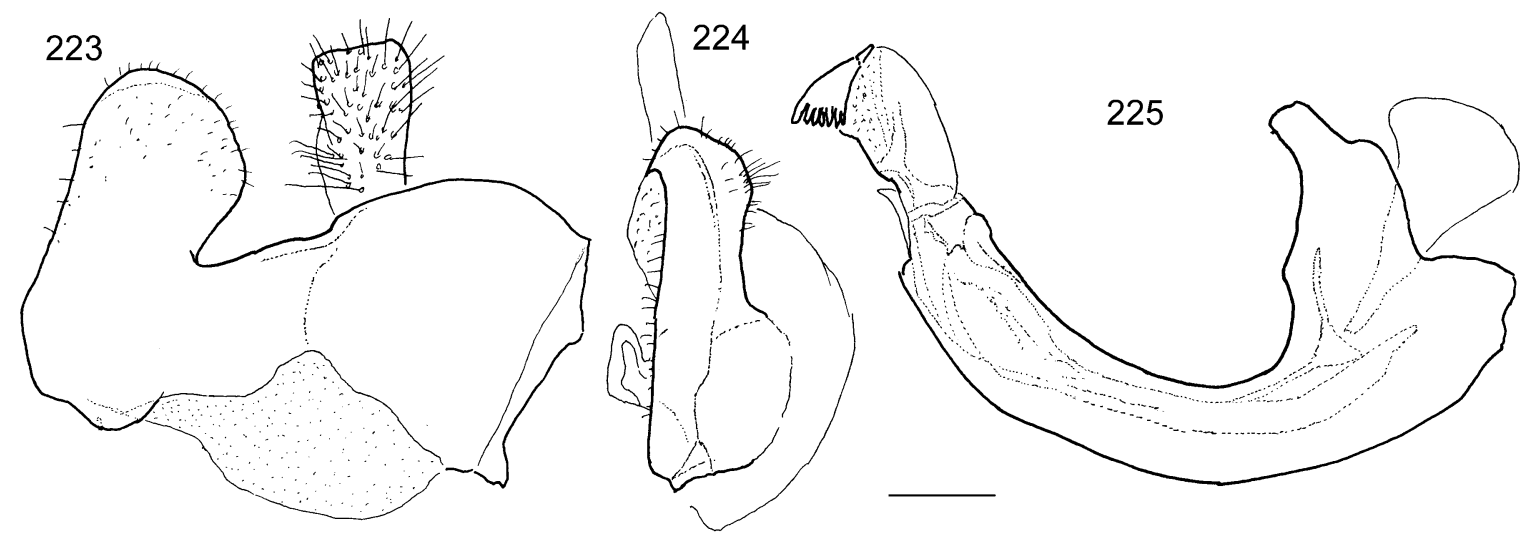

Figs 223-226. Merodon quercetorum sp. n., male genitalia. 223 - epandrium, lateral view; 224 - left surstyle, anterior view; 225 hypandrium, lateral view; 226 - apical part of hypandrium, anterior view. Scale $0.2 \mathrm{~mm}$.

Ricarte (CEUA); 1 9 , P.N. Cabañeros 15.ix.2004, Leg. A. Ricarte (MNMS); 1 0 , 1 \&, P.N. Cabañeros 14.ix.2004, Leg. A. Ricarte (CEUA); 1 9 , P.N. Cabañeros 14.ix.2004, Leg. A. Ricarte (NSEC); 10ิ, P.N. Cabañeros 15.ix.2004, Leg. A. Ricarte (NSEC). Balearic Islands, Ibiza: 1 đo, Figueretes ix.1982, Leg. R.L. Veenendaal (CEUA). Algeria: 20, Bône 5.ix.1896 (B.M1896-273), Leg. A.E. Eaton (ZMAN) det. as Merodon moenium.

Etymology. The name luteihumerus is descriptive of the pale colour of the humerus (postpronotum) in males and females.

Biology. Preferred environment: Open areas in evergreen thermophilous oak Quercus ilex and $Q$. suber with scattered Mediterranean brushwood on stony ground. Flowers visited: Urginea maritima. Period of flight: September.

Iberian distribution. Cabañeros National Park (Montes de Toledo) in Central Spain (Fig. 253)

Range. Spain, Algeria.

\section{Merodon natans (Fabricius, 1794)}

Figs 75, 78, 198-201

Syrphus natans Fabricius, 1794: 283.

Diagnosis. Species with hairy cx and reduced hairs on pa; medium sized (9-12 $\mathrm{mm})$; basoflagellomere elongated, bf $=1.8$ (Figs 75, 78); scutum and tergites II-IV with clear white pollinose stripes; male genitalia: PL and AL lobes well separated, L-shaped; hypandrium broadened after central straightened part; thecal ridge folded (Figs 198-201).

Material examined. Published: Marcos-García (1988a): Spain, Soria: Miño de Medinaceli 28.viii.1984, Leg. MarcosGarcía.

Biology. Preferred environment: Forest/open ground, herb-rich open areas in thermophilous Quercus forest and phrygana with Cistus scrub; also in orchards in southern Europe. Flowers visited: Solidago sp. Period of flight: April-May and August-October.

Iberian distribution. Sierras de Urbión (Fig. 253).

Range. Spain, France (from Paris basin south), Italy, former Yugoslavia, Greece (inc. Rhodes), Cyprus, Bulgaria, Israel and the Caucasus mountains.

\section{Merodon nigritarsis Rondani, 1845}

Figs 3, 4, 15, 18, 202-204

Merodon nigritarsis Rondani, 1845: 264.

Diagnosis. Medium sized (11.6-15.3 mm), slender species with relatively short body hairs, olive-brown groundcolour; cx bare and pa with reduced hairs; tergites III, IV always with whitish pollinose stripes; colour of tergites III, IV very variable, from dark to almost completely red (avidus group); tarsi darkened dorsally; basoflagellomere 1.5 times longer than pedicel (Fig. 15), male genitalia: PL oval, narrow; AL triangular; hypandrium with small L and a pair of basal humps; S elongated (Figs 202-204).

Material examined. Unpublished material: Spain, Albacete: Riopar; Sierra de Alcaraz; Alicante: Caveta del Buitre, Agres; El Menetjador, Alcoi (CEUA \& NSEC); Foia Ampla, Agres; Font Roja, Alcoi; Mas de Cano, Xixona (CEUA \& NSEC); Mas de St. Ignaci, Xixona; Almería: Arroyo Caramel, Vélez Blanco; Burgos: Villadiego; Murcia: Embalse de Risca, Moratalla; Tarragona: Espluga de Francoli; Valencia: Mas del Parral, Bocairent. Published material. Marcos-García (1985b) as $M$. avidus; Marcos-García (2000).

Additional published records. Andreu (1926); Hurkmans (1993).

Biology. Preferred environment: forest/open ground; herb rich, dry semi-arid, open areas in evergreen Quercus ilex and $Q$. suber forest/maquis, Pinus matorral and Mediterranean scrub. Flowers visited: Rosmarinus officinalis. Period of flight: May-August.

Iberian distribution. Pyrenees, Cantabrian Range and mountains of the Centre, East and South of Spain (Fig. 253).

Range. Uncertain due to confusion until recently with related species of the avidus group, but it has been recorded from Austria, southern France, Greece, Hungary, Italy, former Yugoslavia, Poland, Spain, Switzerland and Turkey.

Merodon obscuritarsis Strobl in Czerny \& Strobl, 1909 stat. $\mathbf{n}$.

Figs 84, 90, 98, 102, 205-210

Merodon spinipes obscuritarsis Strobl in Czerny \& Strobl, 1909: 204.

Merodon fuerteventurensis Barkemeyer, 2002: 131 syn. n. 

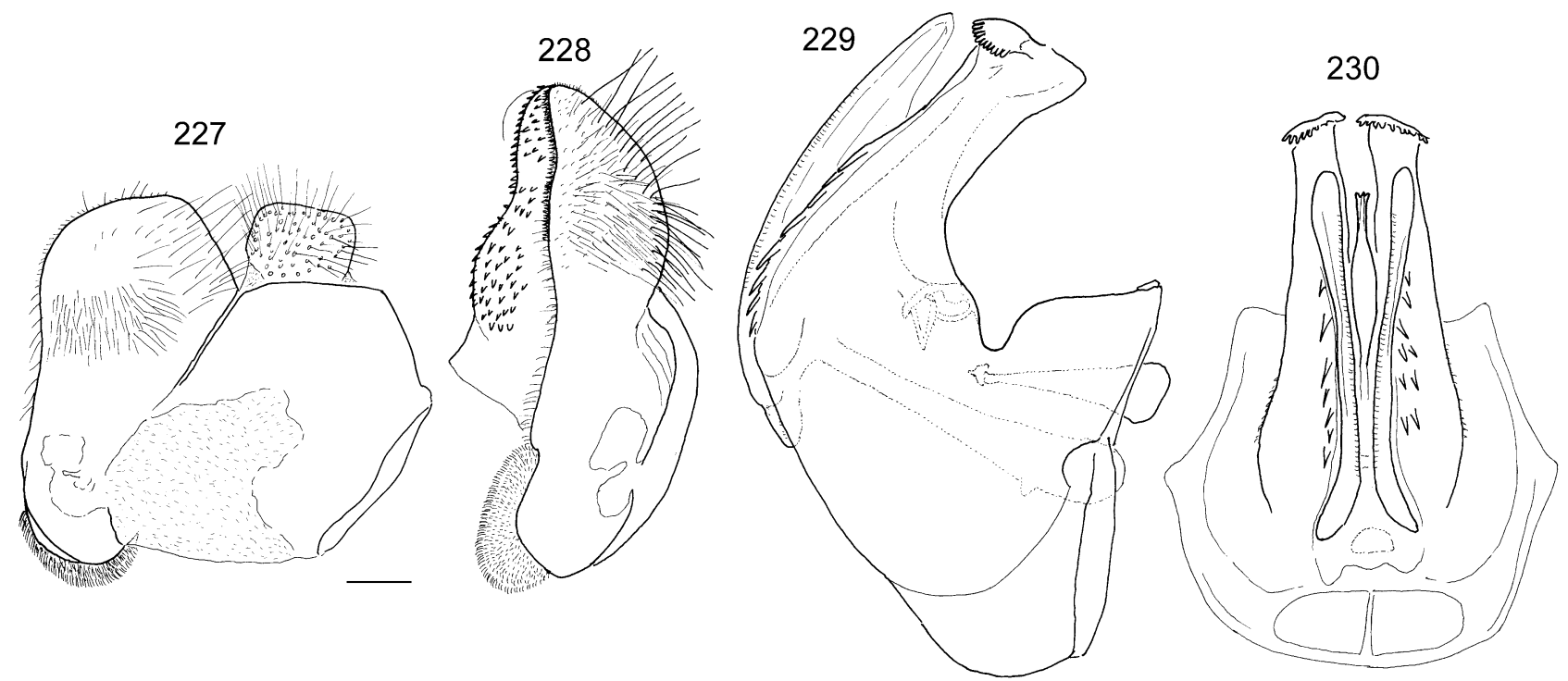

Figs 227-230. Merodon segetum, male genitalia. 227 - epandrium, lateral view; 228 - left surstyle, anterior view; 229 - hypandrium, lateral view; 230 - hypandrium, anterior view. Scale $0.2 \mathrm{~mm}$.

Merodon spinipes obscuritarsis: lectotype (designated here): male "spinipes v. obscuritarsis / Chinchon, 24./5., Dusmet" (Spain) (NMBA). Identity: valid species. Paralectotypes: male "spinipes v. obscuritarsis / Bayona, VII-1906, Dusmet” (Spain) [conspecific with lectotype]; female (same labels as lectotype) [identity: Merodon nigritarsis Rondani, 1845]. This species is widespread in the Iberian Peninsula and clearly different from the $M$. avidus (spinipes) group of species.

Merodon fuerteventurensis: holotype (original designation): male "Spanien (Kan. Ins.): Fuerteventura: Umg. La Oliva (N' La Oliva); lg. Barkemeyer, 4.3.2002. 7 aufgelassene Felder mit Opuntien und Euphorbien; $218 \mathrm{~m} \mathrm{u}$. NN" (Canary Islands, Spain) (ZMUC) [holotype is missing]. Paratype: male [same as holotype, only datum different "5.3.2002."] (BC). Identity: A junior synonym of Merodon obscuritarsis Strobl in Czerny \& Strobl, 1909. The ranges of variablity of $M$. obscuritarsis examined from the Iberian Peninsula and Northwest Africa contain the morphological features of populations from the Canary Islands.

Diagnosis. Medium sized (13.6-15.6 mm) short haired species with hairy cx and reduced hairs on pa; bf $=$ male 1.0-1.1 (Figs 90, 98), pale body hairs, yellowish and greyish; on central part of tergites III, IV short, adpressed and mixed black and pale hairs; tergites III, IV with white pollinose stripes (Fig. 84); male genitalia: PL rounded in lateral view, with notch on upper margin; surstyle margin with more or less strong marginal thorn; AL with apical prominence twisted and pointed medially; hypandrium with thecal ridge folded; S hammer-like (Figs 205-210). M. obscuritarsis is related to $M$. arundanus sp. n. but can be easily distinguished by ad-pressed yellow-greyish hairs on tergites (long, erect, reddish in M. arundanus sp. n.), less folded theca and smaller thorn on surstyle margin.

Variability. Species can vary in pollinose spots and stripes on frons, scutum and tergites. In male genitalia, size of notch on PL, shape of marginal thorn and direction of apical prominence on AL are very variable.

Remark. Merodon tricinctus Sack, 1913 is closely related and can be a synonym of $M$. obscuritarsis, but the relation between these two taxa will be the subject of future studies.

Type material examined. Lectotype: Strobl in Czerny \& Strobl (1909) as Merodon obscuritarsis: 10, "Chinchon, 24./5., Dusmet" (SPAIN) (NMBA). Paralectotype: Strobl in Czerny \& Strobl (1909) as Merodon obscuritarsis: 1 đ, "Bayona, vii.1906, Dusmet" (SPAIN) (NMBA). Paratype: Barkemeyer (2002) as M. fuerteventurensis: 10 , "Spanien (Kan. Ins.): Fuerteventura: Umg. La Oliva (N' La Oliva); lg. Barkemeyer, 4.3.2002. 7 aufgelassene Felder mit Opuntien und Euphorbien; $218 \mathrm{~m} \mathrm{u}$. NN" (Canary Islands, SPAIN) (ZMUC).

Other material examinated. Unpublished material: Spain, Alicante: Caveta del Buitre, Agres; El Menetjador, Alcoi; Foia Ampla, Agres; Font Roja, Alcoi (CEUA \& MNMS); Mas de St. Ignaci, Xixona; Barcelona: Barcelona; La Garriga; Montgat; Ciudad Real: P.N. Cabañeros; Zaragoza: Pina de Ebro. Published material: Gil-Collado, 1930 as M. tricinctus; MarcosGarcía (1990a) as M. tricinctus; Barkemeyer (2002) as Merodon fuerteventurensis (BC).

Additional published records. Van der Goot \& Lucas (1967) as M. tricinctus; Marcos-García (1990) as M. tricinctus.

Biology. Preferred environment: forest, evergeen oak forest $(Q$. ilex) and montane dry Pinus forest. Flowers visited: Apiaceae; Genista sp., Thapsia sp., Euphorbia sp., Caralluma burchardii, Opuntia sp. Period of flight: April-May and July-September.

Iberian distribution. Pyrenees, Central, Penibético and Bético Systems (Fig. 254).

Range (+ data of M. tricinctus). France, Mediterranean basin and North Africa; from Spain eastwards through southern Europe to Greece, Bulgaria, Crimea, Turkey and the Caucasus; also in Israel; in Switzerland and Austria in central Europe.

Merodon ottomanus Hurkmans, 1993

Figs 211-214 


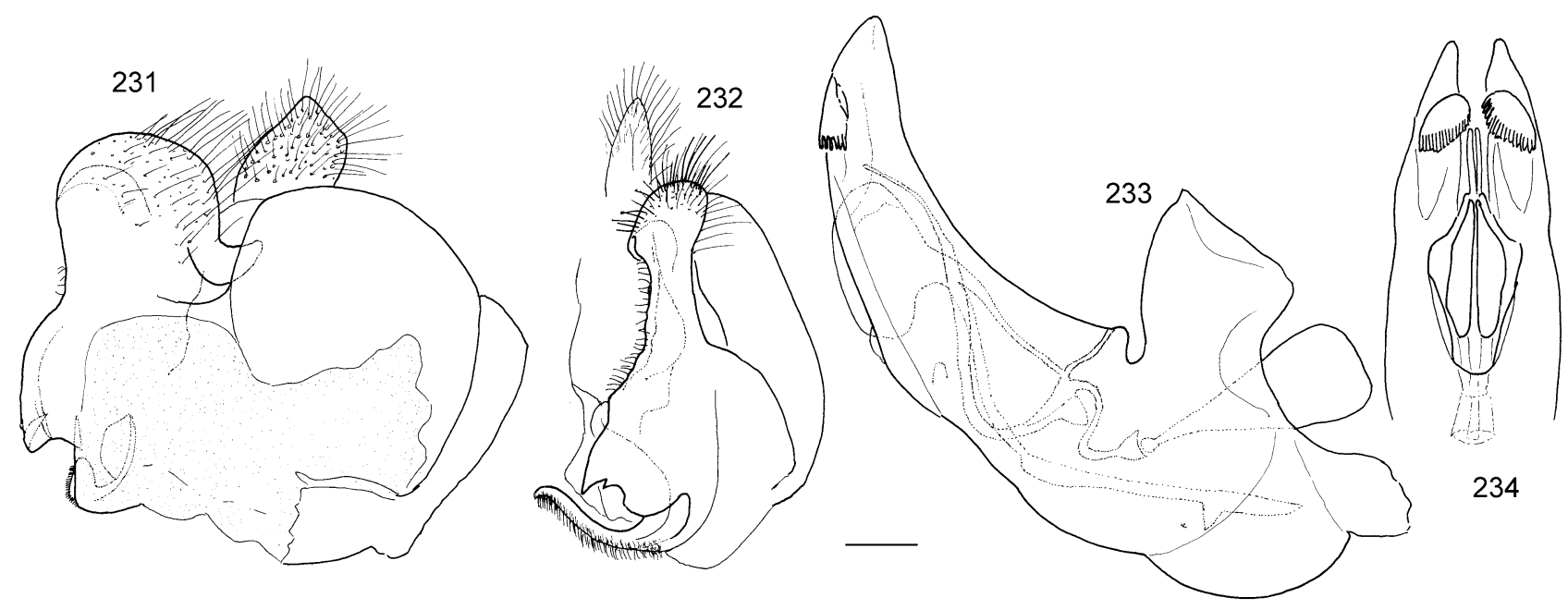

Figs 231-234. Merodon teruelensis, male genitalia. 231 - epandrium, lateral view; 232 - left surstyle, anterior view; 233 - hypandrium, lateral view; 234 - apical part of hypandrium, anterior view. Scale $0.2 \mathrm{~mm}$.

Merodon ottomanus Hurkmans, 1993: 161.

Diagnosis. Small $(8-10 \mathrm{~mm})$ species with olive-brown reflections; cx bare and pa with many hairs; scutum unpollinose; abdomen short and stocky, tergites dark, without pale spots; tergites II, III with small pollinose spots, basoflagellomere reddish; knees, tarsi, basal part and apex of tibiae pale; body hairs pale, except black hairs on vertex, apex of femora, central part of scutum and tergites II-IV; male genitalia: PL oval, with rounded top; surstyle margin slightly convex; AL small, covered with dense short hairs (Figs 211-214).

Variability. Basoflagellomere from orange to brown; black hairs on scutum and pollinose spots on male tergites may be absent.

Material examined. Unpublished material: Spain, Alicante: 1 đै, Caveta del Buitre, Agres 1200 m; 8.-23.v.2001 (MT), Leg. X. Mengual; 1 ㅇ, Foia Ampla, Agres 1060 m; 23.v.-5.vi.2001 (MT), Leg. X. Mengual; 1 \%, Font Roja, Alcoi 29.v.1994, Leg. P.M. Isidro (MNMS); 4ð, Font Roja, Alcoi 10.v.1994, Leg. P.M. Isidro; Valencia: $3 q$, Chelva 25.iv.-9.v.1994, Leg. C. Pérez-Bañón; 2 9, Utiel 10.v.1994, Leg. C. Pérez-Bañón; 10 , Utiel 10.v.1994, Leg. C. Pérez-Bañón; 3 9, Utiel 9.v.1994, Leg. C. Pérez-Bañón; 1 \&, Utiel 9.v.1994, Leg. C. Pérez-Bañón.

Biology. Preferred environment: forest; open areas in Quercus ilex / Pinus halepensis forest and lentisc scrub. Occurs at $2000 \mathrm{~m}$ in Turkey (Hurkmans, 1993. Period of flight: May-June.

Iberian distribution. High mountains of Valencia and Alicante provinces, in the East of Spain (Fig. 255).

Range. Described from Turkey and distributed along the Mediterranean basin.

\section{Merodon parietum Wiedemann in Meigen, 1822}

Figs 83, 93, 215-219

Merodon parietum Wiedemann in Meigen, 1822: 360.

Merodon parietum was described from a single male. In the Meigen collection there is one specimen with original name label and corresponding data. We accept this specimen as the holotype: male "parietum Hgg. Lusi- tania / parietum det. Loew / Lusitania coll. Winthem / Typus" (Portugal) (NHMW).

Diagnosis. Species with hairy cx and reduced hairs on pa; medium sized $(10.3-13.3 \mathrm{~mm})$, short haired species with stocky abdomen; only tergite II with clear reddish lateral spots (Fig. 83); bf =1.1 (Fig. 93); male genitalia: PL rounded; surstyle margin with small marginal thorn, invisible in lateral view; AL with small apical extension; S hammer-like; thecal ridge folded (Figs 215-219).

Type material examined. Holotype: Wiedemann in Meigen (1822) as Merodon parietum: 10, "Lusitania coll. Winthem" (Portugal) (NHMW).

Other material examined. Unpublished material: Spain, Guipúzcoa: Galeseno, San Sebastián; Jaén: Sierra de Cazorla, Natural Park; Salamanca: Laguna de Campanero, Castillejo Martín Viejo. Coll. Seebold (without location) (MNMS). Published material: Marcos-García (1985c) as M. albifrons; Marcos-García (1990b) as M. albifrons; Marcos-García (2000); Kehlmaier (2002) (CEUA \& NSEC).

Additional published records. Peck (1988): Portugal.

Biology. Preferred environment: forest/open ground; open areas in thermophilous Quercus forest and welldrained, non-calcareous grassland. Flowers visited: Chrysanthemum leucanthemum, Myosotis sp., Ranunculus sp., Stellaria sp. Period of flight: March-August.

Iberian distribution. Eurosiberian region, mountainous areas of the Sistema Central and Bético (Fig. 255).

Range. Portugal, Spain, southern France (north to the Dordogne); Greece.

\section{Merodon pumilus Macquart in Lucas, 1849}

Figs 126-129

Merodon pumilus Macquart in Lucas, 1849: 466.

In "Catalogue of Palaearctic hoverflies", Peck (1988) cited $M$. pumilus as a synonym of $M$. aeneus Meigen, 1822. The morphological characters (see the Key) and molecular data (Stähls, unpubl.) of these two taxa are different and we redefined M. pumilus. Identity: valid species. M. pumilus was described from a single female. In the Lucas collection there is one specimen with original 

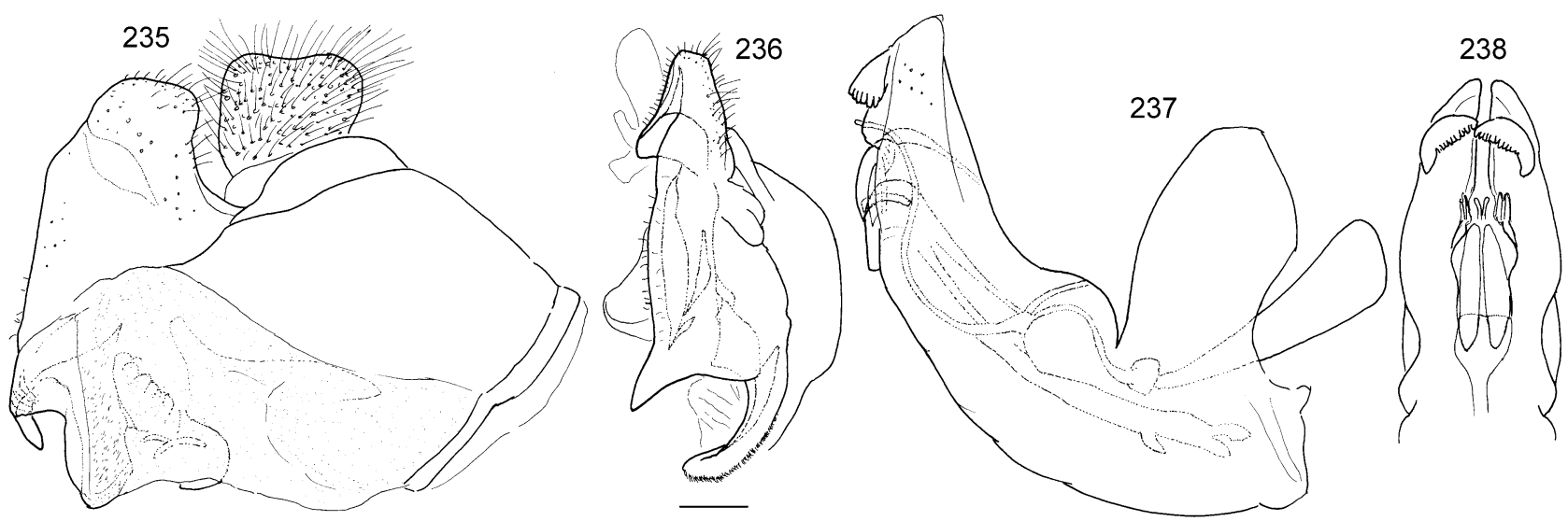

Figs 235-238. Merodon trochantericus, male genitalia; 235 - epandrium, lateral view; 236 - left surstyle, anterior view; 237 hypandrium, lateral view; 238 - apical part of hypandrium, anterior view. Scale $0.2 \mathrm{~mm}$.

name label. We accept this specimen as the holotype: female "pumilus Macq. sp. nova / Type" (Constantine, Algeria) (MNHN, Lucas collection).

Comment. Merodon pumilus belongs to a group of diverse and geographically usually well-separated species that occurs around the Mediterranean Basin (Vujic et al., in prep.). These taxa (aureus complex) are very closely related, and in some cases without clear morphological diagnostic features. M. pumilus is distributed in North Africa and only a few specimens of this species were found in the Iberian Peninsula.

Diagnosis. Small $(8.0-13.3 \mathrm{~mm})$ species with hairy cx and many hairs on pa; short rounded abdomen, and thorn on hind trochanter in male (aureus group of species); abdomen and mesonotum with dense, yellow-reddish hairs in male; female abdomen with shorter, mixed pale and black hairs, tergites II-IV with clear pollinose stripes; tegument of mesonotum and tergites with golden tomentum; hind femora pale haired (with few black hairs in related M. unicolor); at least upper half of eyes black haired (pale haired in M. unicolor); basoflagellomere reddish to dark-brown, legs dark except knees, both ends of tibiae and tarsi in part, which can be paler; male genitalia (practically identical in all species from aureus group): AL undeveloped, ventral margin straight; PL with parallel margins, rounded apically, covered with long hairs; $\mathrm{C}$ can be slender, but without clear prominences; hypandrium narrow, elongated and sickle-shaped; $S$ reduced (Figs 126-129).

Type material examined. Holotype: Macquart in Lucas (1849) as Merodon pumilus: 19 , (Constantine, Algeria) (MNHN).

Other material examined. Unpublished material: Spain, Almería: $19,3 \mathrm{~km} \mathrm{~W}$ Benahadux $230 \mathrm{~m}, 36^{\circ} 55^{\prime} \mathrm{N} 02^{\circ} 28^{\prime} \mathrm{W}$, 12.-27.iv.1999, (MT), Leg. M.E. Irwin; Cáceres: 1 \%, Castañar de Ibor, 9.vi.1982, Leg. E. Galante.

Biology. Preferred environment: Open ground, dry grassland and open areas in thermophilous forest, maquis and matorral. Flowers visited: Apiaceae; Anthericum ramosum, Chrysanthemum leucanthemum, Mentha sp., Ranunculus sp., Solidago sp., Taraxacum sp., Oenanthe croccata. Period of flight: April-June.
Iberian distribution. Sistema Central and Bético in the southern half of Spain (Fig. 257).

Range. Unknown. These are the first data from the Iberian Peninsula.

\section{Merodon quercetorum sp. $\mathbf{n}$.}

Figs 38, 39, 43, 223-226

Male

Head. Antennae red brown; basoflagellomere pale and approximately as long as pedicel and flagellum together; apex acute. Face and frons shiny black with white hairs. Occiput shiny black covered with white pubescence and white hairs. Vertical triangle isosceles with white hairs. Ocellar triangle equilateral. Eyes with white hairs and few black hairs on the upper part.

Thorax. Mesonotum and scutellum dark green with metallic luster, with erect yellowish-white hairs, usually some short black hairs at wing basis. Posterior anepisternum, anepimeron and dorsal part of katepisternum with white hairs. Wings pale-greyish with dark veins. Dorsal and ventral calypteres pale yellow. Halteres with yellow pedicel and brown capitulum. Femora black, only pale towards apex; with long white hairs on the anterior part and short, black and adpressed posteriorly. Tibiae and tarsi yellow, the two-three apical tarsomeres dark. Tibiae and tarsi with yellow hairs and some black ones on posterior part of tibiae and dorsally on tarsi. Hind trochanter with a short thorn with two pointed teeth usually of different size.

Abdomen. Oval, slightly longer than mesonotum; dark green with metallic luster with a band (sometimes interrupted in the middle) of white pubescence on tergites II and III. Colour of abdominal hairs white except two black bands of reclined hairs on posterior third of tergite II and all of tergite III (except central dusted band).

Male genitalia. Similar to M. aureus. AL undeveloped, ventral margin straight; PL rounded on apex. Hypandrium narrow, elongated and falcate; S reduced (Figs 223-226).

\section{Female}

Similar to the male, except for the following characteristics. Frons shiny with white erected hairs, except for a line of anteriorly reclined hairs along the eyes border. 


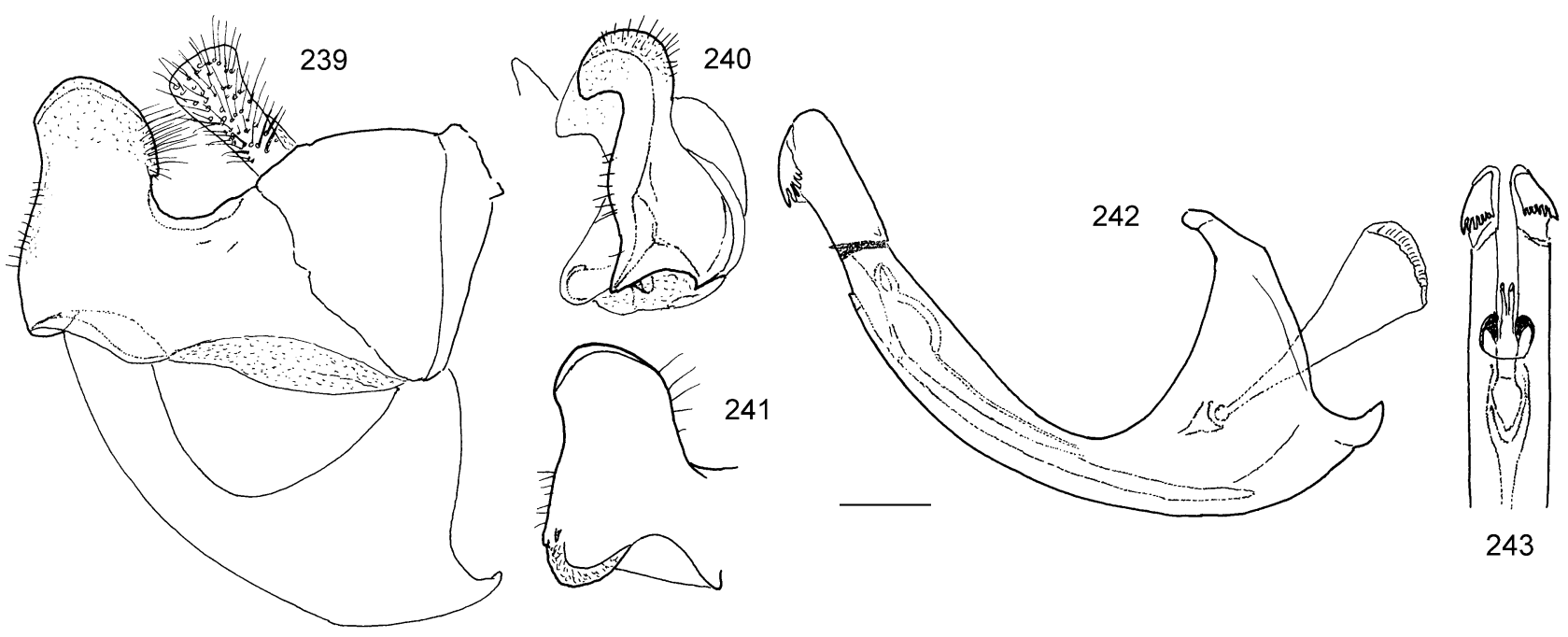

Figs 239-243. Merodon unguicornis, male genitalia; 239 - epandrium, lateral view; 240 - left surstyle, anterior view; 241 - right surstyle, inner view; 242 - hypandrium, lateral view; 243 - apical part of hypandrium, anterior view. Scale $0.2 \mathrm{~mm}$.

Ocellar triangle equilateral with black hairs extended to the upper part of the frons. Abdominal dusted bands conspicuous.

Diagnosis. Small $(7.3-9.3 \mathrm{~mm})$ species with hairy cx and many hairs on pa, short rounded abdomen, and thorn on hind trochanter in male (aureus group of species); mesonotum pale haired, usually with few black hairs at wing basis; in male posterior $1 / 3$ of tergite II and all of tergite III (except central pollinose stripes) black haired; female abdomen with shorter, mixed pale and black hairs, tergites II-IV with clear pollinose stripes; legs black, tibiae and tarsi yellow, the two-three apical tarsomeres dark; apical part of hind femora at least with few black hairs. $M$. quercetorum nov. sp. is similar to $M$. coerulescens Loew but can be distinguished by pale tibiae and tarsi (dark in $M$. coerulescens), brownish ground colour (bluish in $M$. coerulescens) and pale eye hairs (dark on upper third in M. coerulescens).

Type material. Holotype: Spain, Cáceres: 10 , Pto Honduras, Hervás 1450 m; 28.viii.1980, Leg. Marcos-García (CEUA). Paratype: Spain: Alicante: $2 \%$, Caveta del Buitre (Natural Park Mariola), Agres 1200 m; 30.viii.-11.ix.2001 (MT), Leg. X. Mengual (CEUA); 30 , 2 q, Caveta del Buitre, Agres $1200 \mathrm{~m}$; 14.-30.viii.2001 (MT), Leg. X. Mengual (CEUA); 10, Font Roja (Natural Park), Alcoi 30.viii.1993, Leg. P.M. Isidro (CEUA); 1 \%, Font Roja, Alcoi 10.-24.ix.1992, Leg. F. Luna (NSEC); Ávila: 20 , Sierra Candelario, Santiago de Aravalle 2200 m; 29.viii.1980, Leg. Marcos-García (CEUA); Cáceres: 80ิ, 1ㅇ, Pto Honduras, Hervás 1450 m; 28.viii.1980, Leg. Marcos-García (CEUA); 10 , 1 \% , Pto Honduras, Hervás 1450 m; 28.viii.1980, Leg. Marcos-García (MNMS); $1 \delta^{\star}$ Pto Honduras, Hervás 1450 m; 28.viii.1980, Leg. Marcos-García (NSEC); León: 2\%, Pto. Leitariegos 10.ix.1987, Leg. Marcos-García (CEUA). Material from Ávila and Cáceres was published as M. aeneus in Marcos-García (1985a).

Etymology. The name quercetorum is due to the adults of this syrphid species appearing in habitats with Quercus species (Q. rotundifolia, $Q$. pyrenaica and $Q$. faginea).

Biology. Preferred environment: Open high mountainous areas of the Cantabrian Range and Spanish Medi- terranean region. Flowers visited: Crocus salzmannii. Period of flight: August-September.

Iberian distribution. Cantabrian range (North of Spain) and two Natural Parks, La Font Roja and Mariola, both belonging to the Iberian mountain range (Alicante, East of Spain) (Fig. 256).

Range. Spain.

\section{Merodon segetum (Fabricius, 1794)}

Figs 76, 79, 227-230

Syrphus segetum Fabricius, 1794: 289.

Diagnosis. Big species $(15-18 \mathrm{~mm})$ with hairy cx and reduced hairs on pa; basoflagellomere long (bf $=2.2$ ), four times longer than pedicel (Figs 76, 79); scutum in female with two patches of black hairs anteriorly of transversal suture; tergites III, IV without or with very narrow pollinose stripes; male genitalia: anterior margin of surstyle more or less straight; PL broad, oval; inner side covered with strong setulae; AL small, rounded, covered with dense short hairs; ventral margin of hypandrium with strong setae; S elongated (Figs 227-230).

Material examined. Unpublished material: Spain, Cádiz: 10 , 19 , Algeciras, 1.-10.v.1925, Leg. Zerny (NHMW).

Biology. Period of flight: May.

Iberian distribution. South of the Iberian Peninsula (Fig. 255).

Range. Some isolated places of the Mediterranean basin (Crete, Macedonia). These are the first data from the Iberian Peninsula.

\section{Merodon serrulatus Wiedemann in Meigen, 1822}

Figs 8, 13, 24, 26, 116-121

Merodon serrulatus Wiedemann in Meigen, 1822: 360 stat. rev. Merodon lusitanicus Hurkmans, 1993: 181 syn. n.

Hurkmans (1993) published Merodon serrulatus as a synonym of $M$. avidus in his monograph. He designated a lectotype (male) contrary to the original description that contains only one type specimen (female). The depositary Museum is also different (NHMW). We found in the col- 

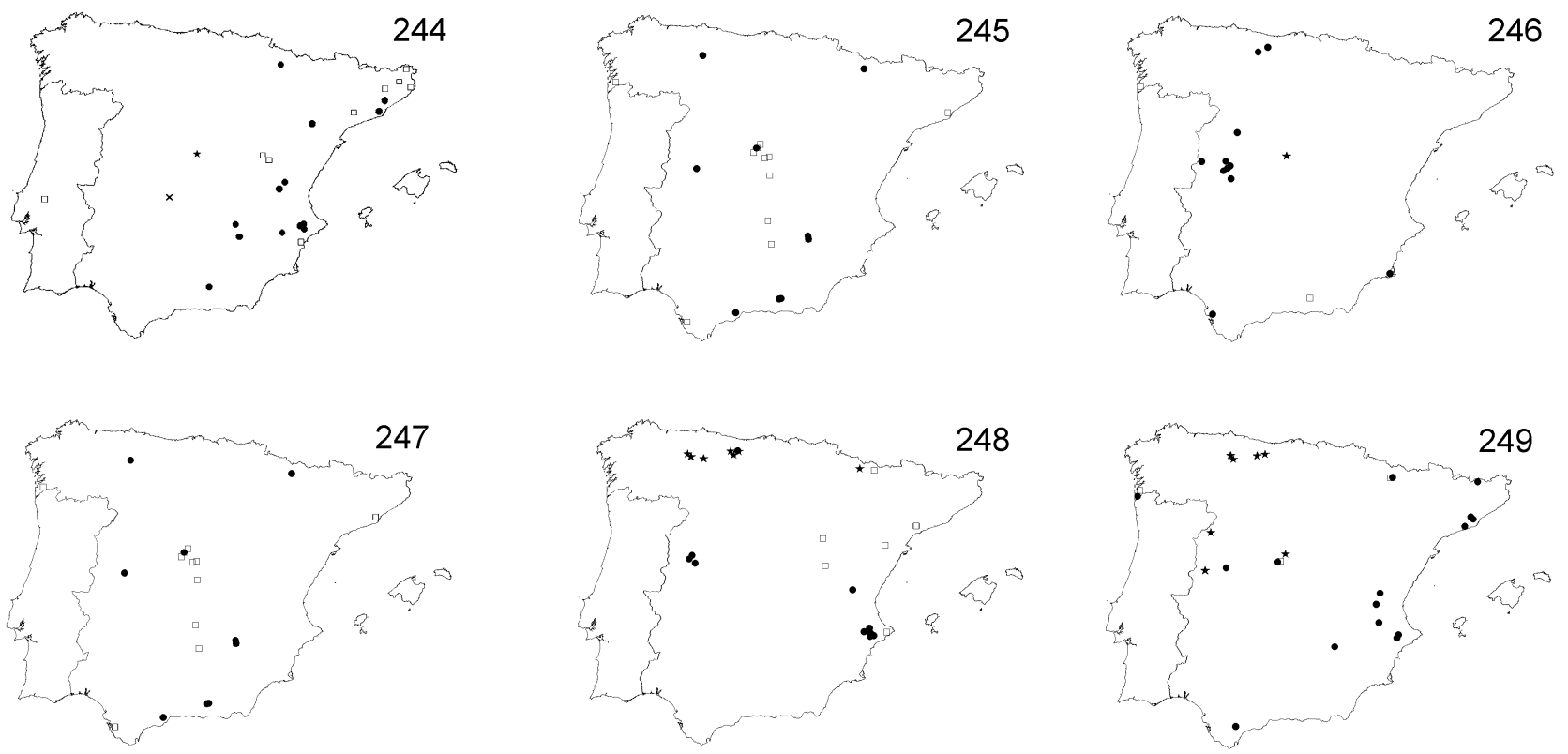

Figs 244-249. 244 - Iberian distribution of a) Merodon albifrons: white square: published material not examined; black circles: examined material; b) Merodon aberrans: black stars: published material not examined; c) Merodon antonioi sp. $\mathrm{n}$. and cabanerensis sp. n.: black cross: examined material. 245 - Iberian distribution of a) Merodon avidus B: white square: published material not examined; black circles: examined material; b) Merodon avidus A: black stars: examined material; c) Merodon arundanus: black cross: examined material. 246 - Iberian distribution of a) Merodon chalybeus: white square: published material not examined material; black circles: examined material; b) Merodon clunipes: black stars: published material not examined. 247 - Iberian distribution of Merodon clavipes. White square: Published material not examined material. Black circles: Examined material. 248 - Iberian distribution of a) Merodon elegans: white square: published material not examined; black circles: examined material; b) Merodon crypticus sp. n.: black stars: examined material. 249 - Iberian distribution of a) Merodon funestus: white square: published material not examined; black circles: examined material; b) Merodon flavus: black stars: examined material.

lection of the Berlin Museum a female specimen with original name label and corresponding data, and accept this specimen as the Holotype: female "serrulatus / Portugal / Hoffmannsegg S. / 915 Type [red label]" (Portugal) (ZMHB). Based on these facts Hurkmans' designation of lectotype from non-type material is incorrect, and we reinstalled $M$. serrulatus as a valid species.

Merodon lusitanicus: Holotype (original designation): female "Portugal, Algarve, Quirteira 27.iv.1985, J.A.W. Lucas" (ZMAN).

Diagnosis. Species with bare cx and reduced hairs on pa; medium sized (10.6-13.3 mm), short haired dark species with olive-brown reflection; antennae dark; legs black; body hairs predominantly pale, except black hairs on vertex, scutum between wing bases, tergites III, IV and apical part of femora; basoflagellomere elongated (bf $=1.9$ ) obviously concave dorsally, arista short (Figs 8, 26); tergite II usually with small pale lateral spots; hind femora thick (Figs 13, 24); male genitalia: PL with lateral hump; AL triangular; L small, $\mathrm{S}$ elongated (Figs 116-121).

Variability. Antennae from black to brown; black hairs can lack on scutum, tergites and femora; knees, apex of tibiae and tarsi ventrally can be paler, pollen of scutum can be less visible; male genitalia shows variability in the shape of surstyle and size of area covered with dense short hairs on AL (Figs 118, 119).

Type material examined. Holotype: Wiedemann in Meigen (1822) as Merodon serrulatus: "Portugal / Hoffmannsegg S."
1 , (ZMHB). Hurkmans (1993) as M. lusitanicus: "Portugal, Algarve, Quirteira 27.iv.1985, J.A.W. Lucas" 1 \& (ZMAN).

Other material examined. Unpublished material: Spain, Albacete: Riopar; Sierra de Alcaraz; Alicante: Caveta del Buitre, Agres (CEUA \& MNMS); El Menetjador, Alcoi (CEUA \& MNMS); Foia Ampla, Agres; Font Retura, Agres; Font Roja, Alcoi (CEUA \& NSEC); Venta Carrasqueta, Xixona; Mas de Cano, Xixona; Sierra del Menetjador, Alcoi; Jaén: Calarilla, Sierra de Cazorla; Valencia: Utiel. Published material: GilCollado (1930) as M. spinipes var. nigritarsis; Marcos-García (1990a) as M. unguicornis.

Additional published records. Hurkmans (1993) as M. lusitanicus: Vilamoura (Portugal).

Biology. Preferred environment: forest/open ground; thermophilous Quercus forest, evergreen oak forest (Q.ilex and $Q$. suber), dry Pinus forest; lentisc scrub; dry well-vegetated, grassland and tracksides. Flowers visited: Apiaceae, Thapsia villosa; Cirsium sp., Helianthemum sp., Potentilla erecta, Thymus sp. Period of flight: April-July.

Iberian distribution. Iberico mountain range (East of Spain), Pyrenees, Cantabrian mountains and Algarve (South of Portugal) (Fig. 257).

Range. Portugal and Spain. These are the first data from Spain.

\section{Merodon teruelensis Van der Goot, 1966}

Figs 80, 231-234

Merodon teruelensis Van der Goot, 1966: 179. 

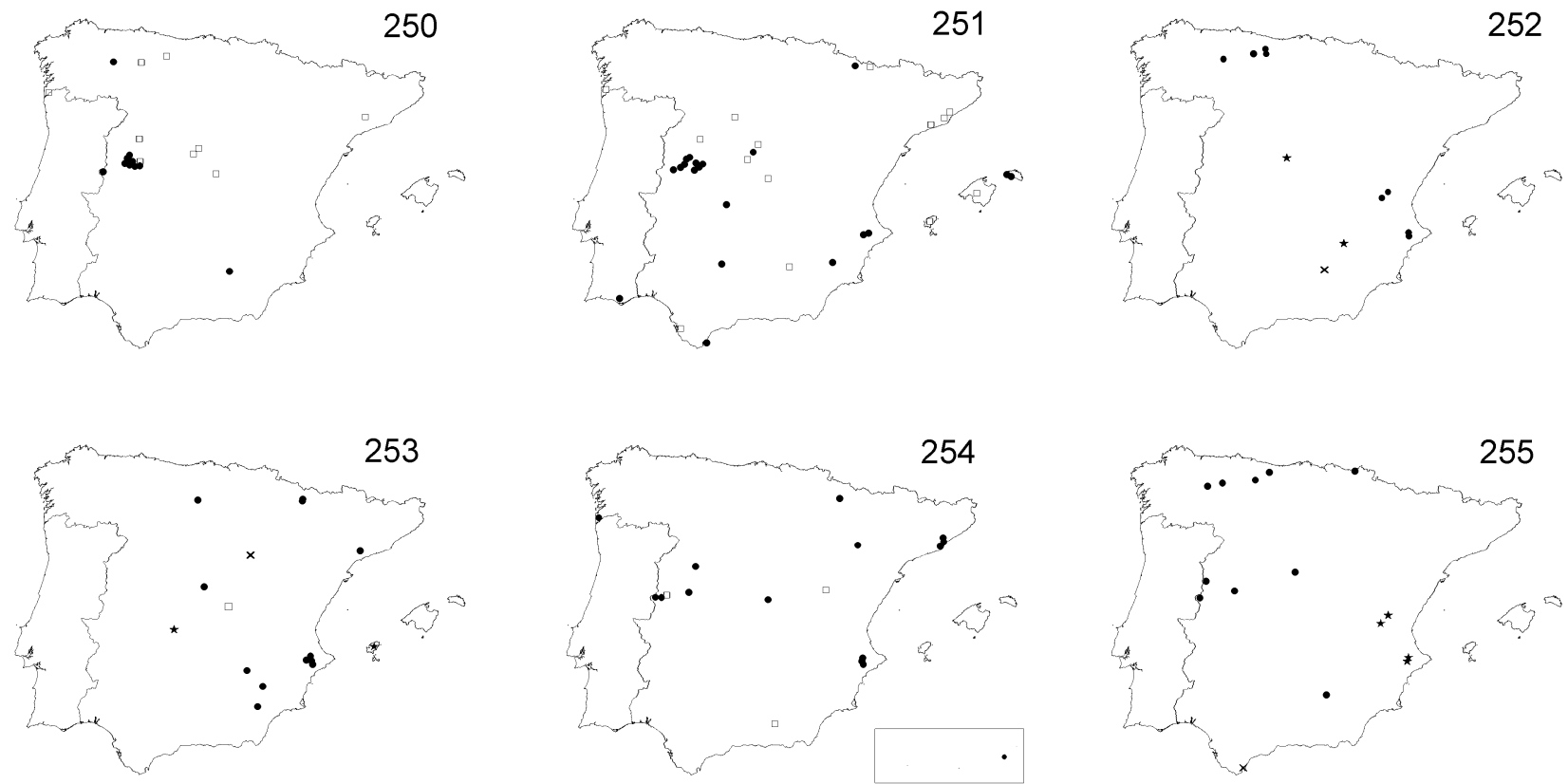

Figs 250-255. 250 - Iberian distribution of Merodon escorialensis: white square: published material not examined; black circles: examined material. 251 - Iberian distribution of Merodon geniculatus: white square: published material not examined; black circles: examined material. 252 - Iberian distribution of a) Merodon legionensis sp. n.: black circles: examined material; b) Merodon longicornis: black stars: examined material; c) Merodon longispinus sp. n.: black cross: examined material. 253 - Iberian distribution of a) Merodon nigritarsis: white square: published material not examined; black circles: examined material; b) Merodon luteihumerus sp. n.: black stars: examined material; c) Merodon natans: black cross: examined material. 254 - Iberian distribution of Merodon obscuritarsis: white square: published material not examined material; black circles: examined material. 255 - Iberian distribution of a) Merodon parietum: black circles: examined material; b) Merodon ottomanus: black stars: examined material; c) Merodon segetum: black cross: examined material.

Diagnosis. Medium (11.3-15.3 mm) sized, long haired species, with black body ground-colour; cx with hairs and hairs on pa reduced; scutum without clear pollinose stripes; tergites III, IV with small or absent stripe of pollen; scutum usually with stripe of black hairs between wing bases; trochanter with clear hump (Fig. 80); legs long haired; tergite II with small brownish lateral spots; male genitalia: PL rounded; marginal thorn small, invisible in lateral view; AL with long, medial prolongation; $\mathrm{C}$ with central apical prominence; $\mathrm{S}$ with large oval apical part (Figs 231-234).

Material examined. Published material: Marcos-García (1985a) as Merodon cinereus; Marcos-García (1990b) as M. equestris equestris.

Additional published records. Gil-Collado (1930) as Merodon cinereus var. subfasciatus; Peris (1958); Van der Goot (1966); Van der Goot \& Lucas (1967).

Biology. Preferred environment: forest/open ground, marshy, open areas in evergreen oak maquis, garrigue, scrub-invaded grassland, and wet meadows. Flowers visited: Senecio sp. Period of flight: May, July-August.

Iberian distribution. Eurosiberian region, Sistema Central and Bético (Fig. 256).

Range. Spain.

\section{Merodon trochantericus Costa, 1884}

Figs 59, 96, 235-238

Merodon trochantericus Costa, 1884: 173.
Diagnosis. Species with hairy cx and reduced hairs on pa; medium sized (13.3-14.6 mm), short haired species with reddish abdomen; hind femora with ventral bulge on basal fifth (Fig. 59); hind trochanter with clear rounded projection (Fig. 59); male genitalia: PL squarish; surstyle margin long, with strong marginal thorn; AL with short apical extension; S hammer-like (Figs 235-238).

Material examined. Published material: Marcos-García (1986) as M. trochanterata: Spain, Burgos, 29.viii.1982, Leg. Marcos-García; Castrovido, 4.viii.1983, Leg. Marcos-García.

Biology. Preferred environment: Forest/open ground; thermophilous Quercus and evergreen oak (Q. suber) forest, maquis, thermophilous forest fringes. Flowers visited: Cistus sp., Euphorbia sp. and Quercus coccifera. Period of flight: May-June and mid July-September.

Iberian distribution. Mountains of the Sistema Ibérico (Fig. 256).

Range. From northern France (Morbihan - extinct?) south to Spain and the Mediterranean; Corsica, Sardinia, Italy.

\section{Merodon unguicornis Strobl in Czerny \& Strobl, 1909}

Figs 42, 239-243

Merodon unguicornis Strobl in Czerny \& Strobl, 1909: 205

Merodon andalusiacus Paramonov, 1929: 185 syn. n.

Merodon bolivari Gil Collado, 1930: 248 syn. n.

Lampetia hispanica Sack, 1932: 319 syn. n.

Merodon unguicornis was described from a single male. In the Strobl collection there is one specimen with 

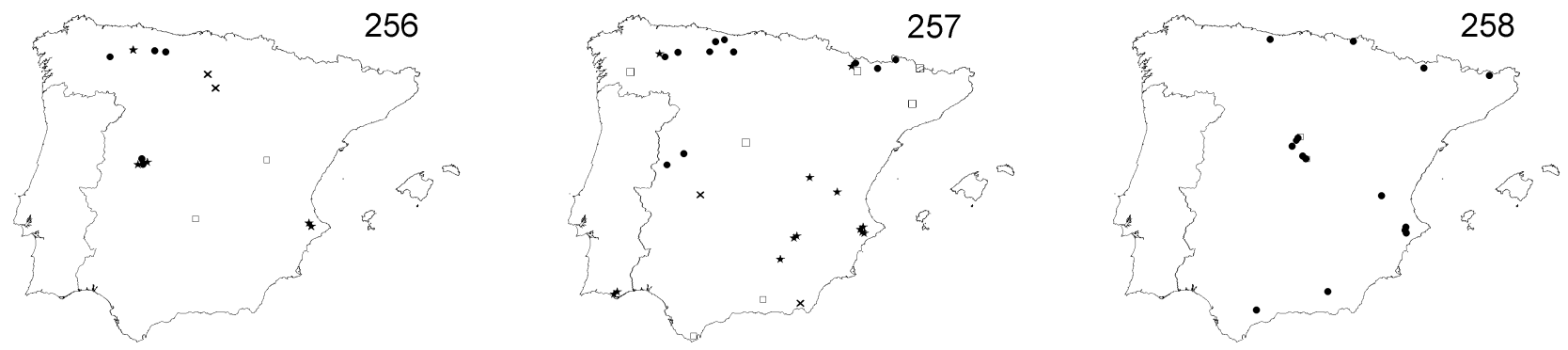

Figs 256-259. 256 - Iberian distribution of a) Merodon teru-

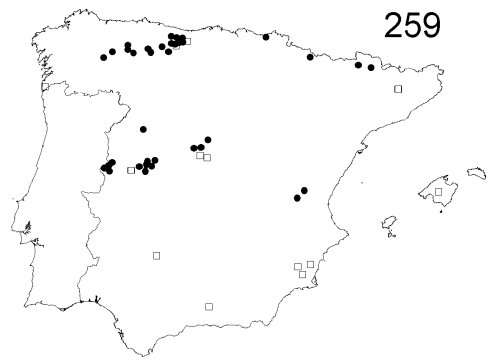
elensis: white square: published material not examined; black circles: examined material; b) Merodon quercetorum sp. n.: black stars: examined material; c) Merodon trochantericus: black cross: examined material. 257 - Iberian distribution of a) Merodon equestris: white square: published material not examined; black circles: examined material; b) Merodon serrulatus: black stars: examined material; c) Merodon pumilus: black cross: examined material. 258 - Iberian distribution of Merodon unguicornis: white square: published material not examined; black circles: examined material. 259 - Iberian distribution of Merodon unicolor: white square: published material not exam-

original name label and corresponding data. We accept this specimen as the holotype: male "unguicornis $\mathrm{m}$. / Spain / Rivas, 21.75. Dusmet" (Spain) (NMBA). This endemic Iberian species was described four times in a short period (Paramonov, 1929: as M. andalusiacus; Gil Collado, 1930: as M. bolivari; Sack, 1932: as Lampetia hispanica).

Merodon andalusiacus: Holotype (original designation): male "Andalusia / Merodon andalusiacus n. sp. Typus / N 322 / Paramonov det." (Spain) (ZMKU).

Merodon bolivari: Holotype (original designation): male "Merodon bolivari Gil tipo Gil Collado det. / Sierra de Guadarrama 10.6.24. Dusmet / Holotipo" (Spain) (MNMS).

Merodon hispanicus: Syntypes: 4 females "Andalusien, Hispania" (Spain) [these syntypes have not been traced; based on their description it is clear that they belong to Merodon unguicornis which is the only species similar to M. aureus (aeneus) with red lateral spots on tergites II and III].

Diagnosis. Small $(7.3-10.0 \mathrm{~mm})$ species with hairy $\mathrm{cx}$ and many hairs on pa, short rounded abdomen, and thorn on hind trochanter in male (aureus group of species); tergite II with reddish lateral spots; tergites unpollinose; thorn on hind trochanter in male very small (Fig. 42); antennae brown; eye hairs pale-brownish, darker on upper part; mesonotum and abdomen pale haired; legs dark, knees and base of tibiae pale; male genitalia: AL undeveloped, ventral margin straight; PL with parallel margins, rounded on apex, covered with long hairs; hypandrium narrow, elongated and sickle-shape; $\mathrm{S}$ reduced (Figs 239-243).

Variability. Usually tergite III also with reddish lateral spots, but they can be small or absent in some specimens.

Type material examined. Holotype: Strobl in Czerny \& Strobl (1909) as Merodon unguicornis: 10 "Rivas, 21.75. Dusmet" (NMBA). Paramonov (1929) as M. andalusiacus: $10^{\dagger}$ ined; black circles: examined material.

"Andalusia" (ZMKU). Gil Collado (1930) as M. bolivari: 10 "Sierra de Guadarrama 10.6.24. Dusmet" (MNMS).

Other material examined. Unpublished material: Spain, Alicante: Caveta del Buitre, Agres; El Menetjador, Alcoi; Foia Ampla, Agres; Font Roja, Alcoi (CEUA \& NSEC); Mas de Cano, Xixona; Mas de St. Ignaci, Xixona; Venta de la Carrasqueta, Xixona; Girona: Setcases; Madrid: Cercedilla, Sierra de Guadarrama; Málaga: El Burgo; Valencia: Utiel. Published material: Gil-Collado (1930) as M. bolivari; Sack (1931) as $L$. hispanica; Peck (1988) as M. bolivari; Marcos-García (1990b) as M. bolivari; Marcos-García (2000) as M. bolivari; Kehlmaier (2002) as $M$. spp.

Additional published records. Arias (1912); Andreu (1926); Gil-Collado (1930); Peck (1988) as M. andalusiacus; Dirickx (1994) as M. andalusiacus.

Biology. Preferred environment: forest/scrub; open Quercus ilex forest and maquis. Flowers visited: Brachypodium sp., Cistus sp., Erinacia anthyllis, Euphorbia sp., Helianthemum sedum, Thymus sp. Period of flight: April-July.

Iberian distribution. Cantabrian mountains, Pyrenees, Sistema Central, Ibérico and Penibético (Fig. 258).

Range. Spain

\section{Merodon unicolor Strobl in Czerny \& Strobl, 1909 stat. $n$.}

Figs 40, 220-222

Merodon aeneus unicolor Strobl in Czerny \& Strobl, 1909: 203.

Merodon unicolor was described as a variety of $M$. aeneus Meigen, 1822 from a single male. In the Strobl collection there is one specimen with original name label and corresponding data. We accept this specimen as the holotype: male "v. unicolor m / Spain. / Typus" (Spain: Escorial) (NMBA). Peck (1988) cited M. unicolor as a synonym of $M$. aeneus. The morphological characters (see the Key) and molecular data (Ståhls, unpubl.) of 
these two taxa are different and we redefined M. unicolor. Identity: Valid species.

Diagnosis. Small $(7.3-11.0 \mathrm{~mm})$ species with hairy $\mathrm{cx}$ and many hairs on pa, short rounded abdomen, and thorn on hind trochanter in male (aureus group of species); abdomen and mesonotum with dense, yellow-reddish hairs in male; female abdomen with shorter, mixed pale and black hairs, tergites II-IV with clear pollinose stripes; tegument of mesonotum and tergites with golden tomentum; hind femora with few black hairs on apical part (pale haired in related $M$. aureus); at eyes pale haired rarely with few black hairs on upper corner (at least upper half with black hairs in $M$. aureus); basoflagellomere reddish to dark-brown, legs dark except knees, both ends of tibiae and tarsi in part, that can be paler; male genitalia: AL undeveloped, ventral margin straight; PL with parallel margins, rounded at apex, covered with long hairs; $\mathrm{C}$ can be slender, but without clear prominences; hypandrium narrow, elongated and sickle-shaped; S reduced (Figs 220-222).

Type material examined. Holotype: Strobl in Czerny \& Strobl (1909) as M. aeneus var. unicolor: Spain: Madrid: 1 o El Escorial (NMBA).

Other material examined. Unpublished material: Spain, Asturias: Arenas de Cabrales; Ávila: Becedas; Pto Peñanegra, Navalmahillo; Cádiz: San Rafael; Guipúzcoa: Galeseno, San Sebastián; Huesca: Selva de Oza; León: Alto de Aralla, Geras; Alto del Pontón, Retuerto; Caboalles de Abajo; Cofiñal (CEUA \& NSEC); Geras; Laguna Arbás, Leitariegos; La Velilla de Valdoré; Murias de Paredes; Pto. Ancares, Balouta; Valle de Casares, La Pola de Gordón (CEUA \& NSEC); Lleida: Escalo; Lugo: Liñares, Louzarela; Salamanca: Navasfrías; Santander: Fuente Dé; Valencia: Utiel; Amieva; Chelva. Published material: Gil-Collado (1930) as M. aeneus unicolor; MarcosGarcía (1985a, b; 1990b) as M. aeneus; Kehlmaier (2002) as M. aeneus.

Additional published records. Röder (1884) as Lampetia aenea; Arias (1912) as M. aeneus unicolor; Andreu (1926) as M, aeneus; Kanervo (1929) as Lampetia aenea; Gil-Collado (1930) as M. aeneus; Gil-Collado (1930) as M. aeneus unicolor; Séguy (1934) as Lampetia aenea; Peris (1958); Séguy (1961) as L. aenea; Pedersen (1971) as M. aeneus; Marcos-García (1981, 1985a, 1990, 2000) as Lampetia aenea.

Biology. Preferred environment: Open ground and wet meadows in mountainous areas (up to $2250 \mathrm{~m}$ ). Flowers visited: Anthemis mixta. Period of flight: April-August.

Iberian distribution. Wide spread in the Iberian Peninsula (Fig. 259).

Range. Spain and Northwest Afria. Western Mediterranean species.

\section{Additional Merodon names treated}

Merodon aureus Fabricius, 1805: 198.

Holotype: female "Germania" (ZMUC) [the type is damaged, only one wing left in collection].

Merodon aeneus Meigen, 1822: 367.

In the Biosystematic Database of World Diptera, Thompson (2004) cited Merodon aureus as a senior synonym of $M$. aeneus. The type of $M$. aeneus (Mühlfeld in Austria) has not been located. Based on the original descriptions of both names, and after examination of Museum material (which fits descriptions) from Germany and Austria, which all belongs to one species, we decided to follow this synonymy.

\section{DISCUSSION}

The Mediterranean basin is considered one of the "hotspots" of biodiversity of the planet (Myers et al., 2000); moreover, species endemism is very high in this region. Climatic variation during the Pleistocene had a decisive influence in shaping the composition and distribution of mediterranean species and communities (Blondel \& Aronson, 1999).

The Old world genus Merodon Meigen, 1803 (Syrphidae, Diptera) is one of the most widespread in the Mediterranean region (Speight, 2006). In a previous catalogue for the Iberian Peninsule (Marcos-García et al., 2002), 30 Merodon species were compiled from the bibliography. In the present study, nine of them have been synonymized, eight new species have been described and six species are cited for the first time for the Iberian fauna. The updated number of the Merodon species registered in the Iberian Peninsula is thus 34. In France, a neighbouring country to the Iberian Peninsula and with a slightly bigger geographical extention, 32 species have been registered (Dussaix, 2004), 50\% of them shared with the Iberian Peninsula.

A $36.4 \%$ of the Iberian Merodon species are also present in the North of Africa and two of them (M. elegans and M. pumilus) are endemic to the Iberian Mediterranean region and Northwest of Africa. This similarity could be explained because the "Ibero-Mauritanian" plate has been a fertile matrix for differentiation in many groups of plants and animals and in this case it seems probable that these species colonized Iberia during the Messinian Salinity Crisis that established a land bridge between the present day Morocco and the Iberian Peninsula 5.6 My ago (Blondel \& Aronson, 1999).

It should be noted that the high number of Iberian endemic species of the genus Merodon $(14=41.2 \%)$, one of the highest through the entire range of this genus, could be related to one distinctive trait of the Mediterranean flora, in addition to sclerophyly and evergreenness, the bulbous life form. These geophytes have a fleshy subterranean storage organ which is usually the only portion of the plant that survives the extended period of summer dormancy. In fact, the Iberian Peninsula is the centre of diversity for some subgenera of Narcissus Spach (Rivera et al., 2003), one of the main groups of feeding plants for the larvae of Merodon species (Rotheray, 1994). Only Turkey surpasses the high number of species and endemicity in the Mediterranean basin with 60 registered Merodon species (Siribiyic, pers. com.), of which only 13 live in the Iberian Peninsula. Turkey is another center of diversity of this genus in the Mediterranean basin.

Although Merodon species are adapted to the xerothermic Mediterranean environment, $50 \%$ of the Iberian species are also distributed along the Eurosiberian region 
of the Iberian Peninsula, with $M$. crypticus being exclusive to this biogeographical area.

On average, levels of endemism increase as altitude increases. In the Mediterranean mountain ranges, whether continental or insular, the percentage of endemic species is very high, albeit quite variable (Blondel \& Aronson, 1999). In the Iberian Peninsula, this fact has been also shown by Gómez-Campo \& Herranz-Sanz (1993) in plant taxa $(31 \%$ are restricted to the mountains and levels of endemism can reach upto 50\%). Concerning to the Merodon species, each Iberian mountain chain comprises some endemic species and more than $60 \%$ of the Iberian species are present in the mountains of the Sistema Central of Spain where the percentage of endemism is the highest (46.2\%).

The adult flight activity of Merodon species throughout the year can be summarised in three phenologic models: early Spring species (45.5\%), early Autumn species $(15.2 \%)$ and species with a longer flight period, from spring to autumn (39.4\%).

It should be noted that all the Iberian and Western Mediterranean endemic species have fortunately at least part of their distribution area inside areas with some degree of protection as National or Natural Parks.

ACKNOWLEDGEMENTS. We are very grateful to the curators of the collections listed above from whom study material was borrowed. Our thanks to the directors of the Cabañeros National Park, Natural Parks of Cazorla, Font Roja, Grazalema and Mariola for allowing us to study Syrphids in these protected areas. We are also grateful to J. van Steenis, C. Palmer, M. Speight, M. Reemer, C. Kehlmaier, A. Ricarte, C. Pérez-Bañón and W. Barkemeyer for the interesting Merodon material from Spain they lend us for this study. Financial support was provided by the Spanish Ministerio de Medio Ambiente (040/2002), Generalitat Valenciana (GV04A-576), Spanish Ministerio de Educación y Ciencia (CGL2005-07213/BOS), Ministry of Science, Technology and Development of the Republic of Serbia (project number 143037) and Provincial Ministry of Science and Technological Development, Autochtonous Province of Vojvodina, Republic of Serbia - project: Maintance of Biodiversity - Hotspots on the Balkan and Iberian Peninsula (Insecta, Diptera, Syrphidae).

\section{REFERENCES}

ANDREU J. 1926: Una lista de sírfidos para contribuir al conocimiento de los dípteros de España. Bol. Soc. Entomol. Esp. 9(5): 98-126.

ARIAS J. 1912: Relación de las publicaciones y trabajos científicos en los que se citan o describen especies de Dípteros de la Península Ibérica. Mem. R. Soc. Esp. Hist. Nat. 7: 241-246.

BARKEMEYER W. 2002: A new species of the genus Merodon Meigen, 1822 from the Canary Islands (Diptera: Syrphidae). Mitt. Int. Entomol. Ver. 27(3/4): 131-136.

BECKER T. 1907: Die Ergbnisse meiner dipterologishen Frühjarereise nach Algier und Tunis, 1906. Z. Syst. Hymen. Dipter. 7: 33-61, 97-128, 225-256, 369-407.

Blondel J. \& Aronson J. 1999: Biology and Wildlife of the Mediterranean Region. Oxford Univesity Press, New York, $328 \mathrm{pp}$.
Claussen C. \& Hauser M. 1990: Neue Syrphidenvorkommen aus Marokko und Tunesien (Diptera, Syrphidae). Entomofauna 11: 433-440.

Compte A. 1958: Los sírfidos de las Islas Baleares. Bol. R. Soc. Esp. Hist. Nat. 4: 25-49.

Costa A. 1884: Notizie ed osservazioni sulla geo-fauna Sarda. Memoria terza. Risultamento delle ricerche fatte in Sardegna nella estate del 1883: Atti Accad. Sci. Fis. Mat. Nat. Napoli (2) 1(9): 1-64.

Czerny L. \& Strobl G. 1909: Spanische Dipteren. III Beitrag. Verh. Zool.-Bot. Ges. Wien 59: 121-301.

De La Fuente J.M. 1926: Dípteros de la provincia de Ciudad Real. Bol. R. Soc. Esp. Hist. Nat. 9: 130-133.

DiRickx H.G. 1994: Atlas des Diptères Syrphides de la Région Méditerranéenne. Documents de Travail de L'I.R.Sc.N.B. $317 \mathrm{pp}$.

DoczKal D. 1996: Description of two new species of the genus Eumerus Meigen (Diptera, Syrphidae) from Corsica. Volucella 2(1/2): 3-19.

Dussaix C. 2004: Insecta, Diptera, Syrphidae de France. (onLine URL: http://perso.wanadoo.fr/cyrille.dussaix/).

Edwards F.W. 1915: Report on the Diptera collected by the British ornithologists' union expedition and the Wollaston expedition in Dutch New Guinea. With a section on the Asilidae by E.E. Austen. Trans. Zool. Soc. London 20: 391-424.

EGGER J.G. 1860: Fortsetzung der Beschreibung neuer Zweiflügler und diagnostische Bemerkungen. Verh. Zool.-Bot. Ges. Wien 10: 663-668.

FABRICIUS J.C. 1781: Species insectorum exhibentes eorum differentias specificas, synonyma, auctorum, loca natalia, metamorphosin adiectis observationibus, descriptionibus. Vol. 2. Hamburgi et Kilonii [= Hamburg and Kiel], 517 pp.

FABRICIUS J.C. 1794: Entomologia systematica emendata et aucta. Secundum classes, ordines, genera, species adjectis synonymis, locis, observationibus, descriptionibus. Vol. 4. Hafniae [= Copenhagen], $472 \mathrm{pp}$.

FABRICIUS J.C. 1805: Systema antliatorum secundum ordines, genera, species adiectis synonymis, locis, observationibus, descriptionibus. C. Reichard, Brunsvigae [= Brunswick], xiv $+15-372+[1]+30 \mathrm{pp}$.

Gil-Collado J. 1930: Monografía de los Sirfidos de España. Trabajos del M.N.C.N. Serie Zoológica. No. 54. Madrid, 377 pp.

Gil-Collado J. 1932: Dípteros de Ibiza recogidos por D. José Giner. Bol. R. Soc. Esp. Hist. Nat. 32: 273-283.

Gómez-Campo C. \& Herranz-Sanz J. 1993: Conservation of Iberian endemic plants: the botanical reserve of La encantada (Villarrobledo, Albacete, Spain). Biol. Conserv. 64: 155-160.

Herrera J. 1988: Pollination relationships in Southern Spanish Mediterranean shrublands. J. Ecol. 76: 274-287.

Hurkmans W. 1993: A monograph of Merodon (Diptera: Syrphidae). Part 1. Tijdschr. Entomol. 136: 147-234.

KANervo E. 1939: Inventa entomologica itineris Hispanici et Maroccani, quod a. 1926 fecerunt Harald et Hakan Lindberg. XXIV Diptera, Syrphidae. Societas Sci. Fenn. Comment. Biol. 7(8): 1-6.

Kehlmaier C. 2002: Hoverflies (Diptera, Syrphidae) from northern Spain, with notes on Pelecocera tricincta Meigen, 1822. Volucella 6: 139-153.

LeClercQ M. 1971: Syrphidae (Diptera) des Pyrénées. (Huesca, Lérida, Andorra, Gerona). Pirineos 27(102): 21-25.

Macquart J. 1849: Diptères. In Lucas H. (ed.): Histoire naturelle des animaux. Zoologie. Sciences Physiques. Explorations scientifique de l'Algérie pendant les années 1840, 
1841, 1842 publiée par ordre du Gouvernement et avec le concours d'une Commission Académique. Paris, pp. 414-503.

Marcos-García M.A. 1981: Contribución al conocimiento de los Syrphidae (Diptera) de la zona noreste de la provincia de Salamanca. Bol. Asoc. Esp. Entomol. 4: 157-171.

Marcos-García M.A. 1985a: Los Syrphidae (Diptera) de las sierras occidentales del Sistema Central español. Subfamilias: Eristalinae, Lampetiinae, Microdontinae, Milesiinae y Cerianinae. Bol. Asoc. Esp. Entomol. 9: 187-210.

Marcos-García M.A. 1985b: Contribución al conocimiento de la sirfidofauna del Pirineo del Alto Aragón. II (Diptera, Syrphidae). Bol. Soc. Portug. Entomol. 1(1): 521-532.

Marcos-García M.A. 1986: Nuevas citas para la fauna ibérica de Sírfidos (Diptera). Miscel. Zool. 10: 205-211.

Marcos-García M.A. 1988: Nuevas aportaciones al catálogo sirfidofaunístico de la Península Ibérica (Diptera, Syrphidae). Bol. Asoc. Esp. Entomol. 12: 327-332.

Marcos-García M.A. 1989: Merodon escorialensis Strobl,1909, stat. nov. (Diptera, Syrphidae). Ann. Soc. Entomol. Fr. 25: $243-247$.

Marcos-García M.A. 1990a: Nuevos datos sobre especies ibéricas del género Merodon Meigen, 1822 y descripción de la genitalia de Merodon unguicornis Strobl, 1909 (Diptera, Syrphidae). An. Biol. 16(5): 49-51.

Marcos-García M.A. 1990b: Catálogo preliminar de los Syrphidae (Diptera) de la Cordillera Cantábrica (España). Eos 66(2): 81-235.

Marcos-García M.A. \& Louis M. 2000: Revisión de las especies de sírfidos de la Colección J. Andreu (Diptera, Syrphidae). An. Biol. 23: 49-62.

Marcos-García M.A., Rojo S. \& Pérez-Bañón C. 2002: Family Syrphidae. In Carles-Torlá M. (ed.): Catálogo de los Dípteros de España, Portugal y Andorra (Insecta). Monografías SEA 8. Sociedad Entomológica Aragonesa, Zaragoza, pp. 132-136.

Meigen J.W. 1822: Systematische Beschreibung der bekannten europaischen zweiflugeligen Insekten. Dritter Theil. SchulzWundermann, Hamm, $x+416$ pp., pls. 22-32.

Milankov V., Vujić A. \& LudošKi J. 2001: Genetic divergence among cryptic taxa of Merodon avidus (Rossi, 1790) (Diptera: Syrphidae). Int. J. Dipterol. Res. 12(1): 15-24.

Myers N., Mittermeler R.A., Mittermeler C.G., Da Fonseca G.A.B. \& KENT J. 2000: Biodiversity hotspots for conservation priorities. Nature 103: 853-858.

PARAmonov S.J. 1929: Dipterologische Fragmente. Trudy Vseukr. Akad. Nauk Fiz.-Mat. Viddilu 13: 179-193.

Peck L.V. 1988: Family Syrphidae. In Soós Á. \& Papp L. (eds): Catalogue of Paleartic Diptera. Vol. 8. Elsevier, Oxford, 363 pp.

Pedersen E.T. 1971: Some Syrphidae from Spain, with descriptions of two new species (Insecta, Diptera). Steenstrupia 27: 229-245.

PERIS S.V. 1958: Análisis biográfico de la fauna de Syrphidae de la Península Ibérica. Publ. Inst. Biol. Apl. 27: 171-176.

Popov G.V. 2000: A new synonym of Merodon tricinctus (Diptera, Syrphidae). Vest. Zool. 34(3): 99-102.

Radenković S., Vujić A. \& ŠImić S. 2002: On the identity and synonymy of two species from Merodon ruficornis Meigen group (Diptera: Syrphidae). Acta Entomol. Serb. 7(1/2): 51-57.

Rivera Núñez D., Obón De Castro C., Ríos Ruiz S. \& Alcaraz ARIZA F. 2003: The origin of cultivation and wild ancestors of daffolils (Narcissus subgenus Ajax) (Amaryllidaceae) from an analysis of early illustrations. Sci. Hortic. 98: 307-330.

RÖDER V. 1884: Ueber von Herrn Dr. Schmiedeknecht in Spanien, bei Elche, Ibiza und auf Mallorca gesammelte Dipteren. Entomol. Nachr. 10(17): 253-257.

RoNDANI C. 1845: Merodon armipes, species nova. Mag. Zool., Paris: No. 154.

Rossi P. 1790: Fauna Etrusca. Sistens insecta quae in provinciis Florentina et Pisana praesertim collegit. Vol 2. Liburni [= Livorno] $348 \mathrm{pp}$.

Rotheray G.E. 1994: Colour guide to hoverfly larvae (Diptera, Syrphidae) in Britain and Europe. Dipter. Digest 9: 1-156.

SACK P. 1913: Die Gattung Merodon Meigen (Lampetia Meig. olim). Abh. Senckenb. Naturforsch. Ges. 31: 427-462.

SACK P. 1932: Syrphidae. In Lindner E. (ed.): Die Fliegen der Paläarktischen Region IV/6. Schweizerbart, Stuttgart, 451 pp.

SÉGUY E. 1934: Diptères d'Espagne. Etude systématique bassé principalement sur les collections formées par le R.P. Longin Navas, S.J. Mems Acad. Cienc. Exact. Fis.-Quím. Nat. Zaragoza 3: 37-39.

SÉGUY E. 1961: Diptères Syrphides de l'Europe occidentale. Mém. Mus. Natn. Hist. Nat. Paris (A) 23: 1-248.

SpEIGHT M.C.D. 2006: Species accounts of European Syrphidae (Diptera), Ferrara 2006. In Speight M.C.D., Castella E., Sarthou J.-P. \& Monteil C. (eds): Syrph the Net, the Database of European Syrphidae. Vol. 54. Syrph the Net publications, Dublin, $252 \mathrm{pp}$.

StubBs A.E. \& FAlK S.J. 2002: British Hoverflies: An Illustrated Identification Guide. 2nd ed. Br. Ent. Nat. Hist. Soc., London, $469 \mathrm{pp}$.

THOMPSON F.C. 1999: A key to the genera of the flower flies of the Neotropical Region with the description of two new genera and eight new species. Contr. Entomol. Intern. 3: 319-378.

Thompson F.C. 2004: Merodon Meigen, 1803. Biosystematic Database of World Diptera, 241 records. http://www.diptera.org/names, accessed on March, 2006.

VAN DER GoOT V.S. 1958: Quelques Syrphides (Diptera) des Pyrénées et de la Sierra Nevada. Entomol. Ber. 18: 93-96.

VAN DER Goot V.S. 1966: Two new species of Syrphidae (Diptera) from Spain. Entomol. Ber. 26: 179-183.

VAN DER GOOT V.S. \& LUCAS J.A.W. 1967: Recolección de sírfidos en Albarracín, provincia de Teruel, durante e lverano de 1965 (Dipt. Syrphidae). Graellsia 23: 111-119.

Van VeEn M. P. 2004: Hoverflies of Northwest Europe. Identification Keys to the Syrphidae. KNNV Publishing, Utrecht, 254 pp.

Vujić A., Radenković S. \& Šımić S. 1996: Merodon albonigrum, a new European species related to Merodon geniculatus Strobl, 1909 (Diptera, Syrphidae). Dipter. Digest (Ser. 2) 2(2): 72-79.

Received March 30, 2006; revised and accepted February 5, 2007 